Portland State University

PDXScholar

Fall 12-12-2016

\title{
Wiki-based Collaborative Creative Writing in the ESL Classroom
}

\author{
Rima Elabdali \\ Portland State University
}

Follow this and additional works at: https://pdxscholar.library.pdx.edu/open_access_etds

Part of the Applied Linguistics Commons, and the First and Second Language Acquisition Commons Let us know how access to this document benefits you.

\section{Recommended Citation}

Elabdali, Rima, "Wiki-based Collaborative Creative Writing in the ESL Classroom" (2016). Dissertations and Theses. Paper 3378.

https://doi.org/10.15760/etd.5269

This Thesis is brought to you for free and open access. It has been accepted for inclusion in Dissertations and Theses by an authorized administrator of PDXScholar. Please contact us if we can make this document more accessible: pdxscholar@pdx.edu. 
Wiki-based Collaborative Creative Writing in the ESL Classroom

\title{
by
}

\section{Rima Elabdali}

A thesis submitted in partial fulfillment of the requirements for the degree of

\author{
Master of Arts \\ in \\ Teaching English to Speakers of Other Languages
}

\author{
Thesis Committee: \\ Nike Arnold, Chair \\ Susan Conrad \\ Kimberley Brown
}

Portland State University

2016 


\begin{abstract}
Despite the growing number of L2 studies examining digitally-mediated collaborative writing, the vast majority of these studies have focused on academic writing tasks. This study examined the dynamics and perceptions of groups of ESL students who used wikis to write collaborative short stories. The study also compared the short stories written in groups with posttest short stories written individually in terms of creativity, accuracy, and complexity. The study involved nine students taking a Creative Writing course in an intensive English program at a large university in the U.S. It followed a multiple case study design; the students were divided into three pairs and one triad (four case studies). For three weeks, the groups engaged in a series of wiki-based and creative writing activities and produced four collaborative short stories. During the following three-week period, the students wrote nine individual short stories using a similar writing prompt to the one used in the collaborative task. For each student, the collaborative and individual writing samples were compared on the three dimensions of creativity, accuracy, and complexity to examine whether collaboration influenced the quality of the product. Further, the dynamics of collaboration were explored through analyzing the wiki discussions and revision histories for each group. Finally, students' perceptions of the task were surveyed through individual interviews and self-assessment questionnaires. While there was not a clear effect of collaboration on the creativity and accuracy of the short stories, the complexity was slightly higher for the majority of the informants. The analysis of the short stories also indicated that ESL students faced difficulty writing in a genre that does not have a strict pre-established outline. Analysis of the wiki discussions
\end{abstract}


and revision history showed trends of group dynamics in the four case studies.

Further analysis of perception data revealed that although the majority of the informants had a negative perception of the collaborative task, they expressed a positive attitude toward the individual creative writing task. 


\section{DEDICATION}

I dedicate this thesis to all those who have supported my endeavor to pursue a master degree and those who encouraged me during my study at Portland State University. 


\section{ACKNOWLEDGMENTS}

My sincere gratitude goes to my dear friend Tara Anderson for her overwhelming support during the data collection and analysis. 


\section{TABLE OF CONTENTS}

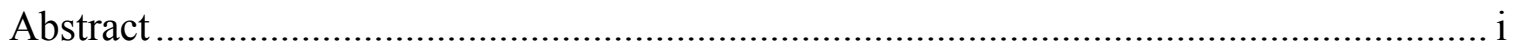

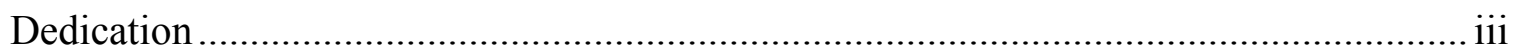

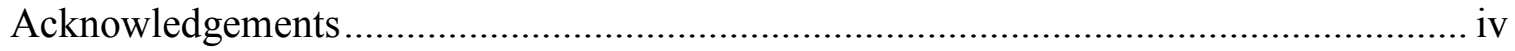

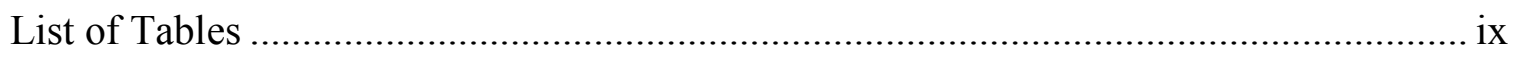

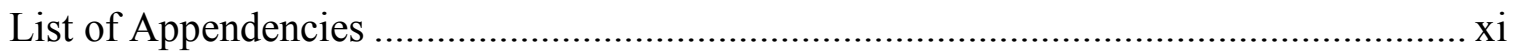

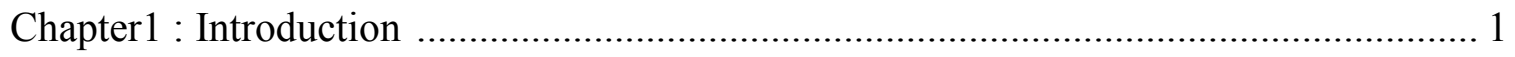

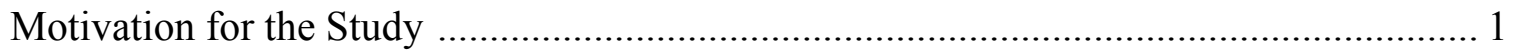

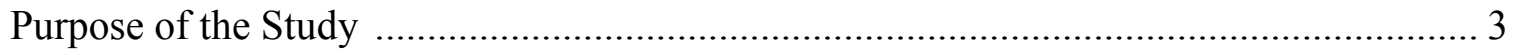

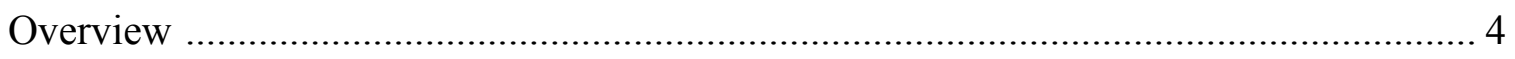

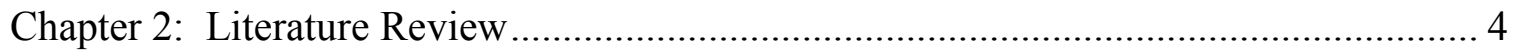

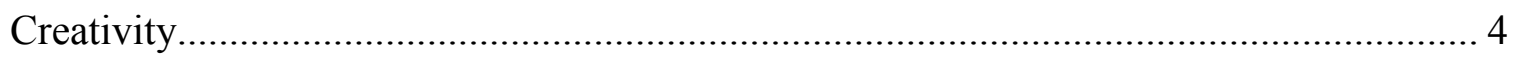

The Creative Process.......................................................................................... 4

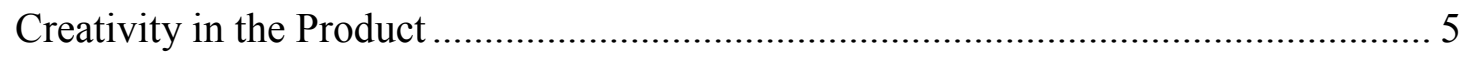

Criterion-referenced Assessment of Creative Writing........................................... 6

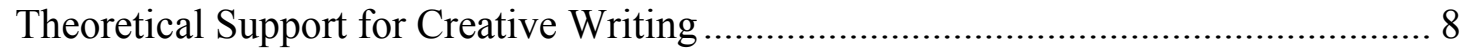

Empirical Support for Creative Writing ….................................................... 10

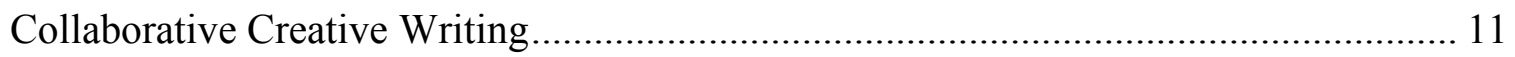

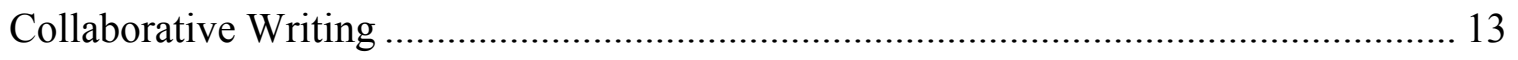

Therotical Support for Collaborative Writing................................................... 13

Empirical Support for Collaborative Writing .................................................. 14

Research Methodologies in Collaborative Writing Studies ................................... 14 


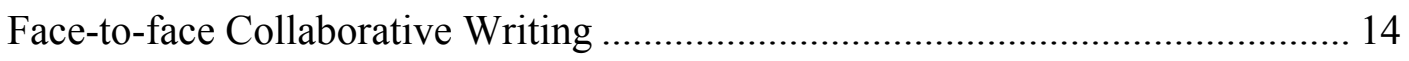

Process in Face-to-face Collaborative Writing Studies ................................... 15

Product in Face-to-face Collaborative Writing Studies .................................. 15

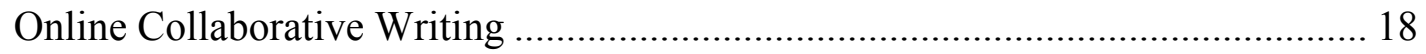

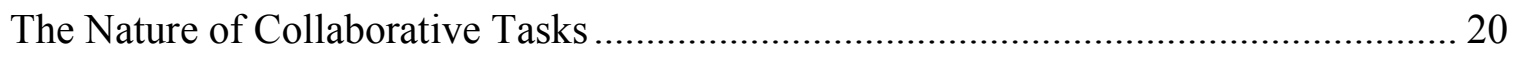

Meaning-oriented Collaborative Tasks................................................................. 20

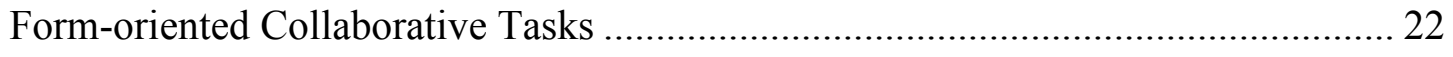

Collaborative Tasks: Form-meaning Continuum........................................... 22

Purpose of the Study and Research Questions........................................................... 24

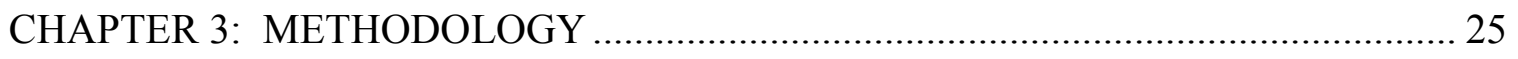

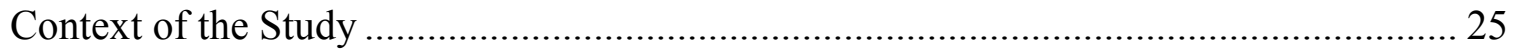

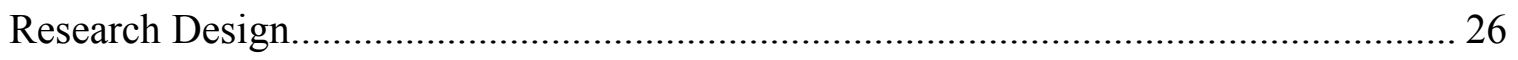

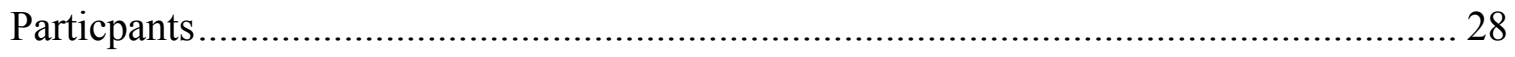

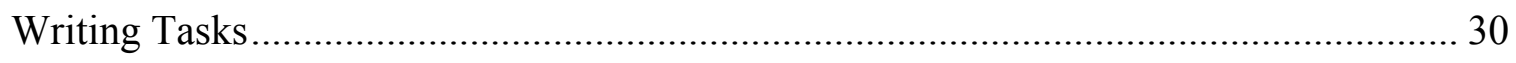

Data Collection Instruments and Procedures ................................................................. 33

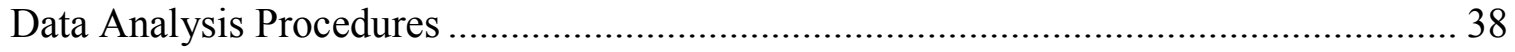

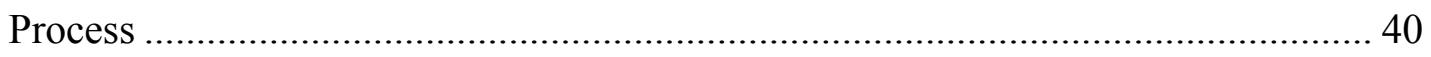

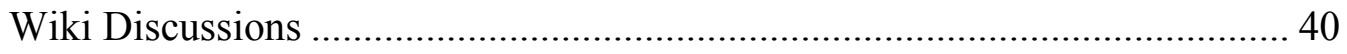

Wiki Revision Histories ........................................................................... 45

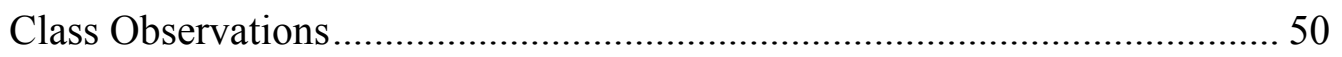

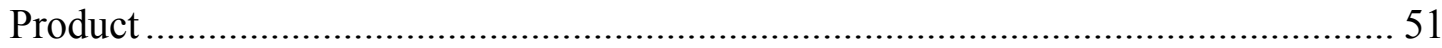

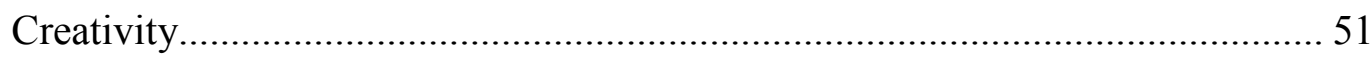

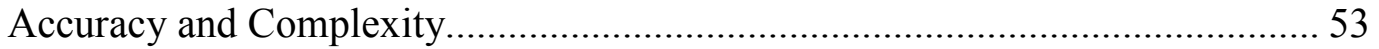




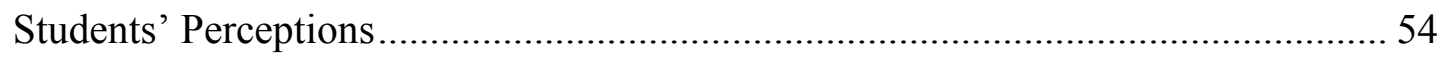

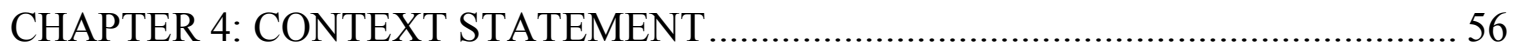

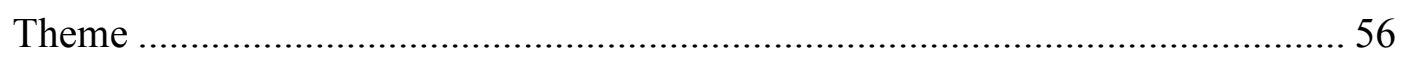

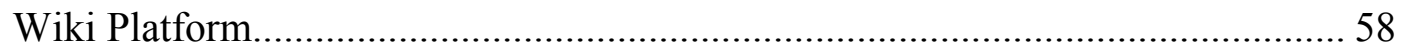

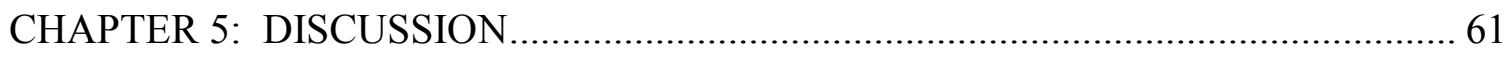

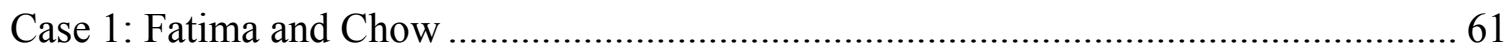

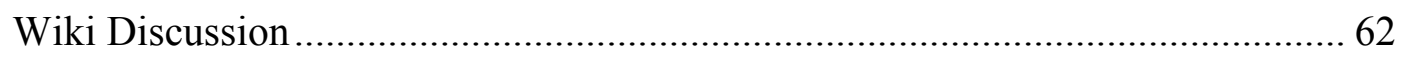

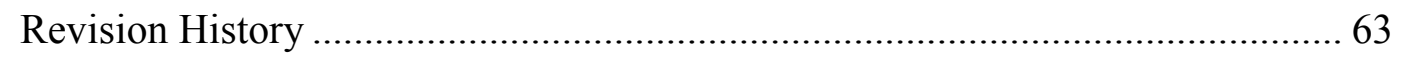

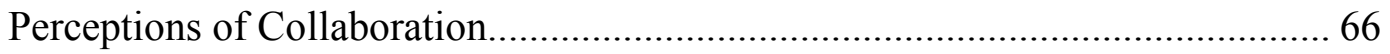

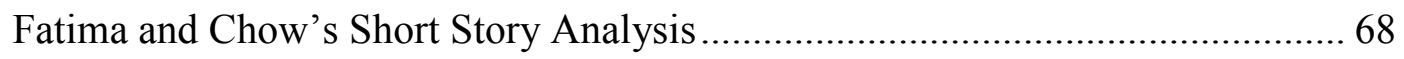

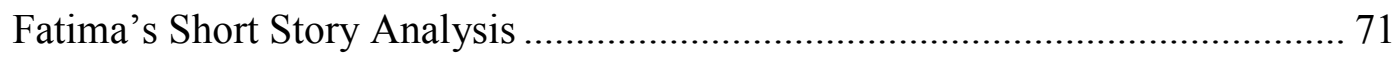

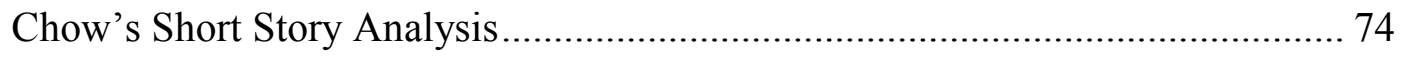

Case 1: Accuracy and Complexity...................................................................... 79

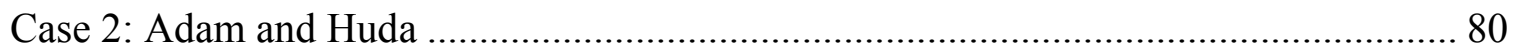

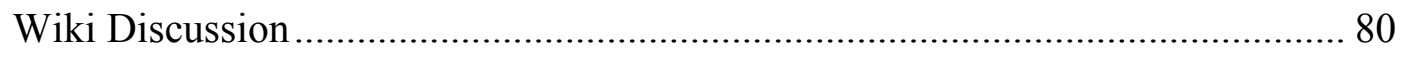

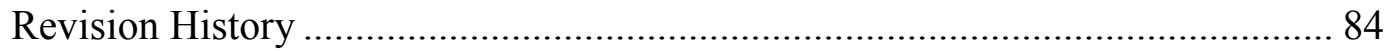

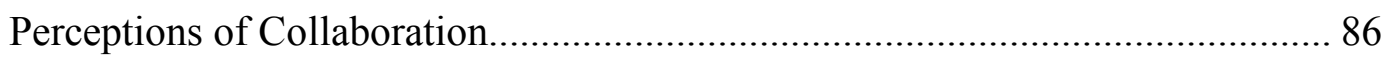

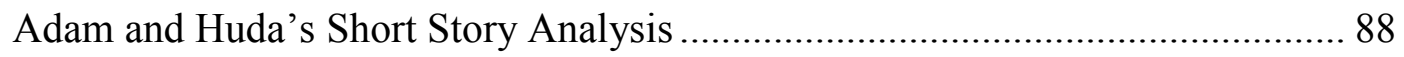

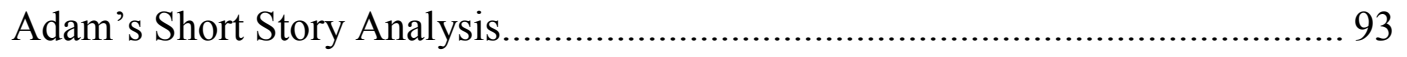

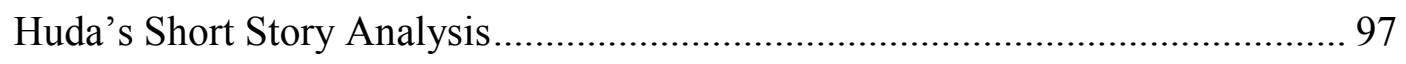

Case 2: Accuracy and Complexity.................................................................. 102

Case 3: Mahmoud, Lei, and Bingwen.......................................................................... 104

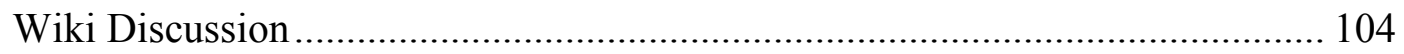




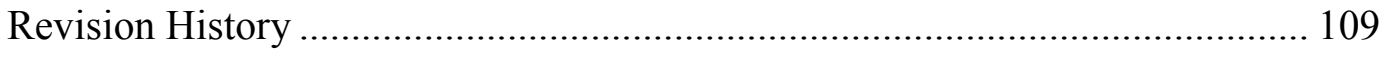

Perceptions of Collaboration........................................................................... 112

Mahmoud, Lei and Bingwen's Short Story Analysis ........................................... 114

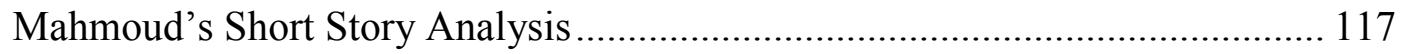

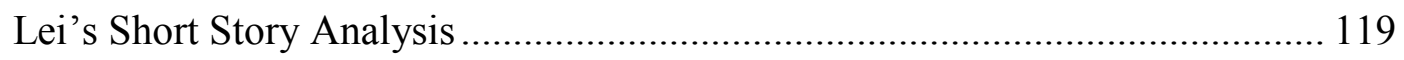

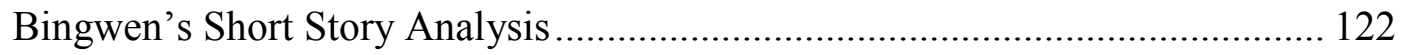

Case 3: Accuracy and Complexity................................................................. 127

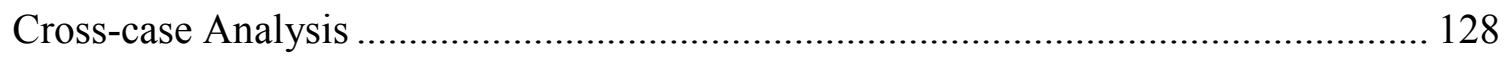

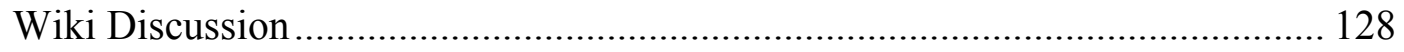

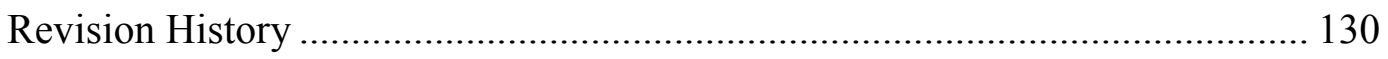

Collaborative Stories vs. Individual Stories........................................................ 131

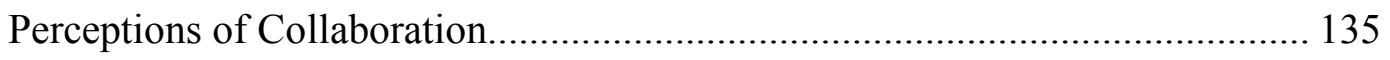

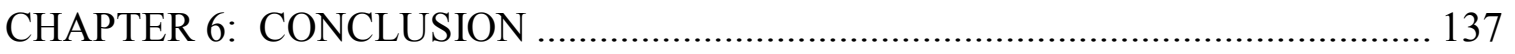

Research Question 1: Process of Collaboration................................................. 137

Research Question 2: Product of Collaboration ............................................... 143

Research Question3: Perceptions of the task ..................................................... 145

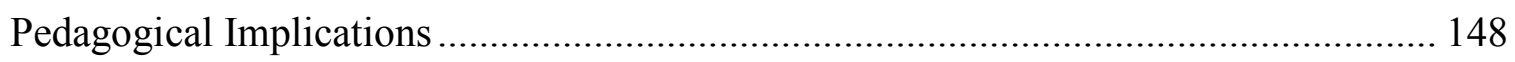

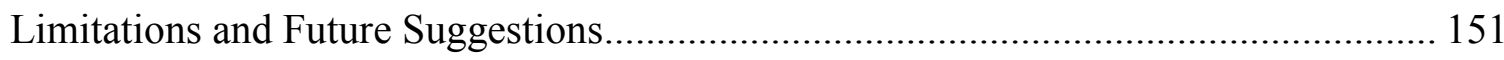

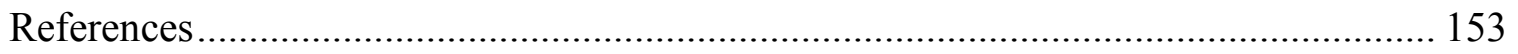

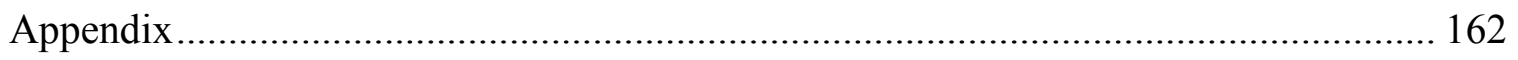




\section{LIST OF TABLES}

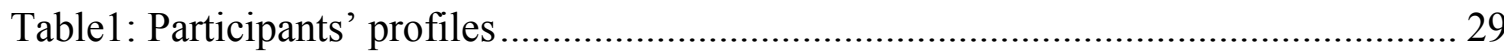

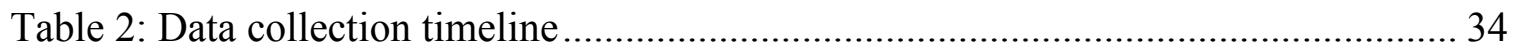

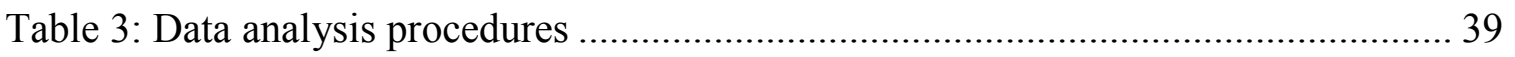

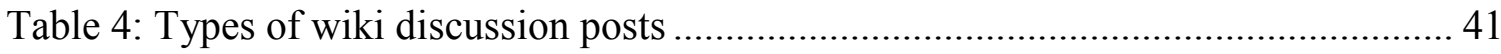

Table 5: Deductive framework to examine creativity in the idea negotiation posts........ 42

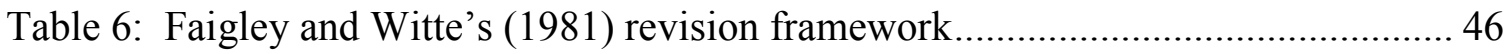

Table 7: Techniques to implement meaning-preserving changes $\&$ meaning changes .... 47

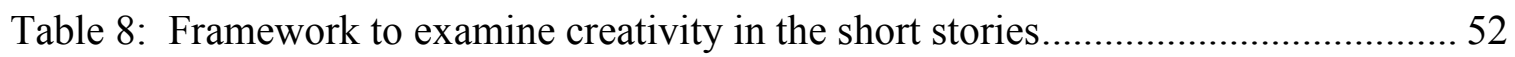

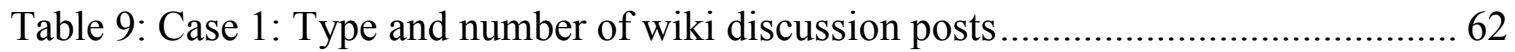

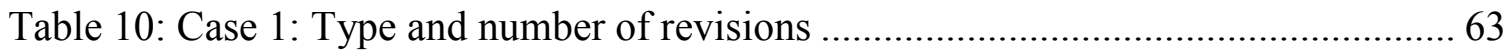

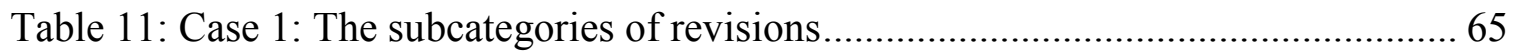

Table 12: Case 1: summary of the qualitative evaluation of creativity ..................78

Table 13: Case 1: results of accuracy and complexity of the short stories ..................... 79

Table 14: Case 2: Type and number of wiki discussion posts ..................................... 80

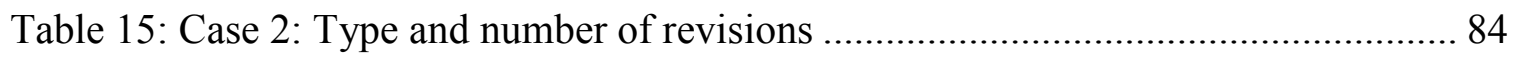

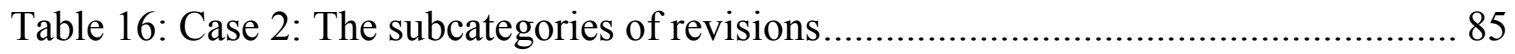

Table 17: Case 2: summary of the qualitative evaluation of reativity.................. 102

Table 18: Case 2: results of accuracy and complexity of the short stories ................... 103

Table 19: Case 3: Type and number of wiki discussion posts................................... 104

Table 20: Case 3: Type and number of revisions ................................................... 109 
Table 21: Case 3: The subcategories of revisions...................................................... 111

Table 22: Case 3: summary of the qualitative evaluation of reativity ..........................126

Table 23: Case 3: results of accuracy and complexity of the short stories ................... 127

Table 24: Cross-case analysis: type and number of wiki discussion posts.................... 129

Table 25: Cross-case analysis: Group roles \& revision behaviors .............................. 130

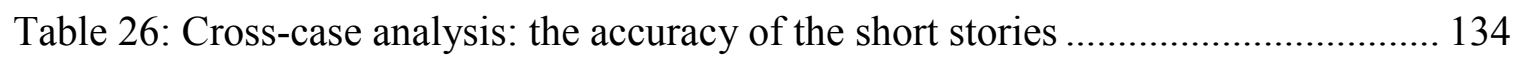

Table 27: Cross-case analysis: the complexity of the short stories ............................. 134 


\section{LIST OF APPENDICES}

Self-assessment Questionnaire.

162 


\section{Chapter 1}

\section{INTRODUCTION}

The field of second language (L2) writing has experienced several paradigmatic shifts as a result of several theoretical frameworks and empirical research findings. These shifts have resulted in the emergence of several teaching frameworks that reflected different conceptualizations and orientations towards teaching L2 writing: the structural model, the functional approach, the expressivist approach, process-oriented writing, content-oriented writing, and genre-oriented writing (Hyland, 2003). Although these frameworks are sometimes presented as historical movements, the "complex reality" of L2 writing is better understood by viewing them as overlapping and complementary perspectives that can be integrated in L2 writing classrooms (Hyland, 2003, p. 2). Given the past susceptibility of L2 writing to paradigmatic changes, it is not surprising that it has continued to be affected by theoretical frameworks, and ongoing technological advances.

The current prominence of social constructivist approaches to learning has naturally influenced discussions and practices in the field of L2 writing. This influence manifests itself in the current emphasis on peer editing and collaborative writing. Several studies have explored the theoretical claims of social constructivist approaches in L2 writing classrooms (Dobao, 2012; Storch, 2005; Storch \& Wigglesworth, 2007; Storch \& Aldosari, 2013). These studies generally suggested that collaborative writing offers opportunities for students to negotiate meanings, co-construct knowledge, and improve language learning. However, collaborative writing studies have mostly focused on 
academic writing activities, and the potentials of collaboration on different writing tasks is worthy of investigation.

Expressivism is another paradigm that has increasingly influenced the field of L2 writing (Hyland, 2003). This perspective highlights the importance of fostering the writer's "aesthetic, cognitive, and moral development" and emphasizes personal voice in second language writing (Burnham, 2001, p. 19). Expressivism has affected L2 writing in terms of goals and task design. Many language educators currently highlight the importance of expressing ideas and content in an appropriate style instead of adopting a form-oriented approach. The influence of expressivism on task design is reflected in arguments for incorporating creative writing tasks and for allowing students to choose writing topics. The expressive nature of these tasks is thought to promote agency, intercultural awareness, language ownership, and understanding of social position and literal capabilities (Buripakdi, 2012; Friere, 1974; Garvin, 2013). However, expressivism has only had a minimal effect on L2 writing (Hyland, 2003), which is reflected in a lack of creative writing tasks in ESL classrooms, and the dearth of rigorous research on the effect of these tasks on language learning.

The digital nature of the twenty-first century has also considerably impacted the field of L2 writing. This effect is reflected in the increasing use of technology in writing classrooms and the wealth of digital programs and applications designed to support various aspects of writing. Several studies have investigated the effect of using technology to support writing skills, and the influence of these technological tools on students' orientation to different writing tasks (Arnold, Ducate, \& Kost, 2012; Ducate, 
Anderson, \& Moreno, 2011; Ducate \& Lomicka, 2008; Kessler, 2009; Kost, 2011; Lee, 2010; Leja, 2007; Oskoz \& Elola, 2012; Zorko, 2009).

This study combines an investigation of these three major influences on L2 writing: collaborative writing, creative writing and technology. Specifically, it examines the influence of ESL learners' digitally mediated collaboration on the creativity, accuracy, and complexity of their jointly produced stories as compared to similar individual writing tasks. In addition, the study examines the process of this collaboration as manifested in the digitally mediated asynchronous interaction of the students and their revision behaviors. Further, the study explores students' perceptions of collaborative creative writing. 


\section{Chapter 2}

\section{Literature Review}

In chapter 2, I present a review of the related literature. The literature review incorporates a discussion of the theory and research in the fields of creative writing, faceto-face and digitally mediated collaborative writing in order to outline the prominent concepts and findings that influenced the design of the current study. Chapter 3 includes a detailed account of task design, data collection and analysis procedures. Before discussing the results of the analyses in Chapter 5, Chapter 4 offers a detailed context statement in which I explain the motivations behind changes that were implemented in task design during the study. Finally, chapter 6 presents the findings, pedagogical implications, limitations, and suggestions for future research. The appendices include the individual and collaborative short stories as well as the self-assessment questionnaire.

\section{Creativity}

Defining creativity continues to be controversial. Creativity has many definitions depending on whether the focus is the process or the product (Huh \& Egbert, 2010). The following sections offer a detailed overview of how previous literature has discussed creativity in the process and the product.

\section{The Creative Process.}

Creativity in the process has been generally discussed as encompassing three creative thinking processes: Combinational thinking; exploratory thinking; and transformational thinking (Boden, 2001). Combinational thinking involves the production of new ideas through association with old ones. Exploratory thinking involves the production of ideas through exploring all the possibilities in a conceptual space while 
maintaining existing rules. Transformational thinking is the process of producing ideas through altering the rules of the conceptual space.

Creativity has also been defined as the capacity to think "fluently" (generate many alternative ideas), "flexibly" (generate ideas from varying points of views), "originally" (create novel ideas), and "elaborately" (provide details). These creative thinking processes are overlapping and ubiquitous to varying degrees in language use (Tin, 2013). That is, language users employ a combination of these processes for humorous and dramatic effects as they engage in daily social interactions. Second language acquisition (SLA) studies that examined creativity in the process have used the above definitions as frameworks of analysis (Huh \& Egbert, 2010; Tin, 2016).

\section{Creativity in the Product.}

Examining creativity in the written product is an ongoing discussion in the creativity literature. Although the predominant notion of creative writing assessment has emphasized its subjectivity and holism (Robinson \& Ellis, 1999; Singleton, 1992), several scholars have recently called for a change in the assessment of creative writing. They argued that the view of creative writing as "automatic, personal, even subconscious necessarily strips the discipline of any academic rigor" (Rodriguez, 2008, p. 167). In line with this argument, Morris and Sharplin (2013) argued against the claim that creative writing assessment is "subjective and impressionistic," and maintained that holistic assessment is no longer appropriate (p. 57). They argued that "observable behavioral characteristics are preferable to idealistic wish lists" (p. 58), and called for consistent and reliable assessment of the observable qualities in the creative writing product. This approach to assessment has become popular among scholars such as Morris and Sharplin 
(2013), Everett (2005), Newman (2007), Weldon (2009), and Rodriguez (2008), who called for using criterion-referenced assessment for creative writing. The following section shows examples of some assessment measures proposed by these scholars.

\section{Criterion-referenced assessment of creative writing.}

- Morris and Sharplin (2013): Language use (original and imaginative use of language; stylistic expressions; control of diction; effective communication of concrete and abstract ideas; effective use of details; and logical organization and coherence), the use of generic conventions, contextual understanding of cultural, social, and historical contexts, awareness of the audience, and the quality of raised issues and ideas.

- Everett (2005): Control of language, organizational coherence, use of details, voice and idiom.

- Newman (2007): Inventive use of language, coherence, unique voice and original observations, Spelling, punctuation, and syntax.

- Weldon (2009): Originality and imagination, use of language, structure, expression of theme, maturity of style, and awareness of the reader.

- Rodriguez (2008): Narrative elements such as plot, setting, time; characters, narration, and point of view, theme and ideology, language (diction), format; punctuation and grammar.

Overall, the reviewed literatures highlight the importance of five categories in assessing creative writing. These categories include generic conventions, language use, themes and ideology, contextual understanding, and reader awareness. These five 
categories of assessment seem to fall within the facets of creativity introduced at the beginning of this chapter. That is, the imaginative and metaphorical use of language suggests an ability to generate a number of alternative ideas (fluency) from varying points of view (flexibility), and demonstrates exploratory thinking. The novel use of language in unexpected ways indicates an ability to generate new ideas (originality) and demonstrates transformational and combinational thinking. The effective communication of concrete and abstract ideas, the effective use of details, and the logical organization and coherence suggest an ability to elaborate (elaboration).

Nevertheless, deductive assessment criteria and especially rubrics are regarded as insufficient by some educators. Donnelly (2015) commented on the creative writing "assessment dilemma" and how deductive assessment measures such as grading rubrics could be perceived as "imposed evaluative practices that may not value or characterize the distinguishing ways in which creative writers learn, think, read, and respond" (p. 224), indicating that an inductive assessment measure is needed to evaluate creative writing. A degree of inductive assessment has also been emphasized by advocates of reference-criterion assessments such as Morris and Sharplin (2013), who stressed the need to develop assessment criteria that are relevant to the task and writing performances of the students rather than imposing a deductive non-negotiable assessment measure. Given the importance of deductive and inductive assessment of the creative product, it is important that future studies assess creativity using a mixture of deductive and inductive measures.

In SLA creativity studies, language play has been particularly emphasized as a feature of the creative product (Tin, 2016). Creativity is defined as "the playful use of 
language to construct new and surprising meaning" (Tin, 2013, p. 387). For example, the advertising slogan "Silence of the stomachs. The serious lamb burger" produces new and surprising meaning by playfully using a well-known movie title, "Silence of the lambs", in a novel context (Tin, 2013, p. 387). The importance of creative language play has been emphasized in language learning (Carter, 2004; Cook, 2000), and is empirically supported by several studies (Bushnell, 2008; Cekaite \& Aronsson, 2005; Kim \& Kellogg, 2007; Pomerantz \& Bell, 2007). Creative language tasks can prompt students to engage in language play, to construct new meanings and to extend old experiences into novel contexts. These creative tasks arguably "destabilize" learners' interlanguage, and motivate them to expand their linguistic repertoire by broadening their vocabulary, retrieving grammar rules, and combining vocabulary in unfamiliar ways. This process is suggested to "prevent cognitive fixation and makes the language memorable" (Tin, 2013, p. 387). The sections below detail theory and research that supports the use of creative writing tasks in language classrooms.

\section{Theoretical support for creative writing.}

Creative writing in language classrooms is supported by language evolution theories. Theories such as emergentism posit that language is a "complex, adaptive, dynamic" system (Tin, 2011, p. 217). The trajectory of language development is motivated by the speaker's need to communicate new, complex, and unfamiliar meanings. This need prompts language users to innovate new linguistic signs to meet their purposes (Toolan, 2003).

This emergenist view of language is not only applicable to the first language (L1) but also to people learning an L2. In contrast to communicative language tasks that 
require language learners to communicate a self-known meaning, which may not be known to the interlocutor, creative writing tasks arguably increase task complexity by requiring language learners to innovate new meanings (Tin, 2013). Complex creative tasks such as poetry or short story writing are thought to destabilize the interlanguage of learners, forcing them to engage in processes of segmentation, reanalysis, and analogy of their linguistic resources, which ultimately lead to language development (Tin, 2011). Additionally, Tin (2013) argued that the sociocultural Vygotskian framework can be applied to creative writing tasks. That is, the process of producing complex and new meanings can initiate a "creative zone" similar to the zone of proximal development. This zone arguably facilitates language development even with the absence of scaffolding ( $\mathrm{p}$. 388).

In addition to the theoretical support discussed above, several claims have been made to support the value of creative writing to language development. Creative writing is believed to engage learners with language on a deeper level of processing than expository writing (Craik \& Lockhart, 1972), as it allows them to engage with imaginative expressions involving both emotion and cognition unlike the communicative referential functions of expository writing (McRae, 1991). Additionally, it can facilitate language development at all levels: grammar, vocabulary, and discourse (Craik \& Lockhart, 1972). Creative writing also allows L2 learners to self-identify with the language, which ultimately reflects on their self-esteem and motivation to learn the language (Zhao, 2015). Furthermore, creative writing has been suggested to empower students and allow them to take ownership of the language. This in turn is said to weaken 
linguistic inequalities and hegemonic practices, and give them more language rights (Buripakdi, 2012).

\section{Empirical support for creative writing.}

Despite the abundance of theoretical claims supporting the use of creative writing tasks in language classrooms, few empirical studies have examined how these tasks might contribute to language development (Tin, 2011). Findings from these studies indicate that creative writing does indeed contribute to complex syntax and creative language use (Tin, 2011). It has also been linked to improved expository writing by providing practice of the narrative elements of story writing (Tickoo, 2001). Creative writing also seems to offer language learners the opportunity to expand their vocabulary, and sentence structures (Garvin, 2013). In addition to linguistic development, the affective benefits of creative writing have been emphasized in research. Studies have suggested that creative writing has a positive effect on students' attitudes towards writing (Chao and Lo, 2011; Garvin, 2013; Tok \& Kandemir, 2015).

Despite the advantages of creative writing in language classrooms, the field of English for Academic Purposes (EAP) has primarily focused on academic writing (Benesch, 2001). As a result, creative writing has been treated circumspectly (Hyland, 2003) and few studies have investigated its use in English for academic purposes (EAP) classrooms. Additionally, few studies examined collaborative creative writing (Chao \& Lo, 2011; Tin, 2011). Thus, exploring collaborative creative writing in (EAP) contexts is warranted. The following sections provides a brief overview of collaborative creative writing studies. 


\section{Collaborative Creative Writing}

Although creative writing has been traditionally characterized as individualistic, "non-directive and personal" (Hyland, 2003, p. 9), the emergence of social constructivist approaches and collaborative pedagogy has highlighted the socially mediated nature of writing. Thus, creative writing is no longer solely seen as an individual act of creativity (Chin, 2014), and has been associated with collaborative approaches to writing. Several studies in first language (L1) contexts have explored the use of collaborative creative writing in the classroom (Bishop, 1995; Cox, 1990; Greeves, 1987; Jones, 1986; Vass, 2007; Yagelski, 1994).

Despite its existence in L1 settings, few studies have investigated collaborative creative writing in L2 classrooms. These studies either examined EFL students' perceptions (Chao \& Lo, 2011) of collaborative creative writing tasks, or examined students' interactions and the effect of different creative writing tasks on language complexity (Tin, 2011). These studies were restricted to foreign language (FL) settings, which indicates the need to explore collaborative creative writing in an ESL context. Thus, the focus of the current study is to analyze students' discussions and revisions while collaborating using a wiki and compares the jointly produced creative writing texts (short stories) to others written individually by the same students on three dimensions: creativity, accuracy, and complexity.

Since the current study implements online collaborative and individual creative writing tasks, the following section explores research on collaborative writing, a majority of which was on academic writing tasks. I will review the research methodologies in face-to-face and online collaborative writing studies. I will then proceed to discuss 
research on the nature of collaborative writing tasks to situate the current study on wikibased collaborative creative writing. 


\section{Collaborative Writing}

Collaborative writing is defined as the co-authoring of a written text by two or more participants (Storch, 2012). Collaborative writing is a combination of both process and product: The process entails active participation from all members throughout the writing process including generating ideas, negotiating structure, and editing the text; and the product is the final written output resulting from this collaborative effort (Storch, 2012). Collaboration does not include the division of independent tasks among group members, and the assembly of the final product. Rather, all participants in collaborative writing tasks are involved in every step of the writing process (Arnold, Ducate, \& Kost, 2012).

\section{Theoretical support for collaborative writing.}

Collaborative writing in language classrooms is supported by several theoretical frameworks. The social interaction and dialogue afforded by collaborative writing tasks are regarded as a fundamental principle for L2 learning in major social theories of second language acquisition (SLA). Long's (1996) interaction theory posits that episodes of meaning negotiation that occur in communication breakdowns can result in comprehensible input, explicit and implicit feedback, and negative evidence. These episodes help language learners notice gaps in their interlanguage system and modify their output, which consequently facilitates language acquisition (Gass \& Mackay, 2007). In view of this theory, collaborative writing offers language learners opportunities for authentic interaction that promotes language learning.

Vygotsky's (1978) sociocultural theory contends that learning is mediated when collaboration occurs between expert and novice participants. The underlying premise of 
the theory lies in the concept of the zone of proximal development, which is defined as the difference between what learners can achieve independently and what they can achieve when scaffolded by the teacher or a more competent peer (Lantolf \& Thorne, 2007). In light of this theory, collaboration scaffolds learners' development to their full potential and mediates language learning. Participants in collaborative tasks pool their expertise to create the final product, a process referred to as collective scaffolding (Donato, 1994).

\section{Empirical support for collaborative writing.}

The importance of collaborative writing has also been demonstrated by empirical research. Studies conducted in face-to-face classroom settings have shown that collaborative writing offers students opportunities to negotiate ideas, structure, and form. This interactive dialogue resulted in increased accuracy (Dobao, 2012; Storch, 2005; Storch \& Wigglesworth, 2007; Storch \& Aldosari, 2013), and increased complexity and task fulfilment of the collaboratively written texts in comparison to those individually produced (Storch, 2005).

\section{Research Methodologies in Collaborative Writing Studies}

\section{Face-to-face collaborative writing.}

Studies on face-to-face collaborative writing have employed two research methodologies to examine the pedagogical advantages of collaboration. The first approach examines the process of collaborative writing while the second one focuses on the final product. The following sections discuss these approaches in detail. 


\section{Process in face-to-face collaborative writing studies.}

The process of collaborative writing has been examined qualitatively at two levels: The first level involves determining the time that participants spend on each of the writing phases (planning phase, composing phase, and revision phase), while the second level involves determining the focus of the learners' interaction episodes. An episode is a single turn or multiple turns in which learners focus on a particular aspect of the task (Wigglesworth \& Storch, 2009). Episodes at this level include task clarification, idea generation, and structure or language related episodes (LREs). LREs are defined as segments of learners' talk characterized by explicit focus on language use (Swain \& Lapkin, 1998), including form-LRES (F-LREs), lexis-LREs (L-LREs), and mechanicsLREs (M-LREs). Studies exploring the process of collaborative writing indicated that collaborating students spent the majority of the time on the composing phase, and paid little attention to the revision phase (Storch, 2005; Storch \& Wigglesworth, 2007; Wigglesworth \& Storch, 2009). They also reported that learners mostly focused on LLREs rather than F-LREs (Storch \& Aldosari, 2013; Storch \& Wigglesworth, 2007; Wigglesworth \& Storch, 2009). One exception was Dobao (2012), who reported an equal focus on F-LREs and L-LREs. The current study incorporates a qualitative analysis of students' wiki discussions during the collaborative writing process. The dialogues are examined for instances of idea negotiations (creativity) and LREs (accuracy and complexity).

\section{Product in face-to-face collaborative writing studies.}

The second approach implemented in face-to-face collaborative writing studies is a quantitative analysis of the final written product. This approach compares individually 
and collaboratively written products in terms of fluency, accuracy, and complexity. The written texts are segmented into t-units, which have been defined as "one main clause plus whatever subordinate clauses happen to be attached or embedded within it" (Hunt, 1966, p.735). Although several criticisms have been voiced against t-unit analyses (e.g., that they do not capture the rhetoric of coordinated clauses and divide the semantic whole) (Bardovi-Harlig, 1992), t-units continue to be the most common analysis unit used to study the linguistic features of L2 learners (Ellis \& Barkhuizen, 2005).

Accuracy in these studies has been operationalized as the ratio of error-free clauses to total clauses, error-free t-units to total units, errors to words (Dobao, 2012), and the number of errors per word counts (Storch, 2005). The most widely used measures include the number of errors per word counts and the percentage of error-free clauses (Ellis \& Barkhuizen, 2005). Although these methods of analysis are criticized for not distinguishing between the type and severity of errors (Bardovi-Harlig \& Bofman, 1989), they account for the distribution of errors in relation to words, clauses, and t-units (Storch, 2005).

In previous studies, complexity has been operationalized as the number of clauses per t-units, the number of dependent clauses per all clauses (Storch, 2005; Wigglesworth $\&$ Storch, 2009), the number of words per clause, and the number of words per t-unit and (Dobao, 2012). However, recent corpus-based studies have raised some doubts about the appropriateness of measuring complexity in terms of clausal subordination. Based on a thorough analysis of oral and written corpora, Biber, Gray, and Poonpon (2011) concluded that these measures only capture clausal complexity, which they argue is an 
oral discourse feature, and do not capture phrasal complexity, which is predominant in academic writing.

Studies examining the product of collaborative writing have yielded contradictory results. Storch (2005) reported increased accuracy and complexity in data commentary texts that were written collaboratively as compared to texts written individually. In contrast, Wigglesworth and Storch (2009) reported a positive effect on accuracy for the argumentative essays produced collaboratively in comparison to those written individually. However, no effect on complexity or fluency was found. Congruent with these findings, Dobao (2012), comparing the effect of the number of participants on collaborative writing, found that groups outperformed individual writers and pairs and produced the more accurate texts when working on jigsaw story writing, yet no effect on fluency or complexity was reported. These findings are in line with Storch and Wigglesworth (2007), who found that their participants, working on two different tasks (argumentative essay and data commentary), produced more accurate texts when working collaboratively as compared to texts written individually. However, the collaboration did not have an effect on the complexity or fluency of the texts. Another intriguing finding from this study was that the data commentary elicited more complex and more accurate texts than the argumentative essay. The nature of the task has been observed to be a mediating factor that influences students' orientation to collaborative writing tasks (Storch, 2012), and will be discussed in detail in later sections. 


\section{Online collaborative writing.}

Technological advances have greatly facilitated collaborative tasks. Many technological tools such as blogs, chats, and wikis are used to mediate this collaboration. The field of L2 writing has paid special attention to the use of wikis in collaborative writing tasks. A wiki is a website that allows learners to collaboratively create and edit a written text (Arnold et al., 2012), and thus wikis "challenge the historical understanding of writing as a solitary endeavor" (Oskoz \& Elola, 2012, p. 148), and facilitate collaboration in writing. Because the dynamics might differ in technology-mediated collaboration, it is important to distinguish between face-to-face and online collaborative writing. The following section describes common trends and methodologies used in online collaborative writing.

There is a growing body of literature examining the use of wiki-based collaborative writing tasks in language classrooms. Within the limited existing research, attention has been mostly directed to the writing process such as group dynamics (Arnold et al., 2012; Zorko, 2009), wiki revision behaviors (Arnold et al., 2012; Kessler, 2009; Kost, 2011), wiki discussions (Elola \& Oskoz, 2010a; Oskoz \& Elola, 2012), and students' perceptions and attitudes toward collaborative writing tasks (Ducate, Anderson, \& Moreno, 2011; Elola \& Oskoz, 2010a; Kost, 2011; Lee, 2010; Zorko, 2009). These studies generally concluded that students tend to prioritize meaning over form in their wiki discussions and revisions and that they express positive perceptions of collaboration. However, even with the integration of wikis in some language classrooms, few wiki studies have examined the effect of this online collaboration on the final written product 
(Mak \& Coniam, 2008) or combined an investigation of both product and process (Elola \& Oskoz, 2010a; Kost, Arnold, \& Ducate, 2014).

Additionally, the findings of wiki studies do not align with the majority of faceto-face studies, which reported a positive effect on accuracy of the collaboratively written texts. For instance, Mak and Coniam (2008) examined the quality of the writing product in terms of fluency, complexity, and accuracy in a wiki-based study. The results indicated that whereas there was an effect on complexity, no substantial development was noted on accuracy or fluency. Similarly, Elola and Oskoz (2010a) explored learner perceptions of the wiki-based collaborative writing task in addition to the nature of the interaction during the writing process and the quality of the final product (complexity, fluency, and accuracy). They concluded that there were no statistically significant differences between the collaboratively written and individually written texts. Congruent with these findings, Kost et al. (2014) concluded that the degree of wiki-based collaboration during the writing process did not affect the accuracy, length, or cohesion of the final product. The only exception is Bikowski and Vithanage (2016), who reported statistically significant gains in the posttests of the experimental group who worked collaboratively, the majority of wiki studies did not report and effect on the accuracy of collaborative product.

The scarcity of wiki studies examining the process and product of collaborative writing and the incongruence of their results with face-to-face collaborative writing necessitates further research. To address this gap, the current study explores the process and product of collaborative creative writing using a wiki. Since task type has been suggested as a factor influencing collaboration (Storch, 2012), the following section 
reviews studies on the effect of the nature of collaborative tasks on students' attention to form and meaning.

\section{The Nature of Collaborative Tasks}

Several studies have examined the effect of task type on students' collaboration. Some of these studies implemented meaning-oriented tasks such as reflective writing, brochure writing, and story writing (Kessler, 2009; Lee, 2010; Mak \& Coniam, 2008). Other studies compared the effect of a variety of tasks on learners' attention to form (de La Colina \& García Mayo, 2007; García Mayo, 2002; Nassaji \& Tian, 2010; Storch, 2001; Swain \& Lapkin, 2001). These tasks included editing (correcting grammar mistakes in a text), text reconstruction (inserting words into a cloze passage), dictogloss (rewriting a text after listening), and picture jigsaws (co-constructing a text based on pictures).

\section{Meaning-oriented collaborative tasks.}

Collaborative writing studies employing wiki-based meaning-oriented tasks yielded contradictory results regarding students' focus on form and meaning. Kessler (2009) reported a general tendency to focus on meaning rather than form in his wikibased study. Despite explicit task instructions that directed participants to focus on form, form revisions were superficial and sparse. Participants in Kessler's study reported that they perceived the task to be meaning-focused and thus ignored grammatical errors that did not impede meaning. The results indicated that the participants displayed a threshold of tolerance for grammatical errors in meaning-focused tasks. Kessler concluded that learners are more likely to attend to grammar when the primary task is to collaborate on language use. This condition was not provided in the study, since meaning was the 
primary task, and form was a secondary task. In line with this argument, Mak and Coniam (2008) did not report a substantial development in accuracy of the collaborative meaning-oriented wiki-based task (brochure writing) in their study. Contrastingly, Lee (2010) implemented several collaborative meaning-focused wiki-based writing tasks (i.e. story writing) and indicated that the participants collaborated on both meaning and form. Similarly, Arnold et al. (2012) reported that students worked both collaboratively and cooperatively on form revisions in their meaning oriented wiki-based task (expository writing).

This finding is congruent with face-to-face studies that employed collaborative meaning-oriented writing tasks (Dobao, 2012; Storch, 2005; Storch \& Aldosari, 2012; Storch \&Wigglesworth, 2007; Wigglesworth \& Storch, 2009). Findings from these studies indicated that although participants mostly focused on meaning and not form-as evident in the time they devoted to the composition phase vs. the editing phase, and the small number of F-LREs - positive results on the accuracy of the final written product were reported. Storch (2012) contended that these conflicting results were due to a number of factors, such as the number of participants in collaborative tasks, and the degree of explicit grammar instruction. She explained that attention to form in collaborative meaning-oriented writing tasks can be aided through reducing the number of participants (Arnold, Ducate, \& Kost, 2009; Dobao, 2012; Kost, 2011) and employing explicit grammar instruction (Lee, 2010). Studies that employed explicit grammar instruction as a part of their task design are discussed in the following section. 


\section{Form-oriented collaborative tasks.}

The effect of explicit grammar instruction on the process and product of collaborative tasks is evident in face-to-face studies that compared how different collaborative tasks influenced participants' attention to form. Storch (2001) examined the LREs generated by dyads working face-to-face on three tasks: a short composition (meaning-oriented), a text-reconstruction task (form-oriented), and an editing task (formoriented). The results indicated that the short composition generated fewer F-LREs than the other two tasks, with only few dyads attending to form after completing the writing. Similarly, De La Colina and García Mayo (2007) reported that face-to-face textreconstruction tasks (form-oriented) generated more LREs than a story writing picture jigsaw (meaning-oriented) and a dictogloss (meaning-oriented). The findings were in accordance with García Mayo (2002), who indicated that text-reconstruction tasks (formoriented) generated more LREs than did dictoglosses (meaning-oriented). The results are also in line with Swain and Lapkin (2001), who reported that story writing picture jigsaws (meaning-oriented) and dictoglosses (meaning-oriented) generated similar numbers of LREs. Similarly, Nassaji and Tian (2010) concluded that editing tasks (formoriented) yielded higher gains of knowledge of English phrasal verbs than did textreconstruction tasks (form-oriented).

\section{Collaborative tasks: a form-meaning continuum.}

The preceding review of meaning- and form-oriented tasks indicates that face-toface and wiki collaborative writing tasks can be traced along a continuum of form and meaning. Writing tasks which are based on written prompts (i.e. essays, brochures, and reflections), pictorial prompts (i.e. data commentaries and picture jigsaws), or oral 
prompts (i.e. dictogloss) can be regarded as meaning-oriented tasks. The latter two, pictorial and oral prompts, in effect promote meaning more than written prompts because they provide the students with an explicit content to be conveyed in the writing, which aids their attention to form more than meaning. On the other hand, written prompts require the students to develop their own arguments and thus direct their attention to meaning more than from. Meaning-focused tasks generally result in less attention to form and thus fewer LREs. Other tasks such as text reconstruction and editing tasks can be considered form oriented. These tasks direct learners' attention to form and result in more LREs. The review suggests that the more meaning-focused the task, the less attention to form it generates. The more overtly grammar-focused the task, the more likely students will focus on form. Based on the review, creative writing tasks in which learners collaboratively create a written product without prompts are on the meaning end of the form-meaning continuum. It can be speculated that such tasks negatively affect the grammatical accuracy and complexity of the final product because its meaning-focused design encourages learners to focus more on meaning and less on form.

The majority of the discussed studies were face-to-face studies that utilized academic writing tasks (Storch, 2005; Storch \& Wigglesworth, 2007; Wigglesworth \& Storch, 2009). Few studies integrated collaborative creative writing tasks in their design (Chao \& Lo, 2009; de La Colina \& García Mayo, 2007; Dobao, 2012; Lee, 2010; Swain \& Lapkin, 2001). With the exception of Lee (2010), and Chao and Lo (2009), the content of the short stories in all of these studies was predetermined by the teacher using pictorial prompts such as picture jigsaws (Dobao, 2012) or oral prompts such as dictogloss combined with picture jigsaws (de La Colina \& García Mayo, 2007; Swain \& Lapkin, 
2001) . Learners did not have to create imaginative content but rather described or restated existing content. Additionally, few studies combined the use of wikis and creative writing in their task design (Chao \& Lo, 2009; Lee, 2010).

Further, research on whether students orient to form in wiki studies has generated conflicting results (Elola \& Oskoz, 2011). As many scholars argue that wikis promote attention to form (Elola \& Oskoz, 2011), it is worth investigating whether this argument will hold true for creative writing tasks. Thus, the current study explores whether wikibased collaboration influence students' orientation to form as evident in their wiki discussions, wiki revisions, and the accuracy and complexity of the final creative writing product.

\section{Purpose of the Study and Research Questions}

The purpose of my study is to examine the process and product of collaborative creative writing tasks in an English for Academic Purposes (EAP) classroom. Specifically, the study will address the following research questions:

1. How do students collaborate to write a short story using a wiki platform?

2. How do the collaborative short stories compare to individual short stories produced by the same students on the three dimensions of creativity, accuracy, and complexity?

3. How do students perceive the process and product of computer-based collaborative short story writing? 


\section{Chapter 3}

\section{Methodology}

\section{Context of the Study}

The present study was conducted in an English as a second language (ESL) course offered by an Intensive English Language Program (IEP) at a university in the Northwest of the U.S. The IEP program at this university aims to prepare non-native English speakers with the necessary linguistic, cultural, and academic skills to pursue undergraduate and graduate degrees in the U.S. It offers three levels of foundational courses: Level 1 (entry); level 2 (pre-intermediate); and level 3 (intermediate). It also offers two levels of academic preparation courses, Level 4 (upper intermediate) and Level 5 (advanced), as well as pre-entry courses for beginning-level students prior to their enrollment in the entry program. The students are placed at these levels based on their performance on a placement test. After passing a level, students move to the next level. At each level, students are enrolled in Grammar, Writing, Reading, and Listening and Speaking courses. In addition to the core courses, the program offers a variety of Skills Enhancement Courses (SECs) from which students must choose one each term. Examples of these SECs include: Vocabulary Building, Pronunciation, TOEFL and IELTs preparation, and Creative Writing. Students' choice of these courses is dependent on both their interests and their proficiency level. That is, different SECs are open for beginner, intermediate, and advanced ESL students. Unlike the core courses, the main requirement of these SECs is in-class participation rather than out-of-class homework.

The data for the current study was collected from one such SEC, Creative Writing, during winter term 2016. This course is open to intermediate, upper 
intermediate, and advanced ESL students (levels 3-5). The objectives of this course include promoting English learning through expressive and creative writing tasks such as poetry, comics, and short stories. As with all SECs in the IEP, this course aims to supplement core courses with a variety of skills to help students learn the language, adapt to the culture, and achieve a variety of personal and social goals. The class is a two-credit class that, over the course of the 10 -week term, met once a week for the period of two hours. It took place in a computer lab that featured 20 computer stations with Internet service. The computer stations were arranged in four rows and two columns allowing a wide aisle in the middle. The lab also featured a teacher podium with a computer, document camera, and overhead projector at the front of the classroom.

The class was taught by a senior instructor in the IEP program. The teacher had been tutoring and teaching ESL students since 1988. She has been a full time teacher in the IEP for 10 years, during which she has taught a variety of academic writing classes. The teacher had taught the Creative Writing course once before and had implemented similar creative writing projects in her grammar classes. In addition to her experience as an ESL teacher, she had also worked six years in a publishing company where she ran a proofreading department and edited textbooks.

\section{Research Design}

The current study explored how implementing a computer-based collaborative short story writing task in a class of intermediate and advanced ESL students influenced the task process and product. To explore these issues, a mixed methodology that is predominantly qualitative was deemed most appropriate. By capturing "the lived experiences of real people in real settings" (Hatch, 2002, p. 6), qualitative research 
seemed better suited to analyze students' online discussions and explore their perceptions of the collaborative short story writing task. Additionally, creativity is a concept that is difficult to quantify and is more appropriately explored using a holistic approach that does not segment creativity into "isolated, incomplete, and disconnected variables" (Hatch, 2002, p. 9). The accuracy and complexity of the short stories were analyzed quantitatively in order to compare between the individual and collaborative short stories.

The study was designed as a multiple case study with embedded design. A case study is defined as "an empirical inquiry that investigates a contemporary phenomenon within its real-life context, especially when the boundaries between the phenomenon and the context are not clearly evident...[and] relies on multiple sources of evidence, with data needing to converge in a triangulating fashion" (Yin, 1994, p. 13). A case study design was deemed an appropriate research design for the following reasons: (1) the study focuses on exploratory and explanatory research questions (e.g., "what" and "how"), (2) it explores a contemporary rather than a past event and (3) the investigator has little control over the behaviors of the informants. According to Yin (1994), these are the three conditions that make a case study design appropriate for the research inquiry.

The cases or the "primary unit[s] of analysis" (Yin, 1994, p. 21) in the present study are the groups of students working together on a short story. Because each group is comprised of a number of students or "subunits of analysis" (p. 44) from which data was collected and analyzed, a multiple embedded case study design was implemented in the present study. The design allows for a thorough analysis of the subunits leading to a holistic understanding of the overall case and a cross-analysis of the multiple cases (Yin, 1994). 


\section{Participants}

The present study relied on convenience sampling. Students enrolled in the Creative Writing course were requested to voluntarily participate in the study during the second class session. Standard procedures such as consent forms were conducted in compliance with IRB protocol. The nine students in the class all volunteered to participate in the study. Table 1 summarizes the biographical information of the nine informants (names listed are pseudonyms). The informants were from four countries: Saud Arabia (3 students), China (4 students), Japan (1 student), and Ukraine (1 student). The participants varied in terms of their period of study in the IEP program: 24 months (1 student), 20 months ( 2 students), 8 months ( 5 students), and $1^{\text {st }}$ term ( 1 student). Accordingly, their English proficiency levels, as measured by the American Council on the Teaching of Foreign Languages guidelines (ACTFL, 2015), ranged from low intermediate ( 1 student), to mid intermediate ( 6 students), and low advanced ( 2 students). None of the informants had previous experience with creative writing in any language as reported in the final interviews. The informants expressed different reasons for joining the class in a written needs assessment that was conducted at the onset of the course. The majority of the students saw the class as an opportunity to improve their academic writing skills (6 students), while the three remaining students expressed an enthusiasm toward creative writing (3 students). 


\section{Table 1}

Participants' Profiles

\begin{tabular}{ccccc}
\hline Participant & Level & Country of origin & Gender & $\begin{array}{c}\text { Period of } \\
\text { study in } \\
\text { IEP }\end{array}$ \\
\hline Fatima & Low intermediate & Saudi Arabia & Female & 20 months \\
\hline Mahmoud & Low advanced & Saudi Arabia & Male & 20 months \\
\hline Huda & Mid intermediate & Saudi Arabia & Female & 8 months \\
\hline Lei & Mid intermediate & China & Male & 8 months \\
\hline Bingwen & Low advanced & China & Male & 24 months \\
\hline Chow & Mid intermediate & China & Female & 8 months \\
\hline Mei & Mid intermediate & China & Female & 8 months \\
\hline Kyou & Mid intermediate & Japan & Male & 8 months \\
\hline Adam & Mid intermediate & Ukraine & Male & $1^{\text {st }}$ quarter \\
\hline
\end{tabular}

The nine students were grouped into three pairs and one triad: Group 1 (Fatima \& Chow), Group 2 (Adam \& Huda), Group 3 (Mahmoud, Lei, \& Bingwen), and Group 4 (Kyou \& Adam). These group constellations were chosen based on the following factors: cultural background, English proficiency (as observed in their written and spoken output), imaginative ability (as depicted in previous written tasks), and familiarity with science fiction, which was the primary task in the current study (as evident from their responses to activities used to activate their relevant schemata). These factors were considered in an effort to create diverse group constellations.

It is worth noting that the short stories written by students in Group 4 were not included in the analysis for methodological reasons. Students in Group 4 participated in 
the collaborative task, but were absent during the last two class periods and did not complete the individual task. Because of that, data from this group were only used in reference to the first research question about the collaborative process. Their wiki discussion and revision history provided insights into patterns of group dynamics across the groups, which motivated my decision to draw on their data for the cross-case analysis. However, the students in the group did not spend an equal amount of time on their collaborative and individual stories. Thus, comparing their collaborative story to the two individual stories was not deemed insightful for the purpose of the study. As a result, the findings section presents a thorough analysis of the first three groups (Groups 1, 2, \&3) and excludes Group 4. However, data from Group 4 is used in the cross-case analysis and conclusion when appropriate.

\section{Writing Tasks}

The students completed two writing tasks in this course, both of which were related to science fiction. Science fiction was chosen as a theme to encourage the students to step out of their comfort zones and explore imaginative alternatives. The first task, which spanned weeks 3 to 6 , was a collaborative writing task. The groups discussed above used wikis to collaboratively write a short story responding to a prompt. The prompt was given in the form of a movie trailer. The teacher showed an excerpt from The Guardians of the Galaxy, which exhibits an emotional scene of a young boy, Peter, losing his mother to cancer. Immediately following her death, the boy runs out of the hospital and is abducted by a spaceship. Twenty-six years later, Peter is shown on another planet stealing an orb and fighting aliens. After watching the excerpt, the teacher led an activity in which the students collectively wrote the opening paragraph of the short story. The 
students orally narrated sentences, words, and phrases while the teacher wrote the following paragraph on the board.

"Do not give up" those were the lyrics to the song Peter was listening to in the waiting room. He was a six year-old boy sitting alone, his legs shaking. He was watching his mother suffer in the hospital. His mother's pale, weak fingers slid a small wrapped gift to him as she was struggling to take her last breaths. The moment her soul left, Peter's grief erupted in an angry cry. He immediately ran out of the hospital. Suddenly, a huge spaceship pointed a magic light on the boy. He was dragged into the ship in a funnel of waves.

The task was for the students to collaboratively write a short story depicting Peter's life between the time of his abduction and his adulthood. The teacher provided general questions as pointers for the students to explore in their short stories, e.g. who took the boy, why?. The groups also brainstormed ideas in a face-to-face activity. After the initial face-to-face brainstorming, the groups used their shared wiki pages to make plot decisions and write their collaborative short story.

The second writing task was an individual writing task that spanned weeks 7 to 9 in the term. The theme and prompt of this task was similar to the collaborative writing task. Students watched trailers of several time-travel movies (e.g. Dr. Who, Back to the Future, Bill and Ted's Excellent Adventure). After watching the trailers, the students individually brainstormed ideas for their short stories by responding to the following questions: who, what, where, when, and how? These questions were meant to aid the 
development of a time-travel plot. After brainstorming, the teacher led the students as they wrote the following whole-class opening sentence for their individual stories.

One stormy day with dark black clouds traveling overhead, [Character's name] ...pulled his hood on his head when he noticed ...

The students were then asked to use individual wiki pages to write their short stories using the above opening sentence and their brainstormed ideas. It is worth noting that although the individual short story task was thematically similar to the collaborative task, there were some notable differences. The individual short story task was deliberately designed to be less controlled than the collaborative task. Unlike the collaborative task, in which the students used The Guardians of the Galaxy as a framework for their writing, the individual short story task was designed to provide examples from several movies rather than a specific framework. The teacher's rationale was that this design would allow students to explore different creative scenarios rather than adhere to a specific framework. Accordingly, the opening sentence was deliberately less detailed and more general than the one used in collaborative task in order to allow more room for individual creativity.

Throughout the writing process, the teacher and I implemented several activities to guide the students in their writing. These activities included:

- Hands-on training sessions to familiarize the students with the technology.

- In-class reading of a sample short story (Hemingway's A Day's Wait) 
- Discussions and activities targeting features of the creative genre including narrative structure, written style, figurative language, and sensory details.

- Mini lectures on creative thinking processes.

- Ongoing written and oral feedback on the stories.

- Discussions of the assessment rubric.

Due to the qualitative nature of the study, data collection and analysis influenced instruction at various stages including changing the theme of the short stories and the wiki platform. In the next chapter, I offer a thorough account of the motivation and effect of these changes so that the reader can have a better understanding of the context.

\section{Data Collection Instruments and Procedures}

Data collection consisted of a range of techniques such as class observations, document analysis (individual and collaborative short stories, wiki discussions, and wiki archived pages), individual interviews, and self-assessment questionnaires (see Table 2 for the data collection timeline). This variety of data collection methods was combined to achieve triangulation, which can offer a "multifaceted understanding" of case studies (Hood, 2011). All data involved some sort of disciplined documentation: audio-taping, archived web pages, written field notes, and immediate or subsequent memos. 


\section{Table 2}

Data Collection Timeline

\begin{tabular}{lc}
\hline \multicolumn{1}{c}{ Procedure } & Deadline \\
\hline Observations & Week 1-10 \\
Collaborative short story writing $\backslash$ wiki discussions & Weeks 3-6 \\
Submission of the collaborative short stories & Week 6 \\
Individual short story writing & Weeks 7-9 \\
Submission of the individual short stories & Week 9 \\
Interviews and self-assessment questionnaires & Week 10 \\
\hline
\end{tabular}

Throughout the term, I conducted participant observations to gain an understanding of instruction, students' behaviors, and group dynamics. These data are directly related to the first research question: how do students collaborate to write a short story? Following the suggestions in Cowie (2011), I used Spradley's (1980) key dimensions of observation as guidance during the observations. These dimensions included: space, actors, activities, objects, acts, events, time, goals, and feelings. I also created a three-column field note template as recommended by Cowie (2011). The lefthand column to record context-related notes (time and place), the middle column is for the field notes, and the third column is for comments and memos. The field notes recorded during the observations included: Methodological notes that described teaching and data collection procedures; Observation notes that described students' behaviors, reactions, comments, and question; Personal notes tracking the development of my thinking, attitudes, and concerns; and Immediate memos recording brief analytical 
interpretations. Spradley's dimensions and the observation template allowed me to "systemize" the observations and "avoid centering on particular events or incidents" and ignoring others (Cowie, 2011, p. 172).

In addition to the observations, I was also involved in lesson planning. I met weekly with the class teacher and my thesis adviser to debrief the observations and memos from the previous class. These weekly meetings allowed me to discuss the ongoing data analysis process, which informed future instruction and data collection. Additionally, these debriefings helped me determine the focus of subsequent observations as well as questions to be asked in the final interviews and self-assessment questionnaires. Besides lesson planning, I led a short presentation on the concept of creativity at the onset of the term, and another brief overview of the rubric toward the middle of the term. I occasionally interacted with the students in class to collect data relevant to specific behaviors observed at the time of the observation. This involvement allowed me to establish rapport with the informants and ask contextualized questions targeting specific behaviors during class time.

The documents analyzed in this study included wiki discussions and archived pages. The students used two wiki platforms (Pbworks \& Google Docs) to compose their individual and collaborative short stories, and to participate in online discussions with their group. The online discussions were collected electronically. During the third week, I copied the online discussions from the two online platforms into a qualitative data analysis software (ATLAS.TI) and continued to update the software with the ongoing discussions up until week 6 in the term. To examine the collaboration process as manifested in the wiki revision history, I copied the wikis archived pages into Microsoft 
Word documents at the end of week 9. I used the comment function to analyze the implemented changes qualitatively. The changes were categorized according to their focus and later counted. The wiki discussions and revision history were analyzed to explore the first research question: how do students collaborate to write a short story on a wiki platform?

In addition to the wiki discussions and archived wiki pages, the collaborative and individual short stories were collected electronically. At the end of week six, I copied the four collaborative short stories from the shared Google Docs into ATLAS.TI. I followed the same procedure for the nine individual short stories at the end of week nine. These data were used to explore the second research question: how do the collaborative short stories compare to individual short stories produced by the same students on the dimension of creativity? The collaborative and the individual short stories were copied into Microsoft Word documents to conduct the quantitative analysis related to accuracy and complexity.

To explore the third research question: how do students perceive the process and product of computer-based collaborative short story writing, individual interviews and self-assessment questionnaires were used as a data collection method. The individual interviews were conducted during week 10 of the term and audio-recorded for the purpose of the analysis. I met individually with the informants for approximately one hour to explore their perceptions of the collaborative and individual short story writing tasks. The interviews were semi-structured and followed an interview guide. Based on the data collection and analysis throughout the term, I identified a set of topics and tentative questions to be discussed in the interviews (Patton, 1990). Occasionally, I used 
conversational interviewing techniques to further explore specific responses and encourage interviewees to expand their answers (Patton, 1990). Immediately after each interview, I took brief Interview notes and memos. The interviews were transcribed and copied into ATLAS.TI to be qualitatively analyzed using an inductive approach (Hatch, 2002).

The students were also asked to complete a self-assessment questionnaire during the interviews (See the Appendix for the self-assessment questionnaire). While the interviews were focused on the students' perception of the process, the self-assessment questionnaire was used to have students self-evaluate the individual and collaborative short stories (product). Self-assessment can provide a unique emic perspective that objective measures may fail to capture. The questionnaire consisted of rubric criteria that was shared with the students during class. To complete the questionnaire, the students had to assign their individual and collaborative short stories a score ranging from 1-5 based on a given criterion (e.g. characterization, plot, and figurative language). Upon completion, open-ended questions were used to have the students choose the most effective story and justify the scores they assigned the two stories based on the rubric.

The specific analysis procedures for all the data outlined above is discussed thoroughly in the following section. 


\section{Data Analysis Procedures}

As is typical with qualitative research, data collection and analysis followed an iterative process. The preliminary data analysis of the observation reports, the wiki discussions, and the initial drafts of the stories contributed to decisions regarding instruction and subsequent data collection. These changes in the instructional methodology will be discussed in detail in the next chapter.

As mentioned in earlier sections, the current study examined: (1) the process of collaboration by examining the wiki discussions, wiki revision history, and class behaviors, (2) the product by comparing the collaboratively written and individually written short stories, and (3) students' perceptions of the process and product of computer-based collaborative short story writing by conducting interviews and selfassessment questionnaires. Table 3 summarizes the data analysis procedures for each research question. 
Table 3

Data Analysis Procedures

Research Question Data Data Analysis Method

\begin{tabular}{|c|c|c|c|c|}
\hline \multirow[t]{2}{*}{1} & $\begin{array}{l}\text { How do ESL } \\
\text { students } \\
\text { collaborate to } \\
\text { write short } \\
\text { stories on a } \\
\text { wiki-platform? }\end{array}$ & Wiki revision history & - & $\begin{array}{l}\text { Qualitative and Quantitative } \\
\text { Analysis } \\
\text { - The function and number of } \\
\text { posts: inductive analysis } \\
\text { Quantitative \& Qualitative } \\
\text { Analysis } \\
\text { - The nature and number of } \\
\text { revisions: deductive } \\
\text { framework }\end{array}$ \\
\hline & & Class observations & - & $\begin{array}{l}\text { Qualitative Analysis. } \\
\text { Inductive Analysis }\end{array}$ \\
\hline 2. & $\begin{array}{l}\text { How do the } \\
\text { collaborative } \\
\text { short stories } \\
\text { compare to } \\
\text { individual } \\
\text { short stories } \\
\text { produced by } \\
\text { the same } \\
\text { students on the } \\
\text { three } \\
\text { dimensions of } \\
\text { creativity, } \\
\text { accuracy, and } \\
\text { complexity? }\end{array}$ & $\begin{array}{l}\text { Final drafts of the } \\
\text { individual and } \\
\text { collaborative stories }\end{array}$ & - & $\begin{array}{l}\text { Qualitative \& Quantitative } \\
\text { Analysis } \\
\text { - Creativity: deductive } \\
\text { framework and inductive } \\
\text { analysis } \\
\text { - Accuracy: the number of } \\
\text { errors per } 100 \text { words } \\
\text { - Complexity: the number of } \\
\text { words per } \text {-unit }\end{array}$ \\
\hline 3. & $\begin{array}{l}\text { How do } \\
\text { students } \\
\text { perceive the } \\
\text { process and } \\
\text { product of } \\
\text { computer- } \\
\text { based } \\
\text { collaborative } \\
\text { short story } \\
\text { writing? }\end{array}$ & $\begin{array}{l}\text { Interviews \& } \\
\text { self-assessment } \\
\text { questionnaires }\end{array}$ & - & $\begin{array}{l}\text { Qualitative Analysis. } \\
\text { Inductive analysis }\end{array}$ \\
\hline
\end{tabular}




\section{Process.}

How do ESL students collaborate to write short stories?

To explore the first research question, I examined the process of collaborative short story writing as manifested in students' wiki discussions, wiki revision history, and class behaviors.

\section{Wiki Discussions.}

I used a qualitative data analysis software, ATLAS.TI, to code the data from the wiki discussions. The data in the wiki discussions were analyzed inductively following the steps suggested by Hatch (2002). I started by identifying a frames of analysis, which is the main conceptual category and level of specificity used to analyze the data (p.164). After a couple of trials, I found that the most appropriate "frame of analysis" was to analyze single posts based on their functions in the interaction (p.164). Based on this frame, I examined the data and grouped similar posts together. This step led me to create "domains" or categories of posts that seemed to serve the same function (p.166). After identifying the most "salient domains" in the data (p.167), I assigned codes to the domains and refined them based on examples and counter examples from the data. These domains led me to classify the posts to five types. Codes and definitions are provided in Table 4. I finally ran a cross-domain analysis looking for relationships among different domains in the four case studies. 
Table 4

Types of Wiki Discussion Posts

\begin{tabular}{cl}
\hline Code & \multicolumn{1}{c}{ Definition } \\
\hline Idea negotiation posts & Posts in which students discuss ideas or content. \\
Language related posts & $\begin{array}{l}\text { Posts in which students explicitly comment on or discuss } \\
\text { word choice or grammar. }\end{array}$ \\
Phatic communication & $\begin{array}{l}\text { Posts in which students exchange small talk to establish } \\
\text { posts }\end{array}$ \\
Procedural posts & $\begin{array}{l}\text { Posts in which students interact to clarify procedural } \\
\text { issues (e.g., guys what else we should do?). }\end{array}$ \\
Product posts & $\begin{array}{l}\text { Posts in which students write excerpts of the short story } \\
\text { in the wiki discussion board instead of directly editing } \\
\text { the wiki page. (e.g. he said "how can I use it?" the man } \\
\text { said "it depends on whether you want to save the world } \\
\text { or damage it...." }\end{array}$ \\
\hline
\end{tabular}

To gain an understanding of the collaboration process, I counted the number of each type of post for the four case studies. Further, I analyzed the idea negotiation posts for creative thinking processes verbalized during the idea exchange. Because the current study compared the final collaborative product to an individual product in terms of creativity, examining creativity in the process of the wiki discussions seemed complementary. The assessment of creativity in the process is especially important in the case of ESL students who may engage in creative thinking processes during the discussion but lack the sophisticated linguistic means to showcase their creativity in the product. Accordingly, I adapted a deductive framework based on previous conceptual frameworks on creativity. The framework contained codes capturing the most common 
creative thinking processes discussed in creativity literature. It initially contained nine codes: transformational thinking, combinational thinking, and exploratory thinking (Boden, 2001); fluent thinking, flexible thinking, original thinking, and elaborative thinking (Guilford, 1967); chaotic thinking and ordered thinking (Finke, 1996). Table 5 below presents the original codes and their definitions.

Table 5

Deductive Framework to Examine Creativity

\begin{tabular}{ll}
\hline \multicolumn{1}{c}{ Code } & \multicolumn{1}{c}{ Definition } \\
\hline Exploratory Thinking & $\begin{array}{l}\text { Thinking that explores the ideas inherent in a given conceptual } \\
\text { space (reality) using existing rules and potentials. }\end{array}$ \\
Combinational Thinking & $\begin{array}{l}\text { Thinking that produces new unfamiliar ideas by associating old } \\
\text { or familiar ideas in novel and valuable ways. }\end{array}$ \\
Transformational Thinking & $\begin{array}{l}\text { Thinking that alters one or more rules of the given conceptual } \\
\text { space (reality), enabling the production of new ideas that could } \\
\text { not be generated before the rule change. }\end{array}$ \\
Fluent Thinking & $\begin{array}{l}\text { The ability to rapidly produce a large number of ideas. } \\
\text { Flexible Thinking }\end{array}$ \\
The ability to simultaneously consider variety of approaches to \\
solve a problem. \\
Original Thinking
\end{tabular}


During the preliminary qualitative analysis, it became evident that some codes were not represented in the data (e.g. fluent thinking, chaotic thinking, and flexible thinking). As illustrated by the definitions, fluent and chaotic thinking reflect thinking that is most likely to occur in the brainstorming stages of writing. Because the students completed the brainstorming stage during a face-to-face activity, the data were not captured in the wiki discussions. Thus, the wiki discussions did not include examples of fluent and chaotic thinking. Similarly, flexible thinking was not observed in the wiki discussions, perhaps due to the nature of the task since this form of thinking usually emerges in problem solving tasks. Therefore, these codes were excluded from the revised framework. Ordered thinking was merged with combinational thinking since both types of thinking include associating and extending ideas from various sources. Finally, original thinking was not included in the revised framework due to the abstract and vague nature of the definition. Accordingly, the revised framework consisted of the following four codes: exploratory thinking, combinational thinking, transformational thinking, and elaborative thinking.

Exploratory thinking was defined as ideas that fall within the conceptual space provided by the task prompt. Ideas were operationalized as entries proposing or discussing content related to the short stories. A conceptual space is a "disciplined way of thinking that is familiar to a certain social group" (Boden, 2004, p. 3). The conceptual space in this study was established by the introduction of the characters and setting in the movie trailer. It includes a reality where aliens coexist with human beings. Accordingly, ideas explored within the boundaries of that conceptual space were coded as manifestations of exploratory thinking. For example, "lets talk about ship? or others?" 
(Lei, $\mathrm{WD}^{1}$, Jan 1, 2016) reflects exploratory thinking because the presence of a spaceship was already established in the movie prompt. In contrast, transformational thinking was defined as ideas that alter or extend the rules of the presented reality. These ideas were coded as instances of transformational thinking. For instance, "The Evil Ship? or what?" (Mahmoud, WD, Jan 1, 2016) represents transformational thinking since the idea that a ship can be evil in itself was not introduced in the movie prompt and thus extends the rules of the conceptual reality.

The definition of combinational thinking was extended to include not only unfamiliar combinations of familiar ideas but also ideas that extend, or build on old ideas. For example, "how about his dad is evil" (Bingwen, WD, Jan 1, 2016) builds on ideas of the evil ship and the father, who was mentioned in the movie prompt. Finally, entries that provide or invite details to elaborate on previous ideas were coded as elaborative thinking. e.g. " $i$ think he finally know his father is a bad guy and he want a war, and peter stop him maybe kill him" (Bingwen, WD, Feb 2, 2016) This quote represents an elaboration of ideas that were previously agreed upon by adding details to implement the ideas.

Although these codes were often overlapping when applied to the data, peeranalysis and discussion of the data allowed me to draw tentative distinctions between these codes when possible. For example, combinational and elaborative thinking were sometimes difficult to distinguish, as both extend previously presented ideas. In order to draw a line between these two codes, ideas were only coded as combinational if the

\footnotetext{
${ }^{1} \mathrm{WD}$ refers to the wiki discussion, which is the source of the quotes used here to clarify the framework. These conventions will be described in detail in the discussion chapter.
} 
resulting idea is unfamiliar and is not predictably implied by the original idea. Ideas were codes as elaborative when they are predictably foreseeable by the original ideas, and only extend the original ideas with specificity and detail. It was also tricky to distinguish between exploratory and transformational thinking, especially because the chosen science fiction prompt is inherently transformational in the sense that it introduces a reality where little boundaries exist. In order to distinguish these two codes, ideas that were based on the laws of physics presented in the prompt were coded as exploratory. Ideas that extend, alter, or tweak the presented laws of physics were coded as transformational. That is, the presence of humans and aliens, and space travel was already established by the prompt and thus ideas that adhere to laws of physics possible in these realms were coded as exploratory thinking. Only ideas that alter or generate new laws of physics were codes as transformational thinking.

It is worth noting that only the idea negotiation posts were analyzed for creativity. Product posts, in which students wrote their contributions in the discussion boards, were excluded from this analysis. Although these product posts could indicate certain creative thinking processes, it is difficult to trace the creative thinking processes from a finished product since the product is a "fossilized" representation of the process (Tin, 2016, p.435). On the other hand, interactional episodes "create a natural environment for thinking processes to be expressed and verbalized, and thus help in discovering the micro-genetic developmental processes" (Tin, 2016, p.439)

\section{Wiki Revision Histories.}

The archived pages of the wikis were analyzed qualitatively and quantitatively. The nature of these revisions were first examined using a qualitative framework (Faigley 
$\&$ Witte, 1981). The framework distinguished two types of revisions: surface changes and meaning changes. Surface changes are revisions that do not add new information or delete existing information. Meaning changes involve revisions that lead to the development of content. These two categories are further classified into subcategories as shown in Table 6.

Table 6

Faigley and Witte's (1981) Revision Framework

\begin{tabular}{|l|c|c|c|}
\hline \multicolumn{2}{|c|}{ Surface Changes } & \multicolumn{2}{c|}{ Meaning Changes } \\
\hline Formal changes & $\begin{array}{c}\text { Meaning- } \\
\text { preserving changes }\end{array}$ & $\begin{array}{c}\text { Microstructure } \\
\text { changes }\end{array}$ & $\begin{array}{c}\text { Macrostructure } \\
\text { changes }\end{array}$ \\
\hline
\end{tabular}

Surface changes are broken into two sub-categories: formal changes and meaningpreserving changes. Formal changes are proof-reading revisions such as verb forms, plural morphemes, articles, pronouns, spelling, capitalization, punctuation, and format. Meaning-preserving changes are changes that paraphrase existing concepts in the text but do not alter them. These meaning-preserving changes are implemented using the following techniques: additions, deletions, substitutions, permutations, distributions, and consolidations. Definitions and examples of these techniques are presented in Table 7. 
Table 7

Techniques to Implement Meaning-preserving Changes \& Meaning Changes

Technique Definition Example*

\begin{tabular}{lll}
\hline Additions & $\begin{array}{l}\text { The addition of words or phrases } \\
\text { to "raise to the surface" a concept }\end{array}$ & $\begin{array}{l}\text { You pay two dollars }=>\text { you } \\
\text { pay a two dollar entrance fee }\end{array}$ \\
that can be inferred. &
\end{tabular}

Deletions

The deletion of words or phrases

Several rustic looking

to force inference of a previously

restaurants $=>$ several rustic

explicit concept.

restaurants

Substitutions

The substitution of words or larger

Out-of-the-way spots $=>$ out -

units with words or larger units

of-the-way places

that represent the same concepts.

Permutations The rearrangements of words or

Springtime means to most larger units in the text.

people $=>$ spring time, to most people, means

Distributions The distributions of a single unit

I figured after walking so far (sentence) into more than one unit (sentences).

for the least it could do would be to provide a relaxing dinner since I was hungry $=>$ I figured the least it owed me was a good meal. All that walking made me hungry.

Consolidations The consolidation of two or more And there you find Hamilton's units (sentence) into one unit pool. It has cool green water (sentence) surrounded by 50-foot cliffs and lush vegetation $=>$ And there you find Hamilton's pool: cool green water surrounded by 50-foot cliffs and lush vegetation. 
* The examples used are taken from Faigley and Witte's (1981)

The second type of revisions in the framework is meaning changes. Meaning changes are classified into microstructure changes and macrostructure changes. The distinction reflects the difference between minor and major changes in meaning. Microstructure changes are revisions that have little effect on the overall meaning of the text. These revisions can be adjustments or elaborations of concepts that would not change the summary of a text. Macrostructure changes are changes that have more impact on the bigger picture. These revisions can change the direction of the text or alter its summary or plot outline.

To distinguish between macro and microstructure changes, I examined whether the revision resulted in a change of the plot outline. Revisions that altered elements of the plot were coded as macrostructure changes. Revisions that adjusted or elaborated the existing plot structure were coded as microstructure changes. The same techniques that are used to implement meaning-preserving changes are employed in meaning changes (see Table 7 for definitions and examples). The difference between meaning-preserving changes and meaning changes is that meaning changes do not paraphrase existing concepts but rather contribute to minor (microstructure) or major (macrostructure) content development.

In order to count the number of revisions implemented in each category, a consistent unit of analysis was needed to code the revisions in each category. In accordance with Arnold, Ducate, and Kost (2009), the t-unit was deemed the most appropriate unit to code the macrostructure changes especially because the students in this study usually implemented these changes in the form of sentences. 
In the case of the microstructure changes and meaning-preserving changes, the unit of analysis was the single word. Because students in this study usually implemented microstructure and meaning-preserving changes by adding, deleting, or substituting words, phrases, and sentences, using the single word as a unit of analysis allows for a more accurate reflection of individual contributions. However, using the word as a unit of analysis was problematic when students implemented revisions through consolidation or distribution. Students in this study usually consolidated or distributed t-units by adding or deleting a coordinating or subordinating conjunction. Accordingly, counting all the words seemed to misrepresent the nature and weight of the revision. That is, a student might receive credit for the 25 words that constitute the two t-units when all they did was adding or deleting one conjunction. A possible way to resolve this issue was to count these revisions as instances or t-units. However, because other revision techniques such as addition, deletion, and substitution were counted as words, I decided to use the word as a consistent unit of analysis in meaning-preserving and microstructure revisions. Using a consistent unit of analysis allowed me to count a total for each type of revision and compare between the students in a group. Whenever consolidation or distribution are counted as words, an asterisk is used to indicate the exact number of t-units that were consolidated or distributed.

The formal changes were counted as instances rather than words. Although some of the subcategories could have been counted as words such revisions on verb forms, and capitalization, other subcategories such as punctuation and format could not be counted as words since they were not implemented on an identifiable unit of analysis. These 
revisions seemed to be better counted as instances. Accordingly, all formal revisions were counted as instances for the sake of consistency.

To sum up, different units of analysis were used to count the different types of revisions. The macrostructure changes were counted as t-units. The meaning-preserving and microstructure changes were counted as words. The formal changes were counted as instances. Once coded, the number of changes implemented in each category was counted to capture any quantitative difference between the members of each case study.

\section{Class Observations.}

The analysis of the observations' field notes followed a rigorous process of reflecting, synthesizing, and discussions. Immediately after class, I typed my field notes and immediate memos in a Word Document. I reflected on the filed notes and immediate memos, which were recorded during the observations, and synthesized the information into an observation report. The report consisted of a thorough analysis of the notes, an observation audit trail, and subsequent memos. These subsequent memos included: Research notes that connected the observations with studies related to the current study; Theoretical notes that linked the observation data with the theories underpinning the current study; and Interview topics that I later used to formulate the interview guide and tentative questions (Patton, 1990). I discussed the observation report weekly with the class teacher and thesis adviser. Based on these discussions, I revisited the observation reports and made necessary adjustments to my interpretations. Insights gleaned from these observation reports informed instructions in substantial ways as will be discussed in the next chapter. 


\section{Product.}

How do the collaborative short stories compare to individual short stories produced by the same students on the three dimensions of creativity, accuracy, and complexity?

A mixed methodology was used to compare the individually written and collaboratively written short stories on the three dimensions of creativity, accuracy, and complexity. While the latter two were analyzed quantitatively, the nature of creativity is better examined through qualitative analysis. Below is a thorough description of the analysis procedures for each dimension of comparison.

\section{Creativity.}

Studies with a product-oriented approach to creativity in SLA have examined creativity in terms of the "formal and functional features of creative texts" (Tin, 2016, p. 435). Creativity is often depicted as a form of language play (Carter, 2004) that is employed at three levels: form, meaning, and use (Cook, 2000). Additionally, knowledge of generic conventions is considered an important assessment criterion in general creativity research (Morris \& Sharplin, 2013; Rodriguez, 2008). Accordingly, I developed a deductive framework to examine the creativity of the product in this study. In accordance with general and SLA creativity research, the framework included categories examining the narrative structure of the short stories and language use. Specifically, it consisted of the following codes: plot development, character description, setting description, themes, point of view, figurative language, and sensory descriptions (see Table 8 for definitions of the codes). In addition to the deductive framework discussed above, creativity in the product was also analyzed inductively. Due to concerns 
outlined in the literature review about the restrictive nature of deductive approaches, the current study incorporated an inductive analysis of the short stories following the inductive analysis framework outlined in Hatch (2002). The inductive analysis gave rise the following codes: pace of narration, scene transitions, and genre, which are also defined below.

Table 8

Framework to Examine Creativity in the Short Stories

\begin{tabular}{cl}
\hline \multicolumn{1}{c}{ Code } & \multicolumn{1}{c}{ Definition } \\
\hline Plot Development & $\begin{array}{l}\text { Parts of the plot: exposition, rising action, climax, falling action, } \\
\text { resolution, and surprises. }\end{array}$ \\
\hline Character Descriptions & $\begin{array}{l}\text { Descriptions of the characters using a variety of techniques: } \\
\text { Actions, thoughts, reactions, physical descriptions, dialogue, } \\
\text { background information, possessions, and idiosyncrasies. }\end{array}$ \\
\hline Setting Descriptions & $\begin{array}{l}\text { Description of the setting using sensory details: sight, sound, } \\
\text { touch, smell, and taste. }\end{array}$ \\
\hline Point of View & $\begin{array}{l}\text { The point view used to narrate the events of the short story. Ex. } \\
1^{\text {st }} \text { person, } 2^{\text {nd }} \text { person , or } 3^{\text {rd }} \text { person point of view (limited, } \\
\text { multiple, or omniscient } 3^{\text {rd }} \text { person point of view) }\end{array}$ \\
\hline Expression of Theme & The theme explored and developed in the short story \\
\hline Figurative Language & Examples of similes, metaphors, hyperbole, and personification. \\
\hline Sensory Details & $\begin{array}{c}\text { Descriptions that employ the five senses: sight, sound, touch, } \\
\text { smell, and taste. }\end{array}$ \\
\hline Pace of narration & $\begin{array}{l}\text { The pace by which a scene is developed, as reflected in the } \\
\text { amount of details used to develop a scene. }\end{array}$ \\
\hline scene to another \\
\hline of the genre
\end{tabular}




\section{Accuracy and Complexity.}

To calculate accuracy and complexity, I segmented the individual and collaborative short stories into t-unit and counted the number of t-units in each story. Complexity in this study was operationalized as the number of words per t-units. This measure was deemed appropriate as it accounts for overall complexity (Norris \& Ortega, 2009) and is consistent with measures used in previous studies (Dobao, 2012; Storch, 2005; Wigglesworth \& Storch, 2009). Accordingly, I calculated complexity by dividing the number of words by the number of t-units. The complexity of the individual and collaborative stories were then compared using the complexity score. A similar measure was used to calculate accuracy. Accuracy in this study was operationalized as the number of errors per 100 words. This measure is widely used and serves as a general measure of accuracy, as it accounts for the distribution of errors to production units (Storch, 2005), which are words in this case. The current study utilized this measure to make the results comparable to previous research that employed similar analysis methods (Dobao, 2012; Kost, Arnold, \& Ducate, 2014; Storch, 2005; Wigglesworth \& Storch, 2009). The first step in this analysis included the development of a criterion on which the errors were identified. Due to the multilevel nature of the class, it was not possible to develop a fully elaborated set of descriptive grammar categories based on what the students had covered in previous classes. Therefore, the identification of errors was data-driven as recommended by Ellis and Barkhuizen (2005). I examined the individual and collaborative short stories and developed error categories that reflected the errors identified in the data including errors of omissions in which students did not supply a certain form in an obligatory context. I then counted the number of errors and calculated 
accuracy by dividing the number of identified errors by the total number of words and multiplied the result by 100 . I later compared the accuracy results of the individual short stories and collaborative short stories.

\section{Students Perceptions.}

How do students perceive the process and product of computer-based collaborative short story writing?

A predominantly qualitative methodology was used to analyze the interviews and self-assessment questionnaires. The data elicited from the students during the interviews was analyzed qualitatively using the inductive analysis steps suggested in Hatch (2002). My framework of analysis for the interview data was broadly defined as an episode expressing an opinion or perception of a component relevant to the study. Based on this frame, I identified some domains or categories of meaning in the interview data. After identifying the most relevant domains, I assigned codes and ran a counter analysis of theses domains based on the data. The major codes emerging from the interview data were: perceptions of collaborating on a creative writing task, perceptions of individual creative writing in the L2, and perceptions of the two wikis (Pbworks \& Google Docs). Finally, I conducted a cross-case analysis of the domains allowing major themes to develop from the data.

The self-assessment rubric, completed during the interviews, was analyzed quantitatively. The scores that the students assigned for different criterion on the rubric were summed to quantitatively represent differences in students' perceptions of the individual and collaborative stories. The results of this analysis enriched my qualitative 
analysis of creativity in the product because the criteria in the self-assessment questionnaire corresponded to the deductive framework I used to analyze the short stories. In addition to the quantitative analysis of the scores, students' justifications of the scores, which was prompted during the interview through open-ended questions, were analyzed qualitatively to shed light on students' perceptions of the collaboration process. 


\section{Chapter 4}

\section{Context Statement}

As mentioned in the previous chapter, task design in this study was adjusted during the course based on an iterative process of data collection and analysis. These changes were motivated by a rigorous analysis of data from class observations and archived wiki pages. Accordingly, the theme of the stories and the wiki platform were changed during the study. These changes also affected the overall design of the study, which led to the adjustment of the pretest-posttest design that was initially intended. The reasons that necessitated these changes may also have implications for creative writing pedagogy. Thus, this section presents a thorough account of these changes.

\section{Theme}

Initially, the theme of the stories was life-changing childhood experiences.

Because the sample short story that was read in class (Hemingway's A Day's Wait) touched on this theme, the theme seemed like an appropriate extension. The students were asked to individually freewrite about a life-changing childhood experience. These individual stories were intended as pretests that would be followed by a collaborative short story writing task and another individual short story as a posttest. Since the focus of the study explores creativity rather than autobiography, several activities were used to help students expand these experiences from autobiographical accounts into imaginative short stories including a mini workshop on creative thinking processes. In the workshop, the teacher and I defined the four facets of creativity (exploratory, combinational, transformational, and elaborative thinking), which match the analysis framework used in 
this study to examine creativity in the idea negotiation posts. The teacher modeled how to expand a factual experience into a short story using a personal incident. She used the think-aloud method to change the experience of losing her son in the park into an imaginative short story by exploring, combining, transforming, and elaborating ideas while still maintaining the core theme of the experience. Finally, the teacher assigned inclass tasks for each facet of creativity. For instance, the students brainstormed questions about their childhood experience to move the story in a different direction (exploratory thinking), e.g. "What if my mother never abandoned me" (Adam, personal communication, Jan 19, 2016). They combined two or more questions to create a theme for their short story (combinational thinking), e.g. "What if my grandmother died but my mother could see her in her dreams" (Huda, personal communication, Jan 19, 2016). They were asked to transform an aspect of reality in their story (transformational thinking), e.g. "what if the doll I bought with the stolen money could move and speak" (Chow, personal communication, Jan 19, 2016). Finally, the teacher introduced the students to figurative language (similes, metaphors, personification, and hyperbole) and sensory details to help students elaborate their short stories with rich details and vivid descriptions (elaborative thinking).

Despite this extensive instruction, the students experienced difficulty manipulating the details of factual incidents and personal experiences as evident in some comments they shared with me in casual interactions inside and outside class.

"I could do think outside the box. The experience is so...It is my mother's death" (Mahmoud, personal communication, Jan 19, 2016)

"But I cannot change her death" (Huda, personal communication, Jan 19, 2016) 57 
"It is easier to create a story than to add imagination to a real experience" (Fatima, personal communication, Jan 25, 2016)

In addition to these comments, Adam seemed self-conscious about sharing the story of his mother's abandonment of him on a wiki. Although he wrote about the experience in his freewrite, he changed the topic and wrote about his recent travel to the U.S. and his career plans when instructed to share his individual story on the wiki.

Overall, the theme of life-changing childhood experiences involved personal and sensitive experiences for many of the participants. Thus, they struggled to imaginatively alter the events of these experiences and to share these sensitive experiences with the world. These observations as well as follow-up discussions with the class teacher, the thesis adviser, and another faculty member triggered the change of the topic to science fiction.

Due to the time constraints that resulted from these unanticipated difficulties, the individual short story pretest was cancelled. Accordingly, the design was adjusted to only include the task (collaborative writing) and the posttest (individual writing).The students started their collaborative short story writing using a science fiction prompt. Although the students' output seemed more promising upon the change to science fiction, the participants struggled with the wiki platform. An account of the problems they faced is presented in the next section.

\section{Wiki Platform}

PbWorks was initially used as a platform for the groups' online collaboration. The decision was motivated by the fact that PbWorks is a widely used platform in the IEP with which the students were already familiar. Although the platform is most appropriate 
for asynchronous collaboration as it only allows one person to edit the page at a time, this function was not seen as problematic because the students were expected to collaborate asynchronously outside class. However, SECs do not require out-of-class work for the students to pass, which led the students to restrict their participation to class meetings. As a result, the collaborators faced difficulties using PbWorks to communicate and write synchronously. That is, when one group member was editing the page, other group members were blocked. Group members could, nevertheless, use the discussion board synchronously. This platform feature impeded collaboration during class time; participants were observed to sit idly for extended periods of time while waiting for their group member to finish editing the page. Some of the participants were observed using a word document to write or using the discussion board to write sentences. This limitation was aggravated by the fact that eight out of nine participants exhibited slow typing speed. To address this limitation, students were encouraged to collaborate asynchronously to finish their short stories. Due to the requirements of the SECs, the students were not extrinsically motivated to work outside class. The teacher attempted to motivate them extrinsically by offering symbolic prizes for those who collaborate asynchronously. Although this competition spirit did encourage two of the four groups to collaborate outside the class, out-of-class participation was still limited. Further, the teacher tried to tap into the students' intrinsic motivation by announcing that she would compile and publish their short stories in a book. Nevertheless, these attempts did not seem to boost the students' out-of-class participation. Upon follow-up discussions of this problem with the class teacher, the thesis adviser, the decision was made to change the platform to Google Docs, which allows for synchronous collaboration. 
A shared Google document was created for each group during week five. The short stories were copied from the Pbworks and pasted into the Google documents. Members of the group were given editing and commenting rights, so that they could all contribute to writing the stories. The students participated in a training session in which they practiced the different functions including using the comment function as a discussion board since Google Docs does not have a separate discussion board. It is worth noting that students' discussion was significantly curtailed after the change to Google Docs. Contrastingly, students' writing output increased. Possible reasons for these observed changes will be discussed in the conclusion.

In short, the data collection and analysis inspired ongoing changes in the instructional methodology. These changes were presented here to offer a comprehensive understanding of the context. Additionally, these changes served to highlight niches that can be addressed in future research. Suggestions for future research will be discussed in the conclusion. 


\section{Chapter 5}

\section{Findings \& Discussion}

As discussed in the previous chapter, the current study explored the process and product of collaboration as well as students' perceptions. The process of collaboration was examined in terms of the wiki discussions and revision history. The wiki discussions were analyzed to explore the interactional dynamics and creative thinking processes. The archived wiki pages (revision history) were analyzed for revisions. The product of collaboration (collaborative short stories) was compared to the individual short stories in terms of creativity, accuracy, and complexity. Below is a discussion of each case study in light of the research questions.

In this section, quotes are used extensively to allow the informants' voices to support the analysis. These quotes are included verbatim with no correction of grammar or spelling to further reflect the language skills of the informants and present an authentic account of their experiences. The quotes are taken from the final interviews and the wiki discussion boards and will be cited with the informants' pseudonyms, their source (INT for interviews, WD for wiki discussion), and date, for example (Fatima, INT, March 7, 2016) or (Fatima, WD, Jan, 26, 2016). Occasionally, data from the wiki archived pages is used to reflect the nature of group dynamics in the three case studies. These data are cited as follows: (pseudonym, WAP, date).

\section{Group 1: Fatima and Chow}

This group was composed of two female students. Fatima, a 26-year old student from Saudi Arabia who enrolled in the class to improve her academic writing skills and pass the IELTs exam (INT, March 7, 2016), and Chow, a 19-year old student from China 
who also took the class to work on her academic writing skills (INT, March 8, 2016). Both Fatima and Chow were very quiet in class. They rarely participated or asked questions. Fatima seemed to have difficulty keeping up with the class as she occasionally sought Arabic translations from me to clarify task instructions. Unlike Fatima, Chow often rejected the teacher's offer to help when approached individually. As will be discussed below, their reticent behavior in class was also reflected in their wiki discussion.

\section{Wiki discussion.}

Fatima and Chow posted a total of 12 entries in their wiki discussion board. The nature of these posts is summarized in Table 9.

Table 9

Case 1: Type and Number of Wiki Discussion Posts

\begin{tabular}{cc}
\hline Post Type & Number \\
\hline Idea Negotiation posts & 0 \\
Language related posts & 0 \\
Phatic communication posts & 1 \\
Procedural posts & 3 \\
Product posts & 8 \\
\hline
\end{tabular}

Table 9 shows that Fatima and Chow's discussion was extremely limited. It is also clear that they did not negotiate ideas or discuss the development of their shared short story. Due to the absence of idea negotiation posts, the creative thinking processes that are typically manifested in these interactions could not be analyzed for this case study. The table also shows that Fatima and Chow did not engage in discussions about 
language. All of their posts were task-oriented. Instances of phatic communication in which students exchange small talk to establish sociability (e.g. hi, how are you, thank you) were almost absent from their wiki discussion board. On three occasions, they interacted briefly for procedural purposes such as clarifying the task. The majority of their posts were product posts in which they posted excerpts of their short story in the wiki discussion board instead of writing directly in the wiki page. Due to the lack of interactional episodes, it was not possible to examine whether or not Fatima and Chow developed distinct roles through their online discussion. However, the analysis of the revision history below did provide insights into the group roles assumed in this case study.

\section{Revision history.}

As can be seen in Table 10 below, the analysis of the revision history indicates that Fatima and Chow focused on different areas when revising the drafts.

Table 10

Case 1: Type and Number of Revisions

\begin{tabular}{lllll}
\hline & \multicolumn{3}{c}{ Meaning Changes } & \multicolumn{2}{c}{ Surface Changes } \\
\cline { 2 - 5 } & Macrostructure & Microstructure & Meaning Preserving & Formal \\
& Changes & Changes & Changes & Changes \\
Fatima & 36 t-units & 40 words & 7 words & 19 instances \\
Chow & 37 t-units & 128 words & 124 words & 6 instances \\
\hline
\end{tabular}

The number of macrostructure changes was approximately the same for both of them, which indicates that neither Fatima nor Chow assumed leadership of the task, an 
observation that they supported in the final interviews. The analysis also shows that while Fatima implemented more formal changes, Chow implemented a significantly higher number of microstructure and meaning-preserving changes. The changes in each category are further classified into subcategories in Table 11. 
Table 11

Case 1: The Subcategories of Revisions

\begin{tabular}{|c|c|c|}
\hline Revisions & Fatima & Chow \\
\hline 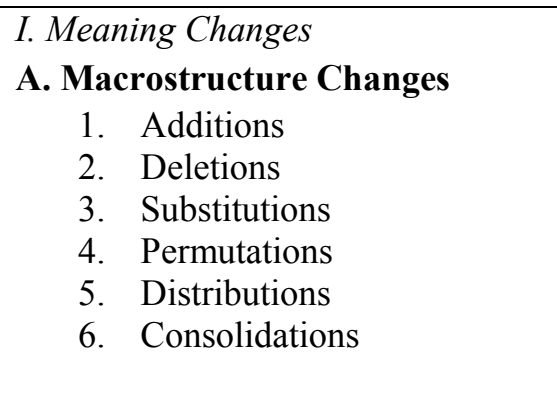 & $\begin{array}{c}\text { Total }=\mathbf{3 6} \text { t-units } \\
32 \\
4 \\
0 \\
0 \\
0 \\
0\end{array}$ & $\begin{array}{c}\text { Total }=\mathbf{3 7} \text { t-units } \\
37 \\
0 \\
0 \\
0 \\
0 \\
0\end{array}$ \\
\hline $\begin{aligned} \text { B. } & \text { Microstructure Changes } \\
\text { 1. } & \text { Additions } \\
\text { 2. } & \text { Deletions } \\
\text { 3. } & \text { Substitutions } \\
\text { 4. } & \text { Permutations } \\
\text { 5. } & \text { Distributions } \\
\text { 6. } & \text { Consolidations }\end{aligned}$ & $\begin{array}{c}\text { Total }=\mathbf{4 0} \text { words } \\
40 \text { words } \\
0 \\
0 \\
0 \\
0 \\
0\end{array}$ & $\begin{array}{c}\text { Total }=\mathbf{1 2 8} \text { words } \\
96 \text { words } \\
29 \\
3 \\
0 \\
0 \\
0\end{array}$ \\
\hline $\begin{array}{l}\text { II. Surface Changes } \\
\text { A. Meaning Preserving Changes } \\
\text { 1. Additions } \\
\text { 2. Deletions } \\
\text { 3. Substitutions } \\
\text { 4. Permutations } \\
\text { 5. Distributions } \\
\text { 6. } \\
\text { Consolidations }\end{array}$ & $\begin{array}{c}\text { Total }=7 \text { words } \\
0 \\
5 \\
2 \\
0 \\
0 \\
0\end{array}$ & $\begin{array}{c}\text { Total }=\mathbf{1 2 4} \text { words } \\
21 \\
3 \\
53 \\
32 \\
0 \\
20^{*}\end{array}$ \\
\hline $\begin{array}{ll}\text { B. } & \text { Formal Changes } \\
\text { 1. } & \text { Verb forms } \\
\text { 2. } & \text { Plural morphemes } \\
\text { 3. } & \text { Articles } \\
\text { 4. } & \text { Pronouns } \\
\text { 5. } & \text { Spelling } \\
\text { 6. } & \text { Capitalization } \\
\text { 7. } & \text { Punctuation } \\
\text { 8. } & \text { Format }\end{array}$ & $\begin{array}{c}\text { Total }=\mathbf{1 9} \text { instances } \\
0 \\
0 \\
0 \\
0 \\
2 \\
9 \\
4 \\
4\end{array}$ & $\begin{array}{c}\text { Total }=\mathbf{6} \text { instances } \\
1 \\
0 \\
0 \\
0 \\
0 \\
4 \\
1 \\
0\end{array}$ \\
\hline
\end{tabular}


* The number represents the number of words in a total of 4 t-units that were consolidated using a coordinating conjunction.

It is worth noting that while Fatima only deleted and substituted her own contributions, Chow implemented microstructure and meaning preserving changes throughout the document and did not restrict them to her own sections. For example, Chow substituted the prepositional phrase in the following sentence that was written by Fatima, "When Peter walked between the people" with another prepositional phrase, “When Peter walked on the street" (WAP, Date, 2016). To revise her partner's and her own contributions, Chow used several techniques such as addition, deletion, substitution, permutation, and consolidation. However, Chow did not delete the macrostructure changes that Fatima implemented and only reworked Fatima's microstructure and meaning-preserving changes. In the interviews, Fatima and Chow commented on several observations that were noted in the wiki discussion and revision history.

\section{Perceptions of collaboration.}

Fatima and Chow both expressed dissatisfaction with the collaborative writing task. Chow commented that she was not comfortable making suggestions in the wiki discussion board. She reasoned that their lack of interaction was due to their "shy" and "passive" personalities, and explained that she had wished for a more "outgoing group

member" (INT, March 8, 2016). Similarly, Fatima stated that it was difficult to negotiate ideas because of differences in age and cultural background (INT, March 7, 2016). Fatima and Chow commented that the product posts, which were common in their discussion board, was an indirect way to "communicate ideas" with each other (Chow, INT, March 8, 2016). Similarly, Fatima reasoned that posting these excerpts was due to 
her lack of confidence about her writing skills and her need for validation from her partner, "I do not dare. I do not know if my writing is correct or not. I wrote there waiting for her to see it." (INT, March 7, 2016). Additionally, Fatima and Chow commented on the difficulty of revising their shared document. Whereas Fatima expressed that she abstained from revising any of her partner's contribution, Chow explained that she was not comfortable changing her partner's major ideas and that she restricted her revisions to the minor details "to be honest, I did not like her ideas, but if change it, maybe make her not happy" (INT, March 8, 2016).

Overall, both Fatima and Chow negatively evaluated the group task. Fatima described their group work as a "clash of ideas." She explained that stories are based on “individual ideas, ” which makes the collaborative task difficult (INT, March 7, 2016). In a similar vein, Chow commented that the challenge to understand and negotiate different ideas was confusing and caused their story to be unclear and incomplete "I like write something use my own ideas. If someone wants add or disagree with me I will confuse." (INT, March 8, 2016). Both Fatima and Chow agreed that these challenges were further aggravated by the genre of writing. As can be seen in the quotes below, they both thought that collaborating on a short story was more challenging than collaborating on academic writing tasks.

I think there is more clashing because this is fantasy. Each one has his own imagination. In the essay, we are discussing a certain topic. She might agree and I disagree, it is possible. But if we both agree. It is going to be the same ideas. $1+1=2$. It is scientific ideas, but here no she has imagination and I have imagination. (Fatima, INT, March 7, 2016) 
The story is creative, means write your think, but essay is not, usually write the truth. (Chow, INT, March 8, 2016)

As will be discussed in the following section, the struggles that Fatima and Chow faced in their collaborative writing task clearly affected their group story.

\section{Fatima and Chow's short story.}

Fatima and Chow's short story has two separate plot structures. Both plots were initiated by Chow and continued by Fatima. The first plot is centered on the main character's quest to protect the gift that his mother had given him prior to her death while the second plot narrates an incident where a group of alien antagonists are fighting the main character over a ball. Below are excerpts exemplifying the narrative elements of the two plots. These excerpts are cited with the writers' pseudonyms and line numbers. As described in the previous chapter, the exposition of the collaborative stories was written collaboratively as a whole class. Thus, discussions of the collaborative stories will not include the exposition.

\section{Rising actions.}

At the moment, a saucer man closed to him and said "do you know what your gift is?" Peter "no, what is it?" "It can change the world" Peter was doubt and said "how can I use it?" The man said "it depends on whether you want to save the world or damage it..." "if you don't know how to use it then you can give it to me, I will take care of it." Certainly no, it's my gift. it is important for me. I can't give you" "Alright, you will meet trouble because of this 'gift'." 
Peter still adheres to the gift, he doesn't gave anyone, people started chase Peter because they want to get the gift. They plan for kidnapping peter because they stole this gift but peter can to flee from them... They talk with his friend when she put the poison in his drink, but his friend refuse this idea. Also she warned peter from this people (Fatima and Chow, lines 8-25)

\section{Climax.}

Peter arrived stranger space, but he doesn't know. Peter ready for open the gift when he alone. Some saucer men tried to stop him and looted his gift, but it has already late. When he open this box, it shot a big light (Fatima and Chow, lines 27-29).

\section{Falling actions.}

All of them lied down and Peter found them might die. Because the gift protect peter and it wiped out the bad guys like explosion. (Fatima and Chow, lines 2930).

\section{Resolution.}

Now peter feel safe when his gift brings with him (Fatima and Chow, lines 30-31).

\section{Rising actions.}

Now, a stranger man who looks like a tree came and said "Thanks for your help." and then he continued "You are my saviour, I have already been shut here many years, because they want to perform an experiment with my body, now I am

free, we need flee this space together." (Fatima and Chow, lines 34-36). 


\section{Climax.}

Suddenly, a green woman appeared, she wanted make friends with Peter and she looked friendly. She talked with Peter about something then suddenly she loot Peter's ball by dagger. Then she get it, Peter fight with her for the ball ... After few periods fights, the ball came back to Peter, and the green women was defeated by Peter and tree man. Theatrically, tree man seized Peter. (Fatima and Chow, lines 39-47).

As illustrated in the excerpts above, the two plot structures in Fatima and Chow's story are not thematically connected. Moreover, the second plot does not include a falling action or a resolution. It is concluded at a climax point where the main character is captured by an antagonist. Although the story features two conflicts (the fight over the gift and the fight over the ball), no identifiable theme can be discerned from the two plots. Additionally, there are minimal descriptions of the characters in the story. The techniques used to develop the characters include: reactions .e.g. "Peter was doubt" (Fatima and Chow, line 11), physical descriptions .e.g. "The tree man had many long branches, and they were able to extending or shortening" (Fatima and Chow, lines 4243) and background information .e.g. "He just was a little boy. His dream was be a hero" (Fatima and Chow, lines 13-14). There are no descriptions of the setting throughout the short story. The story also lacks vivid sensory detail and figurative language. Except for a few examples (i.e., “a green woman”, “it shot a big light”), sensory details are almost nonexistent. Similarly, the story includes only one simile, "it wiped out the bad guys like explosion" (Fatima and Chow, line 30). 
As seen in the excerpts above, the story was developed using a third-person limited point of view, in which the narrator has limited access to the world of the main character. The excerpts also show that although the language used is appropriate for the genre, there is a significant difference in the writing style of Fatima and Chow. That is, whereas Chow favors using dialogue and details to develop the story, Fatima's paragraphs feature a series of abrupt actions that are lacking details and descriptions. This difference in writing style can be observed when comparing the first paragraph of the first rising action to the rest of the plot. The beginning of the rising action, which was written by Chow, is elaborately developed with dialogue. However, the rest of the plot (rising action, climax, falling action, and resolution), which was written by Fatima, is abruptly developed in one paragraph without sufficient details and descriptions. A similar difference in style can be seen in the second plot, which was also initiated by Chow and finished by Fatima. Chow introduced the rising actions with sufficient details and dialogue. However, the rest of the plot was mainly written by Fatima and abruptly developed in one paragraph. The difference in writing style negatively affected the pace of narration; Chow's sections are slowly developed, Fatima's sections, on the other hand, are somewhat accelerated. The inconsistency of the pace caused the story to be disjointed at various points. This disconnection is further aggravated by the lack of scene transitions.

\section{Fatima's short Story.}

For her individual short story, Fatima wrote about a time-travel dream that brought her back to her early childhood. She emphasized some elements of the plot 
structure more than others. Below are excerpts exemplifying the narrative elements of the story. The excerpts are cited with a pseudonym and line numbers.

\section{Exposition.}

In 2016 on Monday, I am very tired at night (Fatima, line 1).

\section{Climax.}

When I wake up, I find myself in 2000. I am single, and I am in Saudi Arabia not in America. I wear my uniform clothes. My bedroom is old, but my mother is not old. My mother tell me Fatima must finish early. You go to your high school and I go with my sister by our chauffeur. I see my old teacher, and I enjoy studying with my old friends. Also we go to schoolyard in preak because we eat some snack. I don't know what is happen (Fatima, lines 1-6).

\section{Falling actions.}

Tuesday, when I wake up I find myself in 2016 in America. I have my daughter. I am happy but I am very sad because I see my family when I was child. Also I see my father and my grandmother. I miss them (Fatima, lines 17-19).

\section{Resolution.}

I want to sleep again. Maybe I can back to 2000 (Fatima, line 19).

As can be seen in the excerpts above, the exposition is abruptly developed in one sentence that introduces the time and character but does not describe the place. The conflict of the story is not developed through rising actions but rather inferred from the climax, which is prematurely introduced in the third sentence. The climax is the main focus of the story. It is developed with more details and descriptions, albeit somewhat abruptly. Similar to the exposition, the falling action and resolution are brief and lack 
details. The abrupt development of scenes was also observed in the sections that Fatima wrote in the collaborative story. Despite the fact that Fatima highlighted the climax more than the other plot elements, she maintained a consistent pace, resolved the conflict, and explored nostalgia as a theme for her short story. All of which was not accomplished in the collaborative story, which featured a series of theme-less actions that are neither resolved nor narrated consistently.

Similar to the collaborative short story, the characters in the story are described minimally. Except for two instances in which the characters are described through reactions. e.g. "I am speechless" (Fatima, line 8), and physical descriptions e.g. "my mother is not old" (Fatima, line 3), characterization is mostly inferred from actions. e.g. "I wear my uniform clothes," "I go with my sister by our chauffeur" (Fatima, line 4). From these actions, the reader can infer that the main character is a student from a wealthy background. Likewise, the setting is not described directly using sensory descriptions or figurative language but rather inferred from actions as can be noted in the excerpt below. In the interview, Fatima commented that her limited vocabulary and her uncertainty about sentence structure prevented her from providing thorough descriptions (Fatima, INT, March 7, 2016).

We go together to our garden house. My grandmother give her animals food. she has chiken, beef, and rabbit and my mother irrigate trees.she implant apple tree, orange tree, Palms and mint (Fatima, line 13).

Although the collaborative story was narrated using the third-person point of view, Fatima opted for first-person point of view to narrate her individual story as seen in 
the excerpts above. Contrary to the collaborative story, Fatima managed to maintain a consistent pace and created smooth transitions between the scenes using time adverbial clauses. e.g. "After we eat dinner" (Fatima, line 16).

In the self-assessment questionnaire, Fatima rated the collaborative story higher than her individual story; on a scale of 30 points, she assigned 19 points to her individual story and 22 points to the collaborative story she wrote with her partner. However, the discussion above indicates that Fatima's individual story is overall more effective than the collaborative story she wrote with her partner. The individual story features a resolved plot, a meaningful theme, a consistent pace, and clearer transitions. While Fatima's superior performance on the individual story could be related to Fatima's negative perception of the group task, it could also be due to perceived topic differences. In the interview, Fatima discussed how the collaborative task (space travel) required more imagination than the individual task (time travel). Although the instructor specifically instructed that students write about something imaginative, Fatima's choice to travel back in time to her own past influenced her approach to the task. She stressed that her inability to "deal with fantasy and create imaginative ideas" was an obstacle in the collaborative story (INT, March 7, 2016).

The second topic was easier. I can go back to my own time. It was not based on fantasy. I do not know how to deal with fantasy. The first topic. I needed to imagine to create ideas. I do not know what I was writing. The second topic, I just relived my past, went back a few years. It something related to me. 


\section{Chow's short story.}

Similar to her partner Fatima, Chow wrote a story about a time-travel experience to her early childhood. The elements of the plot in Chow's story are generally given equal attention. They are developed with adequate details and descriptions. Below are excerpts exemplifying the narrative elements of her story.

\section{Exposition.}

One day, $i$ walked on the street with my friend while my phone rang. it is my mother!....(Chow, line 1).

\section{Rising actions.}

That woman's jean was really ugly." i think "where is my friend?" Omg he became a little boy and lay on the road while he was crying! It's amazing! And then I felt something bad. My clothes were bigger and bigger and I was smaller and smaller. After a while I was same with my friend! we were two little kids!... (Chow, lines 10-13).

\section{Climax.}

i found my little classmates were growing tall, but i still was a little girl, I was shorter than other classmates, It means that $i$ was not able to grow (Chow, lines $32-33)$.

\section{Falling actions.}

I could not go to date with my friends. I could not tell the boy who i like. I did not have pin money, I could not have beautiful dress and makeup. but $i$ have an adult mind (Chow, lines 35-37). 


\section{Resolution.}

Please let me come back 18th birthday party" I wished that when my number 10th 8 years old birthday one surprising thing was caught in a black hole and i found my friends sang the birthday song for me when i opened my eyes (Chow, lines 3840).

The first few lines introduce the setting and characters. The conflict features an unexpected twist that is built up through a vivid description of the rising actions. The falling action and resolution feature less details and descriptions. Nevertheless, they are still effective in showing the results of the climax, and developing the theme of accepting changes, which was not accomplished in the collaborative story.

Similar to the collaborative story, Chow's individual story includes few descriptions of the characters. Characterization is achieved through few sentences that describe the character's background and feelings. e.g. "I won't have too much pressure in my life. My study life would be easier than now. I think I might be happier than now" (Chow, line 20). However, the setting is vividly described using sensory details as seen in the excerpt below.

The bus was not morden bus anymore and the buildings were antiquity. A lot of cars became bicycle, motorbike, and some cars had black smoke. The advertisements were 2006 s products and they had the models that I have never seen before. The people who on street had a strange suit (Chow, lines 6-9). 
There are also two examples of figurative language "Everything was like a movie and flashed my eyes," "seems like a movie, a dream" (Chow, lines $9 \&$ 24).In the interview, Chow commented on her struggle to describe the story due to her limited vocabulary words (INT, March 8, 2016)

The excerpt above shows that Chow used first-person point of view to narrate her individual story, which was not her choice in the collaborative story. Chow explained that first-person point of view allowed her to be included in the story (INT, March 8, 2016). The pace of narration is generally consistent throughout the story, except for some abruptness in the final two paragraphs, which could either be due to the fact that they were written at the end or to the lack of structure. In the interview, Chow discussed how the absence of a pre-established outline (introduction, body paragraphs, and conclusion) in short stories was confusing. She explained that she did not know the level of elaboration needed for each section (INT, March 8, 2016). Another feature that distinguished the two stories was scene transitions. Unlike the collaborative story, clear transitions between the scenes are accomplished in Chow's story through time adverbials. e.g. "six months later..." (Chow, lines 32). A dominant feature of Chow's writing style is the use of dialogue. This feature was also noted in the sections she had written in the collaborative short story. The dialogues in her story are natural and not clichéd, which creates a positive effect for the story.

“mom, don't worry about me I have umbrella and I will eat dinner with my friend,"

Babe, it is time to come back home, you should do your homework. it is $5 p m ! ”$ 
"Mom I see, but I am not little girl......wait...." (Chow, lines 1-5)

The analysis suggests that Chow's individual story is more effective than the story she wrote with her partner. Her individual story features a theme. The setting is more vividly described and the dialogue is more effective. Moreover, the pace is generally more consistent with clearer transitions between the scenes. This analysis is also supported by Chow's responses on the self-assessment questionnaire since she rated her individual story six points higher than the group story. On a scale of 30 points, she assigned her individual story 26 points and the collaborative story 22 points.

Overall, it seems that both informants in this case study performed better on the individual story than on the collaborative story. As seen in Table 12 below, the collaborative story features two plot structures that are not thematically cohesive. There is no overarching theme emerging from the collaborative story, which creates a series of meaningless actions. Additionally, difference in writing style negatively affected the pace of narration in the collaborative story. On the other hand, Fatima and Chow's individual stories are more effective in these regards. 
Table 12

Case 1: Summary of the Qualitative Evaluation of Creativity in the Short Stories

\begin{tabular}{cccc}
\hline & Collaborative Story & Fatima's Story & Chow's Story \\
\hline Plot & Two plotslunresolved & One plot $\backslash$ resolved & One plot \\
Theme & Unclear & Clear & Clear \\
Characterization & Minimal & Minimal & Minimal \\
Setting & No descriptions & Few details & Vivid \\
Point of view & 3 & & description \\
Sensory details & Few details & $1^{\text {st }}$ person & $1^{\text {st }}$ person \\
Figurative language & One example & Few details & Vivid details \\
Pace of narration & inconsistent & None & Few examples \\
Scene transition & ineffective & consistent & consistent \\
Genre & appropriate & effective & effective \\
\hline
\end{tabular}

\section{Accuracy and Complexity.}

Table 13 below shows the results of the accuracy and complexity analysis for the collaborative and individual short stories. As can be seen in the table, although the complexity score of the collaborative story is slightly higher, there is not a clear trend in terms of the accuracy of the short stories. The types of errors identified in the collaborative story and the two individual stories included global errors in structures, verb tenses, and word formations; and local ones such as subject-verb agreement and plural morphemes. Thus, the errors in the individual stories were not more serious than those in the collaborative story and vice versa. 
Table 13

Case 1: Results of Accuracy and Complexity of the Short Stories

\begin{tabular}{cccc}
\hline & Collaborative Story & Fatima's Story & Chow's Story \\
\hline $\begin{array}{c}\text { Accuracy } \\
\text { (The number of } \\
\text { errors per } 100 \\
\text { words) }\end{array}$ & 15 errors/100 words & 13 errors/100 words & 16 errors/100 words \\
$\begin{array}{c}\text { Complexity } \\
\text { (The number of } \\
\text { words per t-unit) }\end{array}$ & 8 words/t-unit & 7 words/t-unit & 7 words/t-unit \\
\hline
\end{tabular}




\section{Group 2: Adam and Huda}

This group consisted of two students: Adam, a 21-year old male from Ukraine who joined the class to improve his writing skills (INT, March 7, 2016), and Huda, an 18year old female from Saudi Arabia who saw creative writing as a way to express her voice (INT, March 7, 2016). Throughout the course, Adam was silent and reserved in class. Like Chow in the first case study, Adam often seemed apprehensive when approached individually by the teacher. Huda, on the other hand, was outgoing and talkative. She usually laughed at the teacher's comments and responded actively to questions.

\section{Wiki discussion.}

Adam and Huda posted a total of 70 entries in their discussion board. The nature of these posts is summarized in Table 14 .

Table 14

Case 2: Type and Number of Wiki Discussion Posts

\begin{tabular}{cc}
\hline Post Type & Number \\
\hline Idea Negotiation posts & 47 \\
Language related posts & 1 \\
Phatic communication posts & 1 \\
Procedural posts & 12 \\
Product posts & 4 \\
\hline
\end{tabular}

Table 14 shows that the vast majority of the posts were interactional episodes in which they discussed the development of their short story. They also interacted for 
procedural purposes such as announcing to each other that they had added to the story. It can also be seen that they posted a few lines of their short story in the discussion boards. These entries were coded as product posts. Although their discussion was generally referential and task oriented (communicating information and ideas) rather than phatic, it was, nonetheless, abundant with formulaic expressions used for politeness purposes such as, "do you think..., would you like to..., can we...I would rather..." (Adam and Huda, WD, 2016). Some of the communicative functions that distinguished the interactional dynamics of Adam and Huda from the other cases were:

(1) Acknowledging each other's contributions, "I Like these changes very much, good job! I think we are good for tomorrow!" (Adam, WD, Feb 1, 2016);

(2) Eliciting feedback from each other "what do u think should i post it ?!"(Huda, WD, Jan 26, 2016);

(3) Building on each other's ideas "give me Ur idea so it's become better!!" (Huda, WD, Feb 1, 2016);

(4) Inviting changes "Hi, Huda, I have made few changes, if you dont like it, you can change it" (Adam, WD, Feb 1, 2016).

Compared to all the other groups, Adam and Huda exhibited extensive negotiation of ideas throughout their online discussions. Their discussion was abundant with examples of creative thinking processes. The following discussion episode (Adam and Huda, WD, Feb 2, 2016) suggests exploratory, combinational, transformational, and elaborative thinking processes.

Adam: and also we can create one idea, it could that times between planets are diferent. 
Adam: so 1 year on another planet it is like 10 minutes on Earth

Huda: yes but we didn't write it yet. So, $i$ think we need to write more about the resolution!

Adam: so he was absent like 3 hours on earth

Huda: so you mean that you want to start writing about him going back to earth?

Huda: Okeey i understand what you mean i liked it!!

Adam: $i$ think we will continue writting this story in a class

Huda: i'll try now to add it to our story

Adam: so it is just idea

Huda: $i$ add it but i'm thinking that 1 year like an hour, so when he go back to his home and it's only hours have gone how did he become that big?!!

Huda: we should find something for that!

Adam: that the point that he was kidnapped to another reality

Huda: so, when he went back to his home he fegerout that his family doesn't recognize him and they don't no him so he have to start a new adventure of his life?!!

Adam: yes, lets leave this new adventure to another chapter Adam: like the end will be that he is starting new adventure on earth Huda: so what about how did he went back? what did happen when he arrived there? and how did he arrived there? and how he will start his new adventure at the end? 
Adam: So he found this stone, and this stone can transport him only once in a month, so it was challenge for him to wait these days, because bad guys were looking for it. Finally he transported himself, and he was at this park from where he was kidnapped

Adam's idea of the time being different between the two planets indicates transformational thinking as it exceeds the boundaries of the conceptual space given in the task prompt (movie trailer). Although the movie indicated the possibility of space travel, differences in timespans were not implied. In the following lines, Adam provided details on how to carry out the idea, which suggests elaborative thinking. Huda also engaged in elaborative thinking when she prompted details regarding the logical implications of Adam's idea "i add it but i'm thinking that 1 year like an hour, so when he go back to his home and it's only hours have gone how did he become that big?!!" She also employed exploratory thinking when she proposed that the main character would start a new adventure "so, when he went back to his home he fegerout that his family doesn't recognize him and they don't no him so he have to start a new adventure of his life ?!!". The idea of the main character commencing a new adventure falls within the boundaries of the conceptual space given in the task prompt. She then goes back to ask questions about the details of the idea, which is indicative of elaborative thinking. In reaction to her questions, Adam proposes the idea of the stone that can transfer the main character back to earth. This idea indicates both combinational and transformational thinking. The idea is created by combining two familiar ideas: the main character's quest to go back to earth, which they had already discussed, and the orb that Adam and Huda saw the main character stealing it in the movie trailer. Additionally, the idea of a stone 
that can transport characters across planets exceeds the limits of the conceptual space provided by the task prompt.

The wiki discussion indicated that Adam and Huda were highly engaged in their negotiation of ideas, though they did develop distinct roles throughout their work together. That is, while Adam seemed to be very prolific when it comes to proposing ideas "I just produce ideas, if you want to add something or change, you are welcome" (Adam, WD, Feb 2, 2016), Huda took on the role of the writer " $i$ 'll try now to add it to our story" (Huda, WD, Feb 2, 2016). This observation was supported by the analysis of the wiki revision history.

\section{Revision history.}

As illustrated in Table 15 below, the distinct roles observed in the wiki discussion can be clearly seen in the number of revisions implemented by Adam and Huda.

Table 15

Case 2: Type and Number of Revisions

\begin{tabular}{lllll}
\hline & \multicolumn{3}{c}{ Meaning Changes } & \multicolumn{2}{c}{ Surface Changes } \\
\cline { 2 - 5 } & Macrostructure & Microstructure & Meaning Preserving & Formal \\
& Changes & Changes & Changes & Changes \\
Adam & 39 T-unit & 124 words & 41 words & 17 instances \\
Huda & 86 T-unit & 410 words & 135 words & 30 instances \\
\hline
\end{tabular}

Table 15 shows that Huda implemented substantially more revisions in each category. This difference in number of implemented changes confirms her role as the writer, which was observed in the wiki discussion. Similar to Fatima and Chow, the number of formal changes is limited in this group. The changes in each category are further classified to subcategories in Table 16 below. 
Table 16

Case 2: The Subcategories of Revisions

\begin{tabular}{|c|c|c|}
\hline Revisions & Adam & Huda \\
\hline \multicolumn{3}{|l|}{ I. Meaning Changes } \\
\hline A. Macrostructure Changes & Total $=39$ t-units & Total $=86$ t-units \\
\hline 1. Additions & 39 & 86 \\
\hline 2. Deletions & 0 & 0 \\
\hline 3. Substitutions & 0 & 0 \\
\hline 4. Permutations & 0 & 0 \\
\hline 5. Distributions & 0 & 0 \\
\hline 6. Consolidations & 0 & 0 \\
\hline B. Microstructure Changes & Total $=124$ words & Total $=410$ words \\
\hline 1. Additions & 124 & 161 \\
\hline 2. Deletions & 0 & 42 \\
\hline 3. Substitutions & 0 & 207 \\
\hline 4. Permutations & 0 & 0 \\
\hline 5. Distributions & 0 & 0 \\
\hline 6.Consolidations & 0 & 0 \\
\hline \multicolumn{3}{|l|}{ II. Surface Changes } \\
\hline C. Meaning Preserving Changes & Total $=41$ words & Total $=135$ words \\
\hline 1. Additions & 3 & 6 \\
\hline 2. Deletions & 1 & 32 \\
\hline 3. Substitutions & 7 & 17 \\
\hline 4. Permutations & 2 & 52 \\
\hline 5.Distributions & 0 & $28^{*}$ \\
\hline 6.Consolidations & $28^{*}$ & 0 \\
\hline
\end{tabular}

\section{Formal Changes}

1.Verb forms

2.Plural morphemes

3. Articles

4. Pronouns

5. Spelling

6. Capitalization

7. Punctuation

8. Format

$\begin{array}{cc}\text { Total }=\mathbf{1 7} \text { instances } & \text { Total }=\mathbf{3 0} \text { instances } \\ 13 & 3 \\ 1 & 4 \\ 0 & 3 \\ 0 & 2 \\ 1 & 6 \\ 1 & 8 \\ 1 & 3 \\ 0 & 2\end{array}$

\footnotetext{
* The number represents the number of words in a total of $2 t$-units that were consolidated using $a$ coordinating conjunction/distributed by making a main clause from an embedded one.
} 
Another similarity between this group and the first one is whether students revised the whole document or restricted their contributions to their own sections. Like Fatima, Adam only implemented microstructure and meaning-preserving changes on his sections. He mostly achieved that by adding and substituting words and consolidating sentences. Huda, one the other hand, was more like Chow; she applied revisions to the whole story regardless of the original writer of a given section. In doing so, she applied several techniques such as addition, deletion, substitution, permutation, and distribution. However, Huda did not revise Adam's macrostructure contributions. In the interviews, Adam and Huda reflected on several of the observations noted above.

\section{Perceptions of collaboration.}

Adam and Huda had different perceptions of the collaborative writing task. On the one hand, Adam generally had a positive perception. Although he did have reservations about the age and background differences between himself and his partner, he generally had a positive impression of the collaborative task. He explained that the collaborative task allowed him to negotiate ideas and make decisions "I had more ideas. I had somebody to talk about this and to see how it works" (INT, March 7, 2016). On the other hand, Huda expressed a negative perception. She commented that it was difficult to negotiate this mutual space especially because it was her first time working collaboratively with a male student. She further added that working alone was more productive in terms of idea generation, which is the opposite of Adam's experience (INT, March 7, 2016). Speaking of her individual story, Huda commented:

It is my own story. I write it more faster. The ideas, it's come directly one after one. I do not have to take a suggestion from someone to write. Is that 
good is that not good? When you write the whole thing, and you do not interrupt, the ideas come out, the thinking is continuous.

Huda's dissatisfaction could have also stemmed from differences in writing style. She expressed that she did not like his writing style and explained that "he like to tell more than to show the feelings. When you read you should imagine the picture I hate short cuts. Like, with Adam he like bla bla bla the end." (INT, March 7, 2016). In fact, Huda stated that the group roles observed in the wiki discussion were deliberate. She explained that she assigned him the role of proposing ideas and herself the role of the writer when she posted the following statement in the wiki discussion board, "just give me your ideas so I can add them to the story" (WD, Feb 1, 2016).

Adam and Huda also commented on the product posts in their wiki discussion board. Similar to Fatima and Chow, Adam reasoned that the product posts were a way to show respect and not to dominate the task. As seen in the quote below, Huda expressed a similar reasoning for posting them.

If I have the idea and I post it directly, he might feel like she posted and she did not take my acceptance about that idea. I liked to see together the ideas. It is good we can now post it. I think it is more respective way (Huda, INT, March 7, 2016).

In the interview, Adam and Huda explained their different approaches to revising the wiki. It seems that Adam and Huda had different perceptions of ownership when implementing revisions. Whereas Huda expressed comfort in revising her partner's sections INT, March 7, 2016), which was observed in the revision history analysis, Adam 
was not comfortable revising Huda's sections. He explained that he did not want to make an impression that his grammar is more advanced than hers (INT, March 7, 2016).

As will be discussed below, the differences in Adam and Huda's perception of collaboration clearly influenced their evaluation of the collaborative and individual short stories.

\section{Adam and Huda's Short Story.}

Similar to Fatima and Chow, Adam and Huda's story features two plot structures. However, Unlike Fatima and Chow, Adam and Huda managed to coherently merge the two plots. The first plot narrates the main character's quest to return to planet Earth. The second plot is centered on the main character's struggle when he realizes that his mother is dead and that his family does not recognize him. Below are excerpts of the narrative elements of the two plots.

\section{Rising action.}

One day he felt very bad, his memories came back. He had been feeling great for 21 years, but after that day, he started remember everything. His families, his house, even his school (Adam and Huda, lines 40-42).

\section{Climax.}

When he came to his mentor whose name was Prof. X, to ask about going back, his mentor was shocked; he had forgotten about expiration date of the injection... So Prof. X had decided to isolate Peter for a few days and give him a new portion of that medicine. But Peter's friend saved him, and Peter fled... (Adam and Huda, lines 44-47).

Falling actions. 
before that his best friend told him a story about the way to Earth. His friend Tom was very smart and investigative, he knew about everything. Also, he liked Peter a lot, once when Tom got in trouble, Peter saved him. They had special task in school and Tom was not very attentive to details, and because of their strong friendship, Peter helped him to finish his part. Because of that, Tom felt like helping Peter with his problem. He would move mountains for him. So mainly, Peter had to steal special stone, which can move him to the Earth... (Adam and Huda, lines 48-54).

\section{Climax.}

He ran through the reception Peter kept asking: "Hey, I just want to ask about a lady her name Maria, can you tell me where I can found here? The nurse

answered him: "Oooh, I'm really sorry she passed away from few hours ago I'm so sorry to tell that!!" He felt like someone slaps his face, and his heart like a broken glass that no one can return it back!! (Adam and Huda, lines 74-80).

\section{Falling action.}

...So, Peter starts a new chapter, looking for a clue to convince his family. He noticed that he still own the map, he opened it and discovered a way leads him for the same spot he was kidnaped from. When he arrived to the location, he investigates about any prints or clues scientists might left after them... (Adam and Huda, lines 89-92).

\section{Resolution.}

There was a sticker at the side of the Box says, "Memory Retrieval "Peter shouted, "Ohh God, here is it I found it, the injections which going to return the 
families memory!!'In the end, Peter finally get it and things become better (Adam and Huda, lines 109-113).

As can be seen in the excerpts above, the first climax features the main character's confrontation with the antagonist. This scene was written by Adam. It is developed abruptly with no sufficient details. Adam developed the falling action by describing past incidents in exhaustive details. These scenes narrate past encounters that the protagonist had with other supporting characters and how these experiences contributed to shaping the falling action. Although these past encounters could have made the plot more credible, the imbalance in details between present and past incidents creates a distance between the climax and the resulting falling action, leading to a distraction from the main plot structure. It can also be noted in the excerpts above that the falling actions of the first plot were not completely resolved, which was exactly what allowed Adam and Huda to transition to their second plot, exploring the main character's attempts to retrieve the memory of his family. The second climax was written by Huda. It is developed more elaborately using descriptive details and figures of speech. Unlike the first falling action, Huda created a more direct continuation between the climax and the resulting falling actions and resolution. Although the two plots were somewhat coherent, it is still difficult to discern a clear theme.

Throughout the story, descriptions of the setting are minimal and lack vivid sensory descriptions e.g. "another plant that contains houses with normal families, fighting schools, police academic..."(Adam and Huda, lines 19-20). More attention, however, is given to the development of the characters, which relied on the following techniques: 
(1) Physical descriptions: e.g. "His mentor was very big and austere" (Adam and Huda, line 45).

(2) Background information: e.g. "He was very close to his mother... He was a very special kid, he had also the ability to study fast ...he was orphan and didn't have the support from someone who can stand by him" (Adam and Huda, line 14-18).

(3) Actions: e.g. "Peter has the strength of character and attractiveness between people from his generous and philanthropist...while walking he saw a man who's requesting some coins to have something to eat. He gave him a pouch of coins" (Adam and Huda, line 57-59.).

(4) Reactions: e.g. "He stands up again on his legs shouting at his emotions he have to keep moving" (Adam and Huda, line 80).

(5) Thoughts and feelings: e.g. "All of his thought was: I won't cry, I won't show the people my emotions, my weakness, breaking heart, losing the power throw my mom deaths ...etc.” (Adam and Huda, line 10-12).

To narrate the story, Adam and Huda employed a third-person omniscient point of view, which allows the narrator access to the intentions and perspectives of all the characters in the story and an ability to comment on them. e.g. "Also, they had spread poisons in Peter's family house that allowed them to forget everything about him. And it looked like they have never had a kid called Peter!! That sounds a terrified feeling how could someone make you forget about your own child” (Adam and Huda, line 31-34).

The writing genre that Adam and Huda used in their story significantly resembled academic writing. There are no sensory details and only a few instances of figurative 92 
language, e.g., "He would move mountains for him," and "He felt like someone slaps his face, and his heart like a broken glass that no one can return it back!!" (Adam and Huda, lines 53 \& 79). They extensively used formal subordinating conjunctions (e.g. further, moreover, furthermore, although, mainly, actually) to transition between scenes, which negatively affected the genre.

Further, many sections in the story present background summaries and lack a depth of descriptions and details. These sections were generally written by Adam. The transitions between these summary-like sections and other descriptive and detailed sections, written by Huda, cause the pace of the story to be inconsistent. For instance, the paragraph below starts with a detailed account of the main character's reaction to being kidnapped. However, it moves to a more general direction by offering a background summary. This writing style, which was a dominant feature of the story, created unexpected and abrupt transitions.

They had plans for everything. after they grabbed him to the spaceship Peter says, "Leave me alone I need my MoooM, MooooooM PLEASE come and take me with you don't leave me opponent in this life aloooone!!!"He was screaming, shouting, crying, and all of his emotions exploded. They drugged him, and gave him an injection which allowed him to forget his past and the coming 21 years he will had. Also, they had spread poisons in Peter's family house that allowed them to forget everything about him...Although, because they were afraid that one day he might remember everything, they forced the adoptive families to give the 
children's daily pills to add it on their foods and waters they drink. This can control the brain neurons. (Adam and Huda, lines 26-36).

Another academic writing feature that is dominant in their story was the use of topic sentences as seen in the paragraph below. These topic sentences made the story predictable as they preview the events to the reader. Consequently, they diminish the effects of surprises and twists in the story. An example is presented below:

But unfortunately, he wasn't remembering that his mother passed away from few hours since he was kidnapped. He ran out back to the hospital.... And the shocked starts from here he ran through the reception Peter kept asking: "Hey, I just want to ask about a lady her name Maria, can you tell me where I can found here? The nurse answered him: "Oooh, I'm really sorry she passed away from few hours ago I'm so sorry to tell that!! (Adam and Huda, lines 73-78).

\section{Adam's short story.}

In his individual story, Adam explored the theme of financial success. Unlike the collaborative story, the story has one plot structure that is fully developed. It includes an exposition that introduces the setting and characters. It also features a rising action in which the main character discovers a way to time travel. This rising action is further developed to a climax, falling action, and a resolution, as can be seen in the excerpts below. 


\section{Exposition.}

One stormy day with dark black clouds traveling overhead, Tom pulled his hood over his head when he noticed a crowded street with a lot of strangers...Tom was a young man who was searching his way... (Adam, lines 1-5).

\section{Rising action.}

He noticed that some action was going on with that cell phone. When he pulled this phone from his pocket he saw these words "Welcome, you are entering to time travel application (Adam, lines 22-24).

\section{Climax.}

So Tom decided to use his device and see how it goes in the future. Unfortunately, Apple shares did not raise high. After he returned back to present he thought that he would invest to another object. In future, he saw that gold was raising pretty good, so he invested all his money and got $20000 \$$ (Adam,lines 41-44).

\section{Falling action.}

He was very happy, it was the easiest way to get money without hard work and risk. He did this operations few times, when he realised that he had enough money for all his life, he stopped this. (Adam, lines 45-47).

\section{Resolution.}

He had enough money to buy a nice property, to invest this money to another start ups, and he managed to provide for himself a nice wealthy life..." (Adam, lines 47-48).

While Adam's short story features the typical plot elements, the climax is developed abruptly and lacks sufficient details, which was also observed in the sections 95 
he wrote in the collaborative story. As a result, the climax fails to create suspense and excitement. Compared to the collaborative story, the plot of Adam's story seemed monotonous.

The writing style of Adam's story is less descriptive and elaborative than the collaborative story. Contrary to the collaborative story where characterization is achieved through several techniques, Adam only narrated background information to describe his main character. As a result, characterization was more effective in the collaborative story. Below is an examples of how the characters are described in his story.

Tom was a young man who was searching his way. He just left his house. His parents lived in a small village, they were farmers...... Every day he worked on that farm, he hated that farm, but it was only one option to earn some money. He was patient and hard worker ... he didn't have any education, so he couldn't find decent job. (Adam, lines 5-34).

Nevertheless, the setting in his story is slightly more effective than the setting in the collaborative story. It features some sensory details and descriptions as seen in the following excerpt, yet there are no examples of figurative language. The difference, however, is not substantial.

He noticed a crowded street with a lot of strangers, who were walking and thinking about their own life and own problems. It was New York, full of strangers. Everybody have their own problems and they don't pay attention to anything what is happening with others. (Adam, lines 2-4). 
It can also be seen in the excerpts above that Adam opted for a third-person limited point of view to narrate his story rather than the third-person omniscient point of view used in the collaborative story.

The pace of narration is inconsistent with some sections (climax, falling action, and resolution) developed more abruptly than others (rising action). The inconsistent pace was observed in the collaborative story as well. There are no scene transitions in Adam's story as can be seen in the excerpt below. The lack of transitions between the first and second scene causes confusion as to whether the action of working hard "Tom worked hard" refers to his work in the farm or in New York. The lack of transitions was also noted in the collaborative story.

Tom was a young man who was searching his way. He just left his house. His parents lived in a small village, they were farmers. Last few years Tom thought that he wanted something more interesting than his family farm, so he decided to try himself in a big city. In a city where dreams come true. It was New York, city of possibilities and frustrations. Tom worked hard, he wanted to have some money, while he is searching his luck. Every day he worked on that farm, he hated that farm, but it was only one option to earn some money. He was patient and hard worker, so finally he earned enough money for the first time in the city of his dream. (Adam, lines 5-12)

Adam's writing style is overall appropriate to the genre unlike the more academic language used in the collaborative story. However, the narration seemed a bit abrupt. The concluding sentence is similar to a restatement of a thesis statement "And we can see, that 97 
this way of thinking built for Tom a nice life" (Adam, line 52). In the interview, Adam explained that writing creatively was difficult for him because he was not used to this sort of writing in his law studies (INT, March 7, 2016)

Overall, it seems that the collaborative story is more effective than the individual story. Although Adam's story focuses on one plot structures, the climax is flat and lacks surprising twists. The characters are described more vividly in the collaborative story. Additionally, the purpose of the narration in Adam's story seems to revolve around supporting a thesis statement rather than to develop a plot, which is indicated by the example in the last paragraph. Overall, it seems that the collaborative story was written more effectively. This analysis is supported by Adam's rating of the stories in the selfassessment questionnaire. On a scale of 30 , he gave 24 points to his individual story and 27 points to the collaborative story.

\section{Huda's short story.}

Like Adam, Huda also explored the theme of financial life changes in her individual story. She addresses poverty and aspirations for better financial circumstances. The plot structure of Huda's short story is fully developed through exposition, rising actions, climax, falling action, and a resolution, all of which are elaborated with details and description as can be seen in the excerpts below.

\section{Exposition.}

One stormy day in Venice island, Italy with dark black clouds traveling overhead, a lady who is 25 years old called Phiona pulled her hood head when she noticed a big, brighten, and shimmering star in the sky...(Huda, lines 1-3). 


\section{Rising action.}

With the star light she whispered in a calmness sound, I would prefer if I was born in another place, with another plushy family!!... (Huda, lines 31-32).

\section{Climax.}

He have told her if she will accept him she's going to live with him happily ever after. And if she disagrees he must return her to the reality... (Huda, lines 96-98).

\section{Falling action.}

In the end, Phiona cerebrate his offer and she noticed that there is nothing she's going to lose in her reality life... (Huda, lines 99-100).

\section{Resolution.}

Finally, they made a huge wedding she wouldn't dream about in her life. And they lived a happily ever after... (Huda, lines 106-107).

Compared to the collaborative story, the plot of Huda's story is more effective. It revolves around a clear theme, which is developed elaborately through the rising actions, climax, falling action, and a resolution. The description of the setting and characters is also more effective in her individual story. As can be seen in the excerpts below, the descriptions of the setting in Huda's story is rich with sensory details and descriptions.

She's in a massive white castle, and a wide garden which is covered with greens, roses, flowers, and a lot of birds and homing pigeons flying around. She found herself in a glamorous, mesmeric, stunning Island (Huda, lines 43-45).

She went back home and slept at her gaily bed, with those woody, crummy windows which interfere the cold weather from everywhere (Huda, lines 33-34). 
This attention to details and descriptions is also applied in characterization, which is more effective in Huda's story than in the collaborative story. The characters are vividly described using the following techniques:

(1) Physical descriptions: "She was wearing a tall dress made from silk, soft, and light fabric. Her face was white as snow with pinky lips. She had a long, easygoing, smooth hair" (Huda, lines 38-39).

(2) Background information: "Her father is died from long time ago, her mother become really old" (Huda, line 26).

(3) Feelings and thoughts: "she was laying on her bed with a pale skin, sharp voice, and blurred eyes staring at the wall reviewing her last perfect memories in her mind; waiting for her soul release from her misery life" (Huda, lines 4-6).

(4) Reactions: "Phiona screams out loud and ran to her room" (Huda, line 52).

A dominant feature of Huda's story is the richness of sensory details and descriptions as seen in the excerpts above. There is one example of figurative language (e.g. I couldn't not to accept it; it will look like I kick the goodness by my leg!) (Huda, line 105). This attention to detail was also observed in the sections written by Huda in the collaborative story. Overall, Huda's story is more effective than the collaborative story in this regard.

Like Adam, Huda used a third-person limited point of view to narrate her story, rather than the third-person omniscient point of view used in their collaborative story. The pace is generally consistent. However, the climax is narrated somewhat abruptly. This abruptness negatively affected the pace of the story making the climax less dramatic and exciting. The dramatic effect is further diminished by the use of topic sentences to 100 
preview coming events in the story. These topic sentences eliminate the effect of surprise that could be generated through narrating the events. The first sentence of the excerpt below disclaims that the main character is going to accept the king's offer to marry her. This information could have been more interesting to read in the dialogue. It is worth noting that the collaborative story had more examples of these topic sentences than Huda's individual story. Adam, however, did not incorporate these topic sentences in his individual story at all.

In the end, Phiona cerebrate his offer and she noticed that there is nothing she's going to lose in her reality life. In both ways her life was miserable; but if she refused that offer she will lose the welfare which came for free!

Phiona went to Martin Suite, She says" I was thinking about what you have said all the night; and I couldn't sleep, I want to tell that I agree for your offer, not only in order for a perfect life, also because I know everything happens for a reason. I couldn't not to accept it; it will look like I kick the goodness by my leg!" (Huda, lines 99-105).

Another feature that resembled the collaborative story is the lack or inappropriate use of transition between the scenes. In Huda's story, scene transitions are occasionally left out creating confusion. More commonly, Huda used academic transition words to transition between her scenes as seen in the following examples. As in the collaborative story, the use of academic transitions negatively affected the genre of writing. (e.g., Whereupon, two of them flew all around..., Furthermore, he have told her..., Moreover, all of what she was thinking about...). 
Overall, Huda's individual story seems more effective than the collaborative story. Although the climax is abrupt, the individual story is elaborated more vividly with details and descriptions and has fewer instances of topic sentences. Additionally, the individual story explores one plot rather than merging two plots. This analyses is supported by Huda who rated her individual story considerably higher than the collaborative story in the self-assessment questionnaire. On a scale of 30 , she assigned 28 points to her individual story and 16 points to the collaborative story.

All in all, the effectiveness of the individual stories as compared to the collaborative story was not consistent in this case study. As can be seen in Table 17 below, although Huda's individual story was more effective than the collaborative story for reasons outlined above, Adam's individual story was less effective than the collaborative story. As discussed earlier, the informants of this case also varied in terms of their attitudes to the collaborative task. Whereas Adam evaluated the collaborative task positively, Huda had a negatives view point towards the collaboration. Their selfassessment of the stories reflected this perception with Adam rating the collaborative short story higher than his individual story and vice versa for Huda. 
Table 17

Case 2: Summary of the Qualitative Evaluation of Creativity in the Short Stories

\begin{tabular}{|c|c|c|c|}
\hline & Collaborative Story & Adam's Story & Huda's Story \\
\hline Plot & $\begin{array}{l}\text { Two plots } \backslash \text { dramatic } \\
\text { climax } \backslash \text { twists }\end{array}$ & $\begin{array}{l}\text { One plot } \backslash \text { flat climax } \backslash \text { no } \\
\text { twists }\end{array}$ & $\begin{array}{c}\text { One plot } \\
\backslash \text { dramatic } \\
\text { climax \twists }\end{array}$ \\
\hline Theme & Unclear & Clear & Clear \\
\hline Characterization & Moderate & Minimal & Rich \\
\hline Setting & Minimal & Minimal & Vivid details \\
\hline Point of view & $3^{\text {rd }}$ person omniscient & $3^{\text {rd }}$ person limited & $3^{\text {rd }}$ person limited \\
\hline Sensory details & None & Few & Rich \\
\hline Figurative language & Few & None & One example \\
\hline Pace of narration & Inconsistent & Inconsistent & Overall consistent \\
\hline Scene transition & Academic transitions & None & $\begin{array}{l}\text { Academic } \\
\text { transitions }\end{array}$ \\
\hline Genre & $\begin{array}{l}\text { Academic writing } \\
\text { features } \\
\text { Topic sentences } \\
\text { Summaries }\end{array}$ & Acceptable & $\begin{array}{c}\text { Overall } \\
\text { appropriate }\end{array}$ \\
\hline
\end{tabular}

\section{Accuracy and Complexity.}

Table 18 below shows the results of the accuracy and complexity analysis for the collaborative and individual short stories. As can be seen in the table, although the complexity score of the collaborative story is slightly higher, there is not a clear trend in terms of the accuracy of the short stories. These results are in line with the results in Case 1, which also showed an increase in complexity for both informants and accuracy for only one of them. As in case 1 , the errors identified in the collaborative story and the two individual stories were overall 
similar with the three stories including both global errors (structure and lexico-grammatical features) and local errors (subject-verb agreement, plural morphemes, and articles).

Table 18

Case 2: Results of Accuracy and Complexity of the Short Stories

\begin{tabular}{cccc}
\hline & Collaborative Story & Adam's Story & Huda's Story \\
\hline $\begin{array}{c}\text { Accuracy } \\
\text { (The number of } \\
\text { errors per t-unit) }\end{array}$ & 10 errors/100 words & 8 errors/100 words & 12 errors/100 words \\
$\begin{array}{c}\text { Complexity } \\
\text { (The number of } \\
\text { words per t-unit) }\end{array}$ & 11 words/t-unit & 10 words/t-unit & 10 words/t-unit \\
\hline
\end{tabular}




\section{Group 3: Mahmoud, Lei, and Bingwen}

This group consisted of three male students: Mahmoud, a 20-year old from Saudi Arabia; Lei, a 20-year old from China; and Bingwen, a 21-year old from China. Whereas Mahmoud joined the class because he enjoys writing (INT, March 7, 2016), both Lei and Bingwen wanted to improve their writing skills (INT, March 7, 2016). Mahmoud, Lei, and Bingwen were the most outgoing students in class. They often responded to the teacher's questions and participated actively in class activities. The three of them usually interacted face-to-face despite being encouraged to communicate using the wiki discussion board. As a result, the discussion boards did not fully capture all the negotiations that occurred between these students. Still, as the following section shows, the wiki discussion of this group was different from the other two groups.

\section{Wiki discussion.}

Mahmoud, Lei, and Bingwen posted a total of 69 entries in their wiki discussion board. The nature of these posts is summarized in Table 19.

Table 19

Case 3: Type and Number of Wiki Discussion Posts

\begin{tabular}{cc}
\hline Post Type & Number \\
\hline Idea Negotiation posts & 39 \\
Language related posts & 1 \\
Phatic communication posts & 22 \\
Procedural posts & 7 \\
Product posts & 0 \\
\hline
\end{tabular}


Table 19 shows that this group negotiated ideas and discussed the development of their story to a moderate degree. All of their posts were interactional and none were product posts. Unlike the other two case studies, this group never posted lines of their short story in the discussion board. Another notable feature of this group's discussion is its abundance with instances of phatic communication. They seemed to engage in off-task small talk to establish rapport and solidarity as seen in the episode below (WD, Feb 2, 2016). This was a predominant feature throughout their online discussions. It is worth noting that this group was the only group that exhibited this sort of interaction. This phatic communication was further developed by using keyboard characters and icons to show emotions (e.g. $\odot$, LOL, XD), which was also a common feature of their discussion.

\section{Lei: hey}

Mahmoud: whats up?

Lei: good how are you?

Lei: so we need talk about climax and change a little?

They did, however, seem conscious of the fact that their discussion is visible to the teacher and researcher. This consciousness of observers is notable in the following discussion episode in which they explored different names for the main character's father.

Lei: what name do you guys want?

Mahmoud: Jack or Jesses. how about Nic or Sean

Mahmoud: Mike 


\section{Bingwen: Abraham}

\section{Lei:}

Bingwen: not common, pretty good $i$ think

Mahmoud: Halaloya

Lei: Sounds bad

\section{Lei:}

Lei: They can see this $\Theta \Theta$

\section{Mahmoud: I can delete it hahahah}

Although the wiki discussion board mostly featured episodes in which Mahmoud, Lei, and Bingwen engaged in phatic communication like the ones above, their discussion included a moderate amount of idea negotiation episodes exhibiting creative thinking processes. An example episode is presented below (WD, Feb 23, 2016).

Mahmoud: alright, so what should we do now? what idea is the best?

Matt: lets talk about ship? or others?

Mahmoud: The Evil Ship? or what?

Matt: you guys choose

Mahmoud: well I think that he is typing right now. this is so weird (:

Mark: how about his dad is evil

Mahmoud: hahahaha that is cool. We should start with his dad is evil

The discussion episode above suggests the following creative thinking processes: exploratory thinking, transformational thinking, and combinational thinking. Lei's suggestion that they focus on the ship indicates exploratory thinking as the idea is within 
the conceptual space provided by the prompt (movie trailer). In the following line, Mahmoud shows evidence of transformational thinking when he conceptualized that a spaceship can be evil in itself, which breaks the rules of the conceptual space. Bingwen's suggestion that the dad is evil indicates combinational thinking because he associated Mahmoud's idea of the evil spaceship with the main character's father who was mentioned in the movie trailer. Similarly, the following discussion episode (WD, Feb 23, 2016) shows an example of exploratory and elaborative thinking.

Lei: so we need talk about climax and change a little?

Bingwen: $i$ think you guys can keep going and write it

Lei: actually $\mathrm{i}$ am not write a lot......lollololololololol

Mahmoud: they can see this guys lol

Mahmoud: we have written more of others

Bingwen: $y e a,: p$

Lei: what about?

Bingwen: how about he kill his father

Lei: that is a sorrowful story

Mahmoud: I just added more go see it guys

Bingwen: hey, peter is rub by pirate, he can't going back

Mahmoud: lets make Peter kills the father

Bingwen: $i$ think he finally know his father is a bad guy and he want a war, and peter stop him maybe kill him

Mahmoud: thats actually better

Lei: yep. 
Lei: sounds like star wars 7 lol

Bingwen: that same like hollewood

Lei: we can to be a scriptwriter

Bingwen: lol $X D$

Bingwen: should we explain why Peter want protect them?? the pirate???

Bingwen's suggestion to kill the father as a climax point indicates exploratory thinking as the idea falls within the boundaries of the established conceptual space. The reason he gives for the killing of the father " $i$ think he finally know his father is a bad guy and he want a war, and peter stop him maybe kill him" suggests elaborative thinking as it shows an ability to carry out an idea using details. The last line in the episode "should we explain why Peter want protect them?? the pirate???" is also an invitation for elaborative thinking.

Throughout their wiki discussion, Mahmoud, Lei, and Bingwen were highly engaged in their discussion of ideas. They also took on distinct roles when approaching the task. Mahmoud seemed to be assuming a leader role by initiating discussions "guys what else should we do?" and making decisions "let's make Peter kills the father." He also acknowledged contributions "hahahaha that is cool. We should start with his dad is evil", elicited feedback "I added some more what do you think guys?", managed the writing process "is someone going to add more?! and invited changes "check it out guys and if you something is not good please feel free to fix it and make it better than it was" (Mahmoud, WD, 2016). 
Bingwen, however, seemed to take on the role of proposing ideas and writing, "how about he kill his father" (Bingwe, WD, Feb 2, 2016). In contrast to Bingwen and Mahmoud, Lei seemed to take a less clearly defined role. He occasionally initiated discussions, "Ok guys, peter hates his father, but live with he, also his father cannot treat peter, so what happen next?" "do you guys think it happen too fast?"'(Lei, WD, Feb 2, 2016). As can be seen in the last discussion episode, he also made several joking comments to express his opinion of the proposed ideas, "sounds like star wars 7 lol," "That is a sorrowful story." These observed roles were confirmed by the three informants in the interviews. The role of the writer, taken on by Bingwen, was also noted in the analyses of the revision history as seen in the following section.

\section{Revision history.}

As can be seen in Table 20 below, the number of implemented revisions reflects the roles observed in the wiki discussion board.

Table 20

Case 3: Type and Number of Revisions

\begin{tabular}{lcccc}
\hline & \multicolumn{2}{c}{ Meaning Changes } & \multicolumn{2}{c}{ Surface Changes } \\
\cline { 2 - 5 } & Macrostructure & Microstructure & Meaning Preserving & Formal \\
& Changes & Changes & Changes & Changes \\
Mahmoud & 19 t-unit & 67 words & 0 words & 7 instances \\
Lei & 27 t-unit & 128 words & 3 words & 21 instances \\
Bingwen & 209 t-units & 53 words & 26 words & 18 instances \\
\hline
\end{tabular}

Table 20 shows that Bingwen implemented substantially more macrostructure changes than Mahmoud and Lei. Mahmoud and Lei focused more on adding microstructure changes to Bingwen's contributions. Throughout their group work, 
Mahmoud and Lei seemed reluctant to adjust content generated by Bingwen. This reluctance could be attributed to an online confrontation that happened earlier in their collaboration. Bingwen started the group composition by writing "when he wake up, he was in a small room, butthe room is really luxurious" (Bingwen, WAP, Jan 26, 2016). Lei revised this sentence by adding a space to separate the coordinating conjunction (but) and the article (the), "when he wake up, he was in a small room, but the room is really luxurious" (Lei, WAP, Jan 26, 2016). Apparently, Bingwen did not appreciate having his sentence revised and deleted the space again. Bingwen and Lei added and deleted the space five times before Lei finally gave up. Later during class, Bingwen himself added the space. It seems that this confrontation led Lei and Mahmoud to infer that revisions on Bingwen's sections are not welcomed. After this incident, Mahmoud and Lei restricted their contributions to microstructure additions that only elaborate on but do not revise Bingwen's sections. This pattern can be observed in Table 21. 
Table 21

Case 3: The Subcategories of Revisions

\begin{tabular}{|c|c|c|c|}
\hline Revisions & Mahmoud & Lei & Bingwen \\
\hline \multicolumn{4}{|l|}{ I. Meaning Changes } \\
\hline A. Macrostructure & Total $=19$ t-units & Total $=27$ t-units & Total $=$ \\
\hline Changes & & & $209 \mathrm{t}-$ \\
\hline 1. Additions & 19 & 25 & units \\
\hline 2. Deletions & 0 & 2 & \\
\hline 3. Substitutions & 0 & 0 & 209 \\
\hline 4. Permutations & 0 & 0 & 0 \\
\hline 5. Distributions & 0 & 0 & 0 \\
\hline \multirow[t]{3}{*}{ 6. Consolidations } & 0 & 0 & 0 \\
\hline & & & 0 \\
\hline & & & 0 \\
\hline B. Microstructure & Total $=67$ words & Total $=128$ words & Total $=$ \\
\hline Changes & & & 53 words \\
\hline 1. Additions & 61 & 112 & \\
\hline 2. Deletions & 5 & 16 & 53 \\
\hline 3. Substitutions & 1 & 0 & 0 \\
\hline 4. Permutations & 0 & 0 & 0 \\
\hline 5. Distributions & 0 & 0 & 0 \\
\hline \multirow[t]{2}{*}{ 6.Consolidations } & 0 & 0 & 0 \\
\hline & & & 0 \\
\hline \multicolumn{4}{|l|}{ II. Surface Changes } \\
\hline $\begin{array}{l}\text { A. Meaning Preserving } \\
\text { Changes }\end{array}$ & Total $=0$ words & Total $=\mathbf{3}$ words & $\begin{array}{c}\text { Total }= \\
26 \text { words }\end{array}$ \\
\hline 1. Additions & 0 & 0 & \\
\hline 2. Deletions & 0 & 0 & 6 \\
\hline 3. Substitutions & 0 & 0 & 4 \\
\hline 4. Permutations & 0 & 3 & 2 \\
\hline 5.Distributions & 0 & 0 & 1 \\
\hline \multirow[t]{2}{*}{ 6.Consolidations } & 0 & 0 & 0 \\
\hline & & & $13^{*}$ \\
\hline
\end{tabular}




\begin{tabular}{lccc} 
B. Formal Changes & Total $=\mathbf{7}$ & Total $=\mathbf{2 1}$ & Total $=$ \\
1.Verb forms & 5 & 1 & $\mathbf{1 8}$ \\
2.Plural morphemes & 0 & 0 & 7 \\
3. Articles & 0 & 0 & 0 \\
4. Pronouns & 0 & 1 & 1 \\
5. Prepositions & 0 & 0 & 0 \\
6. Spelling & 0 & 3 & 0 \\
7. Capitalization & 0 & 2 & 4 \\
8. Punctuation & 0 & 4 & 0 \\
9. Format & 2 & 10 & 0 \\
& & & 6 \\
\hline
\end{tabular}

* The number represents the number of words in a total of $2 t$-units that were consolidated using a coordinating conjunction.

Looking at Table 21 above, we can see that Mahmoud and Lei focused on microstructure changes. These were changes that elaborate on Bingwen's writing by adding minor details. The only instances where they deleted macrostructure and microstructure changes or rearranged meaning-preserving changes were implemented on their own sections or each other's sections. There were a few instances in which they revised Bingwen's writing, but these were very superficial (e.g. format and spelling), which could be a subtle way to claim authorship rights. Mahmoud and Lei's clear focus on microstructure changes might be a result of the previously discussed online confrontation. That is, they could have refrained from focusing on macrostructure changes as these shape the plot of a story. Similarly, meaning-preserving changes are changes made to paraphrase existing content, which are clearly not welcomed by Bingwen. These observed conflicts clearly affected their perceptions of the collaborative task. 


\section{Perceptions of collaboration.}

Mahmoud, Lei, and Bingwen had different perceptions of the collaborative task. Mahmoud expressed a negative attitude towards the collaborative task. He explained that it is difficult to collaborate on a story because individuals have different ideas. He added that he was hesitant to make suggestion fearing to spur a conflict. Mahmoud proposed that a cooperative approach in which each individual works on a section might be better. However, he explained that a cooperative approach might also be difficult in a story in comparison to an essay because short stories cannot be segmented like essays.

essay each paragraph has a main point so if we are three and we are talking about a specific topic each of us is goanna take one main point and write a part after we finish we are goanna.....The story has to be connected together because in essay the second para is goanna talk about something else (INT, March 7, 2016).

In contrast to Mahmoud, Lei expressed a highly positive attitude towards the collaborative task. Despite commenting on misunderstandings, he stated that the collaborative task offered him plenty of ideas.

If I have an apple you have an apple and we exchange, each one has one apple, but if I have an idea and you have an idea and we exchange, we both have two ideas (INT, March 7, 2016).

On the other hand, Bingwen was more neutral in his perception of the collaborative task. Although he acknowledged the value of collaboration in terms of the product "In a group talking to other people can help u make the story better" (INT, 
March 7, 2016), he explained that collaboration does not allow individuals to express their own ideas.

I think sometimes you write it as a group, you cannot write the story that you want, you have to think about other people's opinion and changing your story. When you finish it is not your story (INT, March 7, 2016).

Clearly, ownership of ideas is very important to Bingwen, which could have led him to adopt the dominant role observed in the revision history analysis. Like Mahmoud, Bingwen also suggested a cooperative approach to group writing. Overall, the students in this group expressed different perceptions of the collaborative task. These perceptions could be related to their self-assessment of the individual and collaborative stories as will be discussed in the following section.

\section{Mahmoud, Lei, and Bingwen's short story.}

Mahmoud, Lei, and Bingwen explored the theme of good vs. evil in their story. The elements of the plot in their story are clearly and elaborately developed. Below are excerpts exemplifying the narrative elements of their story.

\section{Rising actions.}

Stock talk to him, "these guys are innocent, they are space travelers, if your father kill them, their planet will revenge. Your father is a captain for 14 years and nobody promote him, he want a war to prove himself!"... "You are the only one can stop your father...help them....stop your father! Please....." Stock die (Mahmoud, Lei, and Bingwen, lines 93-98). 


\section{Climax.}

He hardly hit the floor and stood in front of him preparing to get in a big fight between the father and his son (Mahmoud, Lei, and Bingwen, lines 108-109).

\section{Falling actions.}

After he came back to the hometown... The country give his father a hero funeral. Also Peter keep this secret, about his father wanted to have a war, in his heart forever (Mahmoud, Lei, and Bingwen, lines 134-135).

\section{Resolution.}

When Peter bury his father. He decided to leave this planet. He don't want stay in a place have a lot of bad memory (Mahmoud, Lei, and Bingwen, lines 136-137).

The story features a series of rising actions that causes conflict between the protagonist and his father, leading to a climax point. The results of the climax are developed in the falling actions and the conflict is resolved at the end. A notable feature of this story is its unpredictability. The story features a number of unexpected twists "when he ran to the turret location someone stun him. When he awoke, he found he tied up by someone" (lines 87-88). The incorporation of surprising twists throughout the story prevented monotony and created a positive effect for the reader.

The characters of the story are described using the following techniques:

(1) thoughts and Feelings, "Peter feel helpless."(line 106)

(2) reactions, “He was scared and curious." (line 8)

(3) actions, "Peter suddenly feels nauseated, he run out of the laboratory" (line $80-81)$ 
(4) physical descriptions, "A middle-aged man, whose name is Abraham, came up from the bridge and shout. This is a man in 40 s, as red as Stock” (line 37)

(5) background information: "Peter had a talent for sports; He mastered the most combat skill really fast” (line 54)

The setting of the story is described vividly using sensory details and descriptions "all master room with the panoramic projection technology. In the master room can see the whole picture of the galaxy, Peter could not help marveling at the sound. In the master room, everybody is busy..." (lines 32-34). The story is also rich with descriptive adjectives, sensory details, and figures of speech, e.g. "Three dark years of college spent really quickly" (line 66), "a man came to his room and use his broken English talk to him" (line 11), "they just like clown," "Curiosity prompted him to open the door" (line 76), and “History just remember successful man!” (lines 105-106).

A third-person limited point of view is used to narrate the story; the narrator has limited access to the protagonist's world. However, as the following paragraph shows, some scenes employ a third-person multiple point of view where the narrator has access to the world of the antagonist.

The Peter's father was very angry; he thinks that the behavior of Peter will lose his face, so he often scolded Peter. But gradually after a period of time, just few people can beat him. The time on the street not only exercise his combat he also learned a lot about survivability. But his father was very angry, He thinks that Peter will only fooling around on the street, so he give Peter a restriction. (lines 57-61) 
The pace of the writing is consistent throughout the story. The scenes are equally developed with sufficient details and are connected using time adverbials, which creates clear transitions. e.g. "Two years later, he became guns master sergeant" (line 69). Similarly, the writing style was generally appropriate to the genre. 


\section{Mahmoud's short story.}

Mahmoud's short story narrates the time-travel adventure of a young man to ancient Antarctica. The plot structure of his story is fully developed with an exposition, rising actions, a climax, falling actions, and a resolution. Below are excerpts exemplifying these narrative elements.

\section{Exposition.}

One stormy day with dark black clouds traveling overhead, Ode who was a boy 17 years old from Middle East, pulled his hood his head when he noticed a phone ringing from phone booth in the corner of the street. (lines 1-3)

\section{Rising actions.}

Colorful waves of big circles surprisingly came out of the headphone and pulled and dragged Ode inside of that phone booth. (lines 10-11)

\section{Climax.}

Ode stood in front the King, and Habibo was preparing to punch him in the face. (line 87)

\section{Falling actions.}

“Wake up! Wake up! Wake up Ode! It is almost 7 o'clock," That was Ode's mother Mary trying to wake him up for school. "Omg! I am home," Ode said in disbelief. (lines 90-92).

\section{Resolution.}

Ode found out he was dreaming, and he was very happy because that was just a dream. He woke up and starting to get ready for school. (lines 94-95) 
As can be seen in the excerpts above, the conflict of the story is centered upon the main character's quest to go home. However, the story fails to deliver a theme, which could be related to the lack of attention given to characterization in the story. The main character is only briefly described through background information, as seen in the exposition. Little context is given to the character's motives or life circumstances, which makes it difficult to develop a theme. Unlike the story's main character, the setting is described vividly using sensory details and descriptions. e.g. "Ode woke up around a bunch of different colors of camels and a big tent in the middle of a huge desert with the hot shiny sun in middle of clear sky of clouds" (lines 14-16). A notable feature of the story is the use of surprising twists, which was also noted in the collaborative story. e.g. "Suddenly an old man came out from the tent and saw Ode in front him. The man stopped pulled and pointed his sword on Ode..."(lines 18-19).

Mahmoud used a third-person limited point of view to narrate his story, which was also the point view used in the collaborative story. The writing style is rich with vivid descriptions. e.g. "Ode looked back, gulping and started slowly walking to pick that phone” (line 7), but no figures of speech (similes, metaphors...etc.) are employed. The dialogue in the story is very expressive and natural. e.g. "Blah Blah Blah! Speak language little kid or get the hell out of here!" said Aladdin, confused. "Alright, Alright! man whatever you do not have to believe me" Ode said" (lines 49-50). The pace of the story is generally consistent except for some abruptness towards the end. The falling action and resolution do not address the effects of the climax on the character's life, which creates an abrupt closure. Scene transitions are overall effective. Although there are few examples of academic transition words. e.g. "First of all, Ode said..." (line 24), 120 
the majority of scene transitions are created through time adverbials. e.g. "After long deep weird sleeping, Ode woke up..."(line 14).

Compared to the collaborative story, Mahmoud's individual story seems to be less effective than the collaborative story for the following considerations: There is no clear theme in the story; characters are not described sufficiently; and the pace of narration is not consistent towards the end. Nevertheless, Mahmoud rated his individual story significantly higher than the collaborative story. On a scale of 30 points, he gave 28 points to his individual story and 15 points to the collaborative story. This assessment could be related to the fact that the collaborative story was dominated by Bingwen as was previously suggested in the revision history analysis.

\section{Lei's Short Story.}

Lei wrote a story about a soldier's time-travel adventure to World War I. The plot structure is developed through exposition, rising actions, climax, falling action, and resolution. Below are excerpts of embodying these narrative elements.

\section{Exposition.}

In a secret base, an old man talked to a young soldier "Are you ready? (line 1)

\section{Rising actions.}

General! We are losing control with this machine! (line 11)

\section{Climax.}

A loud voice appear in the battlefield, two "mark 1" tanks appeared. British soldiers feel so confidence because no one break tank before expect break by itself. (lines 103-104)

\section{Falling actions.}


The British soldiers were dumbfounded, Ernst said "Attack! For Deutsche! All weapons fire, a lot of British soldiers died, they cannot believe German soldiers can break tanks (lines 106-110)

\section{Resolution.}

Finally, Ernst and his company won this war. Ernst find he became to like with his company, they will go to more and more war and never stop, but Ernst will do his best for go back home, his story never end (lines 110-112)

As can be seen above, Lei's story includes all the typical narrative elements. The story also features a number of surprising twists. e.g. ,"you can know everything you want when you see your company members, solder Hitler will brought you there, and good luck!" "Hitler!" (lines 42-44). The exposition of the story does not introduce the characters, instead the exposition of the story features a rising action. Although this writing style could increase the dramatic effect of the story, the lack of characterization in the exposition and throughout the story negatively influenced the clarity of the theme. The story revolves around a conflict between the British and the Germans in the story. However, it is not clear how this conflict relates to the main character since his nationality is not introduced. The clarity of the theme is further diminished by the presence of a sub-plot. The sub-plot explores the main character's quest to change the past by influencing Hitler's perceptions of the Jews. Taken together, the presence of the sub-plot and the lack of characterization creates confusion as to the nature of the theme.

The setting of the story is moderately described. e.g. "this is river Somme, now is September 1916, the First World War" (line 36).On the other hand, the story includes several instances of figurative language "he doesn't know he walking on the brink of 
death" (line 35), "they are selfish and drink people's blood" (line 85), "Ernst and his company against wave after wave of enemies" (line 92). Similarly, the dialogue in the story, which was a corner stone of the narration, is expressive and effectively contributed to the story. e.g. "Ok Alex, go to time machine, we just have one chance, if we failed, no time machine, no Alex, no this plan!" (lines 6-7).

As can be seen in the excerpts above, a third-person limited point of view is generally used to narrate the story except for few occasions in which the narrator comments on the thoughts of other characters. e.g. "After that Hall stopped talking, he don't want to make leader to angry to him" (line 61). The pace of the story is generally consistent but is somewhat abrupt towards the end of the story. The falling action and resolution are developed less elaborately in comparison to the other narrative elements, which could be due to that fact that they were written at the end. Scene transitions are effectively created through time adverbials and specific dates. e.g. "In the same time..." “On August 30, 1916...” (lines 21 \& 94.)

Overall, the analysis indicated that Lei's individual story is less effective than the collaborative story. The theme of the individual story is unclear, the characters and the setting are described more vividly in the collaborative story. Finally, the pace of narration is more consistent in the collaborative story than in the individual story. It is worth noting that Lei also rated the collaborative troy higher than the individual story by giving his individual story 15 points and the collaborative story 19 points. 


\section{Bingwen's short story.}

Bingwen's individual story narrates a group of soldiers' time-travel adventure to World War III. The plot structure is fully developed through exposition, rising action, climax, falling action, and resolution. Below are excerpts exemplifying these narrative elements.

\section{Exposition.}

One stormy day with dark black clouds traveling overhead, Steve pulled his hood on his head when he noticed today night is a longer night. He looked at his vicecaptain Schofield, a former SAS (line 2).

\section{Rising actions.}

It's time to act; Steve gave team set out on a helicopter. The helicopter put them on $5 \mathrm{~km}$ away from terminal... (line 70).

\section{Climax.}

The final battle is start, the can hear the soldiers fight with machine warriors... (line 220).

\section{Falling actions.}

The A team stand near the container. Yes, they came back, and that was the longest night for their life. Sakura opens her eyes, he saw Chenguang stand opposite of her. Yes she almost crying, she takes a big hug to Chenguang. (lines 262-264). 


\section{Resolution.}

It's the time to meet our "old friend"." Irina says. "Yes, we have "some bill" that need to work it out with him." Schofield says. Yes, they came back from the future, but they have to build the new future... (lines 277-279).

The theme emerging from the conflict of the story is the value of team work and love. There are several surprising twists throughout the story. e.g. "team ready to fight immediately, but they see them thoroughly confused. A few robots are fire with several human" (lines 102-104). The characters in the story are vividly described in the exposition through physical descriptions, actions, and background information as can be seen in the excerpt below.

Irina is a hacker; she is also a beauty girl in the STAT. She have rich experience in actual combat... Sakura is sticking tongue out piquantly. Chenguang has supercomputing ability, he is the notoriously snipers in Chinese police forces, Steve found him in the World Police Competition and took him to the STAT. Sakura as a medic in Japanese National, graduate at Tokyo university medical major, but she has never participated in combat (lines 33-49).

Unlike characterization, the setting of the story received less attention. Nevertheless, there are few instances in which the setting is briefly described. e.g. "their planes are close to a U.S. military base in Djibouti” (lines 56-57), “"It's in October 2026" (line 118). Throughout the story, there are instances of figurative language. e.g. “One hour passed in a twinkling of an eye," (line 77), and "is night, but the fire making sky like morning” (line 221). 
As can be seen in the excerpts above, a third-person limited point of view is used to narrate the short story. The pace of the narration is consistent throughout the story. The falling actions and resolution are given equal attention as the other narrative elements. Scene transitions are very effective through the use of time adverbials. e.g. " $A$ few days later, two companies of Chinese soldiers are coming to Berlin" (line 198). Another technique that Bingwen used to create effective transitions is the use of dialogue, which is a common feature in his individual story. An example excerpt is presented below.

The relationship with Chenguang and Sakura is very subtle, even they do not speak, but Steve can see that......

"To land in fifteen minutes."

The pilot radioed said to Steve, Steve's thinking is interrupted, and their planes are close to a U.S. military base in Djibouti (lines 53-57).

The analysis of Bingwen's short story in comparison to the collaborative story indicted that both stories are of comparable quality. The plots in both stories are fully developed. The characters and the setting are described in a similar manner. The writing style and pace of narration are effective in both stories. Bingwen himself also rated the two stories equally in his self-assessment questionnaire, giving the two stories 27 points of 30. The equal value of the two stories could be related to the fact that Bingwen contributed the most to the collaborative story as seen in the revision history analysis.

Overall, the effectiveness of the individual stories as compared to the collaborative story is not consistent in this case study. As can be seen in Table 22 below, although the collaborative story is more effective than Mahmoud's and Lei's short stories for reasons outlined above, Bingwen's individual story is equal to the collaborative story. 
As discussed earlier, the informants of this case also varied in terms of their attitudes to the collaborative task. Whereas Lei evaluated the collaborative task positively, Mahmoud had a negative view point towards the collaboration. Bingwen expressed a more neutral perception of the task. Their self-assessment of the stories reflected this perception. For instance, Mahmoud rated his individual story higher than the collaborative story, which corresponds with his negative attitude about collaboration. Lei rated the collaborative story higher than the individual story, which also corresponds to his positive perception of collaboration. Finally, Bingwen's neutral perception of collaboration reflects his rating of the collaborative and the individual story as equal. 
Table 22

Case 3: Summary of the Qualitative Evaluation of Creativity in the Short Stories

\begin{tabular}{|c|c|c|c|c|}
\hline & $\begin{array}{c}\text { Collaborative } \\
\text { Story }\end{array}$ & $\begin{array}{c}\text { Mahmoud 's } \\
\text { Story }\end{array}$ & Lei's Story & $\begin{array}{l}\text { Bingwen' } \\
\text { s Story }\end{array}$ \\
\hline Plot & Well-developed $\backslash$ twists & $\begin{array}{c}\text { Well- } \\
\text { developed } \backslash \text { twists }\end{array}$ & $\begin{array}{c}\text { Well- } \\
\text { developed } \backslash \text { twists }\end{array}$ & $\begin{array}{c}\text { Well- } \\
\text { develope } \\
\text { d } \backslash \text { twists }\end{array}$ \\
\hline Theme & Clear & Unclear & Unclear & Clear \\
\hline $\begin{array}{c}\text { Characteriza } \\
\text { tion }\end{array}$ & Moderate & Minimal & Scarce & Vivid \\
\hline Setting & Vivid & Vivid & Moderate & Minimal \\
\hline Point of view & $\begin{array}{c}3^{\text {rd }} \text { person } \\
\text { limited } \backslash \text { multiple }\end{array}$ & $\begin{array}{l}3^{\text {rd }} \text { person } \\
\text { limited }\end{array}$ & $3^{\text {rd }}$ person limited & $\begin{array}{l}3^{\text {rd }} \\
\text { person } \\
\text { limited }\end{array}$ \\
\hline $\begin{array}{l}\text { Sensory } \\
\text { details }\end{array}$ & Rich & Rich & None & Few \\
\hline $\begin{array}{l}\text { Figurative } \\
\text { language }\end{array}$ & Few examples & None & Few examples & $\begin{array}{c}\text { Few } \\
\text { examples }\end{array}$ \\
\hline $\begin{array}{l}\text { Pace of } \\
\text { narration }\end{array}$ & Consistent & $\begin{array}{l}\text { Generally } \\
\text { consistent }\end{array}$ & $\begin{array}{l}\text { Generally } \\
\text { consistent }\end{array}$ & $\begin{array}{c}\text { Consiste } \\
\mathrm{nt}\end{array}$ \\
\hline $\begin{array}{c}\text { Scene } \\
\text { transition }\end{array}$ & Effective & Effective & Effective & Effective \\
\hline Genre & Appropriate & Appropriate & Appropriate & $\begin{array}{l}\text { Appropri } \\
\text { ate }\end{array}$ \\
\hline
\end{tabular}




\section{Accuracy and Complexity.}

Table 23 below shows the results of the accuracy and complexity analysis for the collaborative and individual short stories. As can be seen in the table, there is not a clear trend in terms of the accuracy of the short stories, which corresponds to the results from the first two case studies. Like Case $1 \& 2$, the collaborative story and the three individual stories reflected similar types of global and local errors. The effect on complexity, however, was less clear in this case. Unlike Case $1 \&$ 2, which showed an increase in complexity for both informants, the effects on complexity are not clear in this case. This observation could be related to group dynamics; the collaborative story was largely dominated by one member who did not welcome revisions from others.

Table 23

Case 3: Results of Accuracy and Complexity of the Short Stories

\begin{tabular}{|c|c|c|c|c|}
\hline \multicolumn{2}{|c|}{ Collaborative Story } & Mahmoud 's Story & Lei's Story & Bingwen's \\
\hline $\begin{array}{c}\text { Accuracy } \\
\text { (The number } \\
\text { of errors per } \\
\text { t-unit) }\end{array}$ & 16 errors/100 words & 9 errors/100 words & $\begin{array}{c}16 \text { errors/100 } \\
\text { words }\end{array}$ & $\begin{array}{c}17 \text { errors/100 } \\
\text { words }\end{array}$ \\
\hline $\begin{array}{c}\text { Complexity } \\
\text { (The number } \\
\text { of words per } \\
\text { t-unit) }\end{array}$ & 8 words/t-unit & 10 words/t-unit & 7 words/t-unit & $\begin{array}{l}9 \text { words/t- } \\
\text { unit }\end{array}$ \\
\hline
\end{tabular}




\section{Cross-case Analysis}

The cross-case analysis below summarizes the findings from all four case studies. Although Group 4 (Kyou and Mei) was not discussed in the previous chapter for reasons outlined in the methodology, the partial data collected from this group were analyzed using the same analysis procedures. Thus, the results of the analysis are used in the following sections when appropriate.

\section{Wiki discussions.}

The analysis of the wiki discussions for the four case studies showed that the groups differed in terms of the number of posts as well as the nature of these posts. As can be seen in Table 24 below, Group 2 (Adam \& Huda) exhibited an extensive negotiation of ideas. Similarly, Group 3 (Mahmoud, Lei, \& Bingwen) posted a considerable number of idea negotiation posts. On the other hand, Group 1 (Fatima \& Chow) \& 4 (Kyou and Mei)'s discussion of ideas was either absent (Group 1) or limited (Group 4). It is worth noting that Group 4's 12 idea negotiation posts only represent a one-way suggestion of two ideas spread over 12 posts rather than mutual engagement and discussion of multiple ideas. Group 1's few posts were mostly product posts. As reported by the majority of informants in this study, these product posts were used as an indirect way to communicate ideas, and negotiate authorship rights. Group 3 was the only group that did not use product posts as a way to communicate ideas. This observation could be due to the working relationship established by the phatic communication posts that were popular in their wiki discussion board. Across groups, students did not engage in a 
discussion on accuracy or complexity of the language. The three occasions noted as language related posts were comments on word choice and spelling.

Table 24

Cross-case Analysis: Type and Number of Wiki Discussion Posts

\begin{tabular}{crccc}
\hline & $\begin{array}{c}\text { Group 1 } \\
\text { Fatima } \\
\text { \& Chow }\end{array}$ & $\begin{array}{c}\text { Group 2 } \\
\text { Adam \& Huda }\end{array}$ & $\begin{array}{c}\text { Group 3 } \\
\text { Mahmoud, Lei, } \\
\text { \& Bingwen }\end{array}$ & $\begin{array}{c}\text { Group 4 } \\
\text { Kyou \& } \\
\text { Mei }\end{array}$ \\
\hline Total number & 12 & 70 & 69 & 30 \\
Nature of posts & & & & \\
Idea Negotiation posts & 0 & 47 & 39 & 12 \\
$\begin{array}{c}\text { Language related posts } \\
\text { Phatic communication }\end{array}$ & 0 & 1 & 1 & 1 \\
$\begin{array}{c}\text { posts } \\
\text { Procedural posts }\end{array}$ & 1 & 1 & 22 & 0 \\
Product posts & 3 & 12 & 7 & 11 \\
\hline
\end{tabular}

Interestingly, the groups that had higher number of idea negotiation posts (Groups $2 \& 3)$ exhibited more instances of and a wider variety of creative thinking processes. That is, whereas Group 1's discussion did not show instances of creative thinking processes and Group 4 only showed few instances of exploratory, combinational, and elaborative thinking, Group $2 \& 3$ exhibited a substantial number of exploratory, combinational, elaborative, and transformational thinking.

It is also worth noting that the groups that communicated more in the wiki discussion board (Group $2 \& 3$ ) seemed to develop distinct group roles (writer/idea proposer/leader). On the other hand, these roles were not observed in the discussion board of Group 1. These roles are further discussed below in the cross-case analysis of the revision history. 


\section{Revision history.}

The analysis of the revision history indicated several trends. First, the students who took a strong leadership role in the wiki discussion board made more macrostructure revision to the wiki than their partners. As seen in Table 25 below, this observation can be clearly seen in Groups $2 \& 3$ where Huda and Bingwen were noted to take the role of the primary writer. Contrastingly, the students in Group 1 did not develop distinct roles in their discussion. Correspondingly, the macrostructure revisions implemented by the two students are almost equal in this group. In Group 4, Kyou initially assumed a leadership role, which is suggested by the slightly higher number of macrostructure changes. However, their group dynamics changed and no distinct roles were noted as the task progressed. It is worth noting that macrostructure revisions are revisions that shape the plot of the story, which indicates that students who controlled these revisions were probably able to substantially influence the plot of the story.

Table 25

Cross-case Analysis: Group Roles \& Revision Behaviors

\begin{tabular}{cllll}
\hline & \multicolumn{1}{c}{ Group 1 } & \multicolumn{1}{c}{ Group 2 } & Group 3 & Group 4 \\
\hline $\begin{array}{c}\text { Wiki } \\
\text { Discussion }\end{array}$ & No distinct roles & Distinct roles & Distinct roles & $\begin{array}{l}\text { No distinct } \\
\text { roles }\end{array}$ \\
& Fatima: $36 \mathrm{t}-$ & Adam: $39 \mathrm{t}$ - & $\begin{array}{l}\text { Mahmoud: } 19 \text { t-units } \\
\text { units }\end{array}$ & $\begin{array}{l}\text { Kyou: } 38 \mathrm{t}- \\
\text { Lei: } 27 \text { T-unit }\end{array}$ \\
$\begin{array}{c}\text { units } \\
\text { Revistructure }\end{array}$ & $\begin{array}{l}\text { Chow: } 37 \mathrm{t}- \\
\text { units }\end{array}$ & $\begin{array}{l}\text { Huda: } 86 \mathrm{t} \text { - } \\
\text { units }\end{array}$ & Bingwen: 209 t-units & Mei: 8 t-units \\
& & & & \\
\hline
\end{tabular}


Another trend that I observed relates to the notion of text ownership. Across groups, there was a student in each group who viewed the collaborative text as a whole and revised all the document. On the other hand, there was a student in each group who only revised their own contributions and refrained from changing their partner's writing. This observation indicates that students in the same group can have varying perceptions of ownership towards the collaborative text. It is worth noting that even the students who made revisions irrespective of the original writer did not change their partner's macrostructure changes, but rather implemented microstructure and meaning-preserving changes. This observation suggests that students perceive the macrostructure changes differently, and perhaps these changes are more likely to be disruptive to the original writer if deleted or revised.

Finally, the number of formal revisions was limited in all groups. Compared to other revisions, students did not seem to prioritize formal aspects of the text in this study. The few formal revisions noted were applied to verb forms, capitalization, and spelling.

\section{Collaborative stories vs. individual stories.}

The students in this study seemed to struggle with the genre of creative writing. The qualitative analysis of the individual stories indicated that some students had difficulty in the following areas: 1) developing a theme, 2) describing the characters and setting, 3) incorporating sensory details and figures of speech, 4) maintaining a consistent point of view and pace, 5) transitioning between scenes, and 6) writing in appropriate register. 
In many of the individual stories, students were unable to develop a theme. The stories featured a series of actions, but no overarching theme emerged and no lesson is learned from the narration. Moreover, the students in all groups commented that it was difficult to describe the characters and setting and add sensory and figurative language because they lacked the necessary vocabulary. Further, the students were sometimes unable to maintain a consistent point of view. Although students often opted for a thirdperson limited point of view, they sometimes switched to a multiple or an omniscient third-person point of view or to a first person point of view in the same paragraph. The inconsistency was also noted in the pace of narration with some important scenes developed abruptly while others of less importance were given more attention. The inconsistent pace was further aggravated by the lack or inappropriate use of scene transitions. Many students seemed to struggle with transitioning between scenes. Transitions were often left out or created using academic transition words. Using academic features was observed widely in the stories. Students seemed to struggle with mastering the appropriate genre, which often led them to write in a more academic register. Examples include relying heavily on formal subordinating conjunctions and topic sentences, writing summaries of scenes, and restating thesis statements.

Many of the struggles discussed above were reflected in the collaborative stories. Added to that, students writing collaboratively seemed to struggle with plot development. That is, two out of the four collaborative stories had two plot structures. Having two plot structures made it difficult to develop a clear theme. There was no overarching theme emerging from these two collaborative stories. Further, the pace of narration in the collaborative stories was more inconsistent than the individual stories. This observation 
could be related to the task prompt used in the collaborative task. The students were asked to write a short story depicting the character's life from the time he was kidnapped to adulthood. This could have been a challenge for the students; they may have tried to summarize large chunks of the character's lifetime in order to fit all of this content, which might have aggravated the problem of the inconsistent pace. While this is a possible interpretation, it is more probable that differences in writing style negatively affected the pace of narration in some collaborative stories, creating abrupt and unexpected transitions and causing the story to be disjointed. This explanation seems more likely because the inconsistent pace and unexpected transition issues were not observed in the group where one student took control of the collaborative task. For instance, Group 3 (Mahmoud, Lei, \& Bingwen) wrote a collaborative story that featured one plot, a clear theme, and a consistent pace, which is probably related to the fact that Bingwen contributed the most ideas and dominated the writing. In contrast, in Group 1, neither Fatima nor Chow claimed control of the task, which led the collaborative story to have two plots, unclear theme, and inconsistent pace. Group 2 (Adam \& Huda) falls in the middle of the spectrum. That is, although Huda contributed the most to writing the story, the ideas mostly came from Adam. Her attempt to incorporate his ideas with hers caused the story to have two plots, unclear theme, and inconsistent pace. Overall, it seems that the group in which one member took control over ideas and writing was the one that actually produced an effective collaborative story.

In short, the qualitative analysis of the collaborative stories as compared to the individual stories did not show a clear effect of collaboration on the struggles discussed above. In the same vein, the overall evaluation of the individual and collaborative stories 135 
did not show a trend. That is, while the collaborative stories were more effective than their individual stories in the case of Adam, Mahmoud, and Lei. For other students such as Fatima, Chow, and Huda, it was the opposite.

Similarly, the effect of collaboration on the accuracy of the stories was not clear. As shown in Table 26, while the number of errors per 100 words decreased in the collaborative story for some students (Chow, Huda, and Bingwen), some of the other students wrote more accurate individual stories (Fatima, Adam, and Mahmoud).

Table 26

Cross-case Analysis: Accuracy of the Short Stories

\begin{tabular}{llll}
\hline Accuracy & \multicolumn{1}{c}{$\begin{array}{c}\text { Group 1 } \\
\text { Fatima \& Chow }\end{array}$} & \multicolumn{1}{c}{$\begin{array}{c}\text { Group 2 } \\
\text { Adam \& Huda }\end{array}$} & $\begin{array}{c}\text { Group 3 } \\
\text { Mahmoud, Lei, \& Bingwen }\end{array}$ \\
\hline $\begin{array}{l}\text { Collaborative } \\
\text { Story }\end{array}$ & 15 errors/100w & 10 errors/ $100 \mathrm{w}$ & 16 errors $/ 100 \mathrm{w}$ \\
$\begin{array}{l}\text { Individual } \\
\text { Stories }\end{array}$ & 13 errors $/ 100 \mathrm{w}$ (Fatima) & 8 errors $/ 100 \mathrm{w}$ (Adam) & 9 errors $/ 100 \mathrm{w}$ (Mahmoud) \\
& 16 errors $/ 100 \mathrm{w}$ (Chow) & $\begin{array}{l}12 \text { errors } / 100 \mathrm{w} \\
\text { (Huda) }\end{array}$ & 16 errors $/ 100 \mathrm{w}$ (Lei) \\
& & & \\
& & & \\
\hline
\end{tabular}

However, there was a minimal effect of collaboration on the syntactic complexity of the stories. Table 27 below shows that for the majority of the informants, the collaborative stories were slightly more complex than the stories they wrote individually. 
Table 27

Cross-case Analysis: Complexity of the Short Stories

\begin{tabular}{lcll}
\hline Complexity & $\begin{array}{c}\text { Group 1 } \\
\text { Fatima \& Chow }\end{array}$ & \multicolumn{1}{c}{$\begin{array}{c}\text { Group 2 } \\
\text { Adam \& Huda }\end{array}$} & $\begin{array}{c}\text { Group 3 } \\
\text { Mahmoud, Lei, \& Bingwen }\end{array}$ \\
\hline $\begin{array}{l}\text { Collaborative } \\
\text { Story }\end{array}$ & 8 words/t-unit & 11 words/t-unit & 8 words/t-unit \\
& & & \\
& & & \\
$\begin{array}{l}\text { Individual } \\
\text { Stories }\end{array}$ & 7 words /t-unit (Fatima) & 10 words/t-unit (Adam ) & 10 words/t-unit (Mahmoud) \\
& 7 words /t-unit & 10 words/t-unit & 7 words/t-unit (Lei) \\
& (Chow) & (Huda) & 9 words/t-unit (Bingwen) \\
\hline
\end{tabular}

\section{Perceptions of collaboration.}

Students' perceptions of the collaborative task were overall negative. Except for two students who expressed a positive perception, the remaining six students had negative or neutral perceptions. The students reported the following reasons for their dissatisfaction with the task: differences in age, gender, education, and cultural background; and differences in individual ideas.

Many students commented on how differences in age, gender, education, and culture impeded their online collaboration, making them less likely to make suggestions or revise the wiki page. Similarly, the students expressed difficulty negotiating a creative task that is based on imaginative ideas. They also commented on ownership of ideas and that it was challenging to navigate the collaborative task. This observation suggests that the genre of creative writing is perhaps difficult to implement as a collaborative task in ESL writing, which could be related to the reasons mentioned above or the difficulty of segmenting the text as expressed by some informants. It is worth noting that students in the same group expressed different perceptions towards the collaborative task. The 
varying perceptions suggest that students in the same group could have entirely different experiences.

Although the focus of this study was to examine students' perception of collaborative creative writing, it is worth mentioning that students expressed highly positive perceptions of the individual task. They stated that creative writing allowed them a space to practice grammar and explore vocabulary without thinking of the macro level structural details of paragraphs and essays. They also commented on how the genre allowed them to express their own ideas rather than citing other references. As Lei explains:

When a baby is born, he do not know how to run. Essay is like run for baby for me. Alot of serious hard difficult words to make an essay Stories are better practice than essays for beginners and I need a tool to show what I can do with English...I use my story to talk to people. (INT, March 7, 2016). 


\section{Chapter 6}

\section{Conclusion}

This study examined how ESL students collaborate to write short stories using wikis, and whether collaboration influences the quality of the final product. In the following sections, I discuss the findings, pedagogical implications, limitations of the study, and suggestions for future research.

\section{Process of Collaboration}

How do students collaborate to write a short story using a wiki platform?

To examine the process, the wiki discussion boards and revision history were analyzed for the four case studies ${ }^{2}$. The analysis of the wiki discussion indicated that although the groups varied in terms of the number and nature of posts, idea negotiation posts were the most common type of posts. The two groups that had a large number of these idea negotiation posts (Group $2 \& 3$ ) articulated more creative thinking processes in their discussion. Specifically, they were the only groups that manifested transformational thinking. This form of thinking represents "the deepest cases of creativity" as it requires the ability to think of an "inconceivable" reality (Boden, 2004, p. 5). It is possible that this form of thinking occurred in the other two groups (Group $1 \& 4$ ), but it was neither verbalized in their discussion nor manifested in their collaborative short story.

In contrast to the idea negotiation posts, language related posts were almost nonexistent. Students in this study prioritized ideas over grammar. This focus on ideas

\footnotetext{
${ }^{2}$ Group 4 was not discussed in the discussion chapter because data from this group are incomplete. The cross-case analysis and conclusion draw on data from this group when relevant.
} 
could be due to the meaning-focused and creative nature of the task as well as the lack of explicit grammar instruction, which has been speculated as a factor affecting students' attention to form (Storch, 2012). Students' lack of attention to form in meaning-focused tasks has also been observed in another study (Kessler, 2009). Although some studies have reported a focus on form in meaning-focused studies (Arnold et al., 2012; Lee, 2010), the task design in these studies seems to promote attention to form by either incorporating explicit grammar instruction (Lee, 2010) or providing rounds of formative feedback (Arnold et al., 2012).

Not only were the wiki discussions void of grammar-related negotiations, students in all groups did not engage in discussions about figurative language and literary devices, although these aspects of creative writing were a focus of class instruction and tasks. In short, it seems that meaning-focused tasks promote more attention to macrostructure aspects of the text rather than grammar, lexical, and stylistic choices.

The analysis of the wiki discussions also shed light on the interactional dynamics of the groups. Different group dynamics emerged in the students' wiki discussions. While one group engaged in frequent phatic communication, the other three groups were taskoriented and did not exchange small talk. Interestingly, the groups that did not establish rapport through phatic communication were most likely to post their contributions in the discussion board rather than directly editing the wiki page. The participants commented that this served as a means to negotiate authorship rights.

The varying group dynamics were also reflected in the different revision behaviors that students showed when applying changes to their shared wikis. Some of them seemed to take on the role of the primary writer. These students applied 
substantially more revisions to the whole document than their group members. On the other hand, some students shied away from revising their peer's contributions and restricted their revisions to their own writing. This reluctance to revise other students' contributions has been observed in other studies (Arnold, Ducate, \& Kost, 2009; Lee, 2010; Mak and Coniam, 2008). The noted differences in revision behaviors indicate that students within the same group interpret the ownership of the text differently.

These varying perceptions of ownership may have given rise to two different group dynamics. In two out of the four cases (Groups $2 \& 3$ ), one student dominated the writing by contributing more revisions to the wiki. The students in these groups did not seem engaged in each other's contributions as manifested in a lack or superficiality of comments about contributions even when invited by the writer. In fact, some students even reported not reading their partner's contributions in the final interviews (Mahmoud and Lei, INT, March 7, 2016). It is worth noting that these groups showed equal contributions and higher levels of engagement with each other's ideas in the wiki discussions. However, this engagement was not observed in the product and the contributions were not equal either. In the other two cases (Groups $1 \& 4$ ), the students contributed a similar number of revisions but were passively permissive of each other's contributions. Instead of discussing and changing ideas, they preferred to individually write their ideas even if these ideas did not connect to their partner's previous contribution. Like Groups $2 \& 3$, Group $1 \& 4$ did not show engagement in each other's contributions. These observed patterns of interaction correspond with Storch's (2009) model of dyadic interaction. The model outlines four patterns of dyadic interaction based on the level of contribution and control over the task and the level of engagement with 
each other's contributions. These patterns include: collaborative (equal contributions and high engagement), expert/novice (unequal contributions and high engagement), dominant/dominant (equal contributions and low engagement), and dominant/passive (unequal contributions and low engagement). It seems that Groups 1 and 4 fit neatly in the dominant/dominant pattern, which is characterized by equal contribution and low engagement, as students in these groups contributed equally to the wiki discussion and revision history but ignored each other's contributions. In contrast, Group $2 \& 3$ seem to have different dynamics in the wiki discussion and revision history. That is, although the actual writing seemed to follow a dominant passive pattern characterized by onemember dominance and low engagement, their wiki discussions reflected equal contribution and high levels of engagement over ideas, which is closer to the collaborative pattern. This finding indicates that groups may have different patterns of interaction in the process and product of collaboration.

These observed patterns of interaction could be due to the genre of the task. Creative writing tasks may not lend themselves well to collaboration. Unlike other academic writing tasks, creative writing tasks are not based on factual information but rather on individual ideas. Thus, there are no common reference points that can be used by the collaborators to resolve conflicts in ideas. The lack of a reference point may have contributed to the dominantldominant pattern in the wiki discussion and revision history (Groups $1 \& 4$ ) or the dominant passive pattern in the revision history (Groups $2 \& 3$ ). That is, in Groups $2 \&$ 3, one student chose to assume a leadership role and dominated the writing in order to avoid linguistic conflicts. In Groups $1 \& 4$ avoided conflicts by not discussing ideas altogether. 
While cooperation may be used to resolve conflicts in other writing tasks by having each member work on a separate section and compiling these sections at the end, it does not seem that cooperation is an effective option for creative writing. As commented by several informants in this study, short stories are difficult to segment for the purpose of cooperation. That is, whereas academic writing tasks can be segmented so that each member is responsible for a paragraph, it is difficult to do that in creative writing since the text is less predictable, not necessarily linear and any given section depends on the previous section.

Not only is collaboration tricky on a macrostructure level, the difficulty can also be observed at the language level. Collaboration on creative writing tasks can be difficult because there are no standards when it comes to word choice, tense, or style. Academic writing tasks, on the other hand, are easier to collaborate on due to the well-established conventions of the genre. After all, it only takes a reference to the Academic Word list or APA style to settle conflicts. In creative writing, there are no such standards in order to allow for individual creativity. The lack of a common reference point to resolve these linguistic conflicts could be the reason behind the minimal number of language related posts and formal revisions. Accordingly, it seems that in a creative writing task, it is more difficult to bridge the gap between the different writing styles and produce an effective collaborative product.

The difficulty to collaborate on creative writing texts also stems from students' perceptions of text ownership. The majority of the students preferred to write the stories individually as it allowed them to "express their voice" (Huda, INT, March 7, 2016). The students seemed to struggle with taking a collaborative approach towards a task that they 
perceived as individual. Unlike an argumentative essay about global warming, the students seemed to identify with their short stories despite the fact that the topic was predetermined. This personal connection to the short stories made collaboration problematic and could have contributed to the interactional dynamics discussed earlier.

In addition to the points discussed above, the genre of creative writing posed a difficulty on an individual level as well. The students were not accustomed to writing without a template or an outline. The uncertainty about the structure of short stories led them to transfer many academic writing features to their short stories. These features included topic sentences, thesis statements, summaries, and formal transitions. The incorporation of these features caused their stories to be inappropriate to the genre of creative writing. The lack of a predetermined structure also affected the pace of the stories. The students seemed unsure about the amount of details and elaboration necessary to develop a scene. As a result, they failed to consistently develop the scenes in the story, with some scenes exhaustively elaborated and others abruptly developed despite being of equal or lesser importance. Further, the students did not have the vocabulary to develop the story effectively. These struggles were further aggravated during the collaboration since students manifested varying degrees of mastery of the genre. In academic writing tasks, it only takes a brief discussion of the formulaic structure of a paragraph (topic sentence, supporting details, and a concluding sentence) or the Academic Word List to negotiate these differences in writing. In contrast, the lack of a reference point in creative writing tasks makes it difficult to do so. These struggles clearly affected the individual and collaborative stories as will be discussed in the following section. 


\section{Product of Collaboration}

How do the collaborative short stories compare to individual short stories produced by the same students on the three dimensions of creativity, accuracy, and complexity?

The short stories written collaboratively were compared to the individual stories in terms of creativity, accuracy, and complexity. The findings did not show a clear effect of collaboration on the creativity of the product. It is worth noting, however, that the collaborative stories written by the groups that showed a dominant passive pattern were more effective than the collaborative stories produced by the dominant $\mid$ dominant pattern groups as the latter led to the production of multi-plot and disjointed or incomplete short stories. In short, the groups that had a dominant member who took charge of the writing (Group $2 \& 3$ ) produced more effective stories than the groups in which both members were dominant (Group 1 \& 4).

Parallel to creativity, collaboration did not show a clear effect on the accuracy of the final products, paralleling the findings of previous meaning-focused studies (Elola \& Oskoz, 2010a; Kessler, 2009; Kost et al., 2014; Mak \& Coniam, 2008). This finding, however, is inconsistent with Bikowski and Vithanage (2016), who reported that the individually written posttest showed statistically significant gains for the experimental group who engaged in a collaborative writing task versus the control group that wrote individually. It is worth noting that the tasks they used in their study were short academic writing tasks such as compare and contrast and persuasive paragraphs. As discussed above, the lack of a common reference point to negotiate linguistic choices in this study could explain the lack of effect on the accuracy of the individual stories. It can also be 
related to the interactional patterns discussed earlier. That is, a dominant student is not necessarily more proficient or capable. Similarly, the act of being permissive of errors and refraining from editing other people's contributions negatively affects the overall accuracy of the product.

There was, however, a minimal effect of collaboration on the syntactic complexity of the short stories. In accordance with Mak and Coniam (2008), who reported higher syntactic complexity in wiki-based collaborative stories, the number of words per t-unit in this study was slightly higher in the collaborative stories than in the individual stories. This finding could be due to the nature of revisions applied to the wiki. That is, the most common revisions that students applied to their partner's contributions included additions to already existing content. The students seemed to prefer this kind of revisions as it allows them to contribute without deleting their partner's contributions. This pattern of revision was also observed by Lee (2010). Since complexity in this study was measured as the number of words per t-unit, these revisions could have led to an increase in the complexity of the collaborative stories. The relative ease with which additions can be made in a wiki as compared to face-to-face collaboration could explain why the majority of face-to-face studies did not report an effect on complexity. The only exception to this result was Group 3. The fact that Group 3 did not write a more complex collaborative story than their individual stories could be due to the online confrontation that was discussed earlier. That is, two of the three students were reluctant to add to content generated by the third dominant group member, which negatively affected the complexity of the collaborative story. 


\section{Perceptions of the Task}

How do students perceive the process and product of computer-based collaborative short story writing?

Students' perceptions of the collaborative task in this study were mostly negative. In addition to task difficulties discussed in previous sections, students reported that differences in age, gender, education, and culture impeded their online collaboration, making them less likely to make suggestions or revise the wiki page. The negative perceptions of students in this study contrast with the findings from Chao and Lo (2011), who reported that students had positive perceptions about wiki-based collaborative creative writing tasks.

Although students' perceptions of the collaborative task in the current study were mostly negative, students expressed strong positive perceptions of the individual creative writing task. Corresponding with the theoretical claims outlined in the literature review (Craik \& Lochart, 1972; Garvin, 2013; Tin, 2011), the students in this study commented that creative writing allowed them an opportunity to practice grammar rules, explore vocabulary, and express their individual ideas.

The fact that students' perceptions of the collaborative creative writing task were different from their perceptions towards the individual creative writing task indicates that perhaps a task that introduces both a new genre and a new mode of collaboration is too demanding. The cognitive demand of online collaboration and creative writing could also explain the discrepancy in perceptions between Chao and Lo's study (2011) and the current study. In their study, Chao and Lo implemented a multi-stage task design in which students alternated between working collaboratively and individually on different 
phases of the story writing process. That is, although the students brainstormed, and revised their texts collaboratively, they actually drafted the texts individually. This task design could have provided "a working model of a writing process that may lead to focus on one objective of process and mitigate extraneous cognitive load of other aspects of writing" (Chao \& Lo, 2011, p. 399). In contrast, the collaborative task in this study was not structured but rather left to the students to negotiate. This lack of guidance may have led the students to experience frustration and negatively evaluate the collaborative task. It is also possible that the design in Chao and Lo (2011) allows more ownership for the students over their short stories, a notion that participants in this study commented on in the interviews. It is worth noting that my involvement in the class allowed me to establish high levels of rapport with the students. The casual relationship and the high comfort level that characterized the interviews could have allowed the students to express their real perceptions of the task, a condition that might not be present in other perception studies.

Interestingly, the fact that the collaboration was mediated using technology was not reported as a problem in this study, which confirms reports from other studies (Ducate, Anderson, \& Moreno, 2011; Zorko, 2009). Technology was not perceived as an impeding factor for many possible reasons. In addition to the hands-on training sessions, the small number of students allowed the teacher and me to provide ongoing support for the students as they navigated the different functions of Pbworks and Google Docs.

Although students did not report technology as an obstacle in the final interviews, the use of different wiki platforms seemed to affect their group dynamics and their written output. That is, the groups' discussions of their stories were minimal in Google 
Docs in comparison to Pbworks. In contrast, the written output was significantly maximized upon the switch to Google Docs. It seems that the different functions of the two wiki platforms affected students' collaboration in different ways. The fact that collaborators can edit pages in Google Docs simultaneously might have caused the written output to increase. However, the lack of a separate discussion board could have caused the discussion to decrease. This observation was confirmed by the students in the final interviews. In short, it seems that the two wiki platforms promote different aspects of collaboration. Whereas Pbworks promotes a focus on the process of collaboration by offering a distinctly identifiable discussion board, Google Docs seems to be more product oriented by allowing simultaneous editing of the page.

It is worth noting that the students in this study used the comment function rather than the chat box in Google Docs. In the interviews, they reported a dissatisfaction with the comment function as a means of online discussions and preferred the visibility and linearity of the Pbworks discussion board. Because the chat box in Google Docs is more similar to the Pbworks discussion board in that it is linear, albeit not always visible, the students' discussion could have been increased by using the chat box rather than the comment function.

\section{Pedagogical Implications}

The findings of the study highlight the importance of task design to ensure successful collaboration. The sections below describe considerations for incorporating wiki-based collaborative creative writing in the ESL classroom.

\section{Multi-phased Writing Tasks.}


The lack of focus on form observed in this study suggests that creative writing and other meaning-focused writing tasks are perhaps more appropriate in ESL writing courses where the focus is on macrostructure aspects of the writing such as content development and rhetorical organization. The importance of form can be highlighted by designing multi-phased writing tasks in which students focus on one aspect (content, form) at a time. This design could minimize the cognitive demand of having to attend to meaning and form at the same time (Chao, and Lo, 2011).

\section{Pre-collaboration Tasks.}

The varying perceptions of text ownership and revision behaviors observed in this study suggest that it is important for teachers to conduct extensive orientation sessions targeting students' perceptions of ownership toward the collaborative texts and assessing their readiness for collaboration. Students should also be trained on how to resolve any conflicts and ensure effective group dynamics. It is also crucial to design precollaboration tasks to establish rapport between group members and ongoing selfassessment tasks to ensure effective collaboration as the task develops.

\section{Assessment of Collaboration: Process vs. Product.}

This study, like the majority of collaboration studies, did not show a clear effect of collaboration on the final product. This finding, however, does not necessarily mean that students do not benefit from these collaborative tasks. As discussed earlier, more creative thinking processes were articulated in the groups that showed higher levels of collaboration while discussing ideas. However, students were not able to maintain this collaboration when writing their collaborative short stories and adopted dominantldominant or dominant $\mid$ passive dynamics. The students identified as dominant 
explained that they controlled the task because they were unsatisfied with their partner's written contributions and overall proficiency level. As a result, their partners were deprived of a chance to participate and possibly enrich the collaborative texts. These issues can be avoided by grouping students of similar proficiency levels, which may create more productive interactional dynamics by making it less likely for one student to dominate. Further, it is important for teachers to emphasize the importance of collaboration in terms of the process by assessing the process as much as they assess the collaborative product. Raising students' awareness of the process can help students avoid conflicts arising from a mere focus on the product, especially because the product may not satisfy individual expectations and cause students to adopt dominant behaviors.

\section{Collaboration and Task Type.}

In addition to training sessions and pre-collaboration tasks, this study suggests that task type should be considered carefully when implementing collaborative writing tasks. It seems that creative writing tasks are difficult to collaborate on due to the lack of a pre-established norm that can be used to negotiate choices and resolve conflicts. The difficulty was further aggravated by the fact that short stories cannot be segmented. Thus, it is important to consider whether the task allows for cooperation and perhaps teachers can suggest different roles that students can take on and have students discuss these roles during pre-collaboration activities. Similarly, it is important for teachers to consider the cognitive demand of the task. The students in this study struggled to figure out the genre and navigate collaboration at the same time. It is possible that more positive results could have been obtained if the students had previous experience with either, a condition that was not present in this study. Accordingly, teachers may reap better rewards if they 
incorporate collaboration in writing tasks with which students are familiar, in order to minimize the potential cognitive overload. Besides task type, this study indicated that some topics such as childhood experiences are too sensitive and perhaps better avoided in language classrooms.

\section{Creative Writing in the ESL Classroom.}

The participants in this study expressed positive perceptions of the individual creative writing task. They reported that it allowed them to explore new vocabulary words and practice grammatical structures without worrying about macrostructure rhetorical conventions, which they perceived as somewhat demanding for students with low language proficiency. The participants also commented on how writing about their own fictional ideas rather than presenting information and citing evidence from other sources allowed them to express their own voices and engage in an authentic conversation with audience. In short, creative writing tasks may allow students a sense of agency and authenticity when using their second language, which theoretically can increase their motivation in learning the language. Thus, ESL writing courses can benefit from incorporating more creative writing tasks. Because most ESL programs are designed to prepare students for academia, these creative writing tasks need not to be a core feature of ESL writing instruction, but can be incorporated through independent projects such as journal writing or poetry readings.

\section{Importance of the Platform.}

Although comparing online platforms was not the purpose of this study, a change of the wiki site in the middle of the study suggested that wiki features such as layout and synchronicity can have a substantial effect on the amount of online discussion and written 
output. Accordingly, it is important for teachers to carefully consider the features of platforms and how these might interfere with task outcomes. That is, if the purpose of the task is for students to engage in a discussion, having a clear and a separate discussion board in the platform is crucial. On the other hand, using a platform that allows for synchronous collaboration can increase the written output of collaborative tasks.

\section{Limitations and Future Suggestions}

As a qualitative study, the small number of informants in this study does not allow for generalizations of the findings. Future studies may replicate this study on a larger sample. A larger sample would allow for the use of statistics to measure any statistically significant changes between the individual and collaborative product.

Likewise, the fact that the study was conducted in 10 weeks is potentially problematic. Ten weeks may not be sufficient to introduce a new genre, and a new mode of collaboration, as well as see gains. Due to time constraints, it was not possible to administer a pretest in this study. Future studies can implement a pretest-posttest design to investigate gains. Additionally, more longitudinal studies are needed to investigate the effect of collaborative writing using delayed posttests.

Another limitation of this study is that it was implemented in an elective class. These classes in the program do not require students to spend substantial out-of-class time on class assignments. Students are mainly required to be present during class time and participate in class activities. The lack of extrinsic motivation to work on their individual and collaborative stories outside class could have negatively affected the stories. Coupled with that is the fact that students reported devoting their time and effort to fulfil the assessment requirements of their core classes. Future research can replicate 
this study in required classes in which students are motivated to work toward a grade. Finally, future studies can look more into how different online platform affect the collaboration process and product.

To conclude, this study explored the process and product of wiki-based collaborative creative writing as well as students' perceptions. Although the conclusions made are not definitive, the exploratory design of this study allowed me to pursue several dimensions that influence the language learning process and outcomes. The dimensions of technology, collaboration, and creativity that were integrated in this study appear to interact and affect language learning in complicated ways. To better understand these integrated task designs that are used regularly in ESL classrooms, we need more studies that both examine each dimension separately and study their combined effects. These studies will offer the field a deeper understanding of these integrated pedagogical tasks. 


\section{References}

American Council on the Teaching of Foreign languages. (2015). ACTFL performance descriptors for language learners ( $\left.2^{\text {nd }} e d.\right)$. Alexandria: VA.

Arnold, N., Ducate, L., \& Kost, C. (2009). Collaborative writing in wikis: Insights from culture projects in German classes. In L. Lomicka \& G. Lord (Eds.), The next generation: Social networking and online collaboration in foreign language learning (pp.58-89). Mahwah, NJ: Lawrence Erlbaum.

Arnold, N., Ducate, L., \& Kost, C. (2012). Collaboration or cooperation? Analyzing group dynamics and revision processes in wikis. CALICO Journal, 29(3), 431448.

Bardovi-Harlig, K. (1992). A second look at T-unit analysis: Rethinking the sentence. TESOL Quarterly, 26(3), 390-395.

Bardovi-Harlig, K., \& Bofman, T. (1989). Attainment of syntactic and morphological accuracy by advanced language learners. Studies in Second Language Acquisition, $11,17-34$.

Benesch, S. (2001). Critical English for academic purposes. Mahwah, New Jersey: Laurence Erlbaum Associates.

Biber, D., Gray, B., \& Poonpon, K. (2011). Should we use characteristics of conversation to measure grammatical complexity in $\mathrm{L} 2$ writing development? TESOL Quarterly, 45(1), 5-35.

Bikowski, D., \& Vithanage, R. (2016). Effects of web-based collaborative writing on individual L2 writing development. Language Learning \& Technology, 20(1), 7999 
Bishop, W. (1995). Co-authoring changes the writing classroom: Students authorizing the self, authorizing together. Freshman English News, 23 (1), 54-62.

Boden, M.A. (2001). Creativity and knowledge. In A. Craft, B. Jeffrey, \& M. Leibling (Eds.), Creativity in education (pp. 95-102). London: Continuum.

Boden, M. (2004). The creative mind: Myths and mechanisms. London: Routledge.

Buripakdi, A. (2012). He marginalized positions of Thai professional writers on the global hegemony of English. Journal of Asian Pacific Communication, 2(1), 4159.

Bushnell, C. (2008). Lego my keego! An analysis of language play in a beginning Japanese as a foreign language classroom, Applied Linguistics, 30(1), 49-69.

Burnham, C. (2001). Expressive pedagogy: practice/theory, thoery/practice. In G. Tate, A. Rupiper, \& K. Schick (Eds.) A Guide to composition Pedagogies (pp.19-35). Oxford: Oxford University Press.

Carter, R. (2004). Language and creativity: The art of common talk. London: Routledge. Cekaite, A., \& Aronsson, K. (2005). Language play, a collaborative resource in children's L2 learning, Applied Linguistics 26 (2), 169-191.

Chao, Y. J., \& Lo, H. (2011). Students' perceptions of wiki-based collaborative writing for learners of English as a foreign language. Interactive Learning Environments, 19(4), 395-411.

Chin, G. (2014). Co-constructing a community of creative writers: Exploring L2 identity formations through Bruneian Playwriting. In D. Disney (Ed.), Exploring second language creative writing: beyond Babel (pp. 119-138). Philadelphia, PA: John Benjamins Publishing Company. 
Cook, G. (2000). Language play, language learning. Oxford: Oxford University Press. Cox, B. (1990). Becoming writers. The Writing Notebook, 8 (2), 17-18.

Cowie, N. (2009). Observation. In J. Heigham \& R.A. Croker (Eds.), Qualitative research in applied linguistics: A practical introduction (pp. 165-181). New York, NY: Palgrave Macmillan.

Craik, F. I., \& Lockhart, R.S. (1972). Levels of processing: A framework for memory research. Journal for Verbal Learning and Verbal Behaviour, 11(6), 617 - 684.

De la Colina, A., \& García Mayo, M. (2007). Attention to form across collaborative tasks by low-proficiency learners in an EFL setting. In M. García Mayo (Ed.), Investigating tasks in formal language learning (pp.91-116). London, England: Multilingual Matters.

Dobao, A. (2012). Collaborative writing tasks in the L2 classroom: Comparing group, pair, and individual work. Journal of Second Language Writing, 21(1), 40-58.

Donato, R. (1994). Collective scaffolding in second language learning. In J.P. Lantolf \& G. Appel (Eds.), Vygotskian approaches to second language research (pp.33-56). Norwood, NJ: Ablex.

Donnelly, D. (2015). Creative Writing as knowledge: What's assessment for to do with it? New Writing: The international Journal of the Practice and Theory of Creative Writing, 12(2), 222-237.

Ducate, L. C., Anderson, L. L., \& Moreno, N. (2011). Wading through the world of wikis: An analysis of three wiki projects. Foreign Language Annals, 44(3), 495524. 
Ducate, L., \& Lomicka, L. (2008). Adventures in the blogosphere: From blog readers to blog writers. Computer Assisted Language Learning, 21 (1), 9-28.

Ellis, R. \& Barkhuizen, G. (2005). Analysing learner language. Oxford: Oxford University Press.

Elola, I., \& Oskoz, A. (2011). Writing between the lines: Acquiring the presentational mode through social tools. In N. Arnold \& L. Ducate (Eds.), Present and future promises of CALL: From theory and research to new directions in language teaching (pp.171-210). San Marcos, TX: CALICO.

Elola, I., \& Oskoz, A. (2010a). Collaborative writing: Fostering foreign language and writing conventions development. Language Learning and Technology, 14 (3), 51-71.

Everett, N. (2005). Creative writing and English. The Cambridge Quarterly, 34 (3), 231252.

Faigley, L., \& Witte, S. (1981). Analyzing revisions. College Composition and Communication, 32, 400-414

Friere, P. (1974). Education for Critical Consciousness. London: Sheed and Ward. Gass, S. M., \& Mackay, A. (2007). Input, interaction and output in second language acquisition. In B. Van Patten \& J. Williams (Eds.), Theories in second language acquisition: An introduction (pp.175-198). Mahwah, NJ: Lawrence Erlbaum Associates.

García Mayo, M. (2002). The effectiveness of two form-focused tasks in advanced EFL pedagogy. International Journal of Applied Linguistics, 12(2), 156-175. 
Garvin, R. (2013). Researching Chinese history and culture through poetry writing in an EFL composition class. L2 Journal, 5(1), 76-94.

Greeves, A. (1987). The challenge of angels. The Use of English, 38 (3), 6-12.

Hatch, A. (2002). Doing qualitative research in educational settings. Albany, NY: State University of New York Press.

Hood, M.(2009). Case study. In J.Heigham \& R.A. Croker (Eds.), Qualitative research in applied linguistics: A practical introduction (pp. 66-90). New York, NY:

Palgrave Macmillan.

Huh, K. \& Egbert, J. (2010). 1+1 does not always equal 2: Exploring creativity, language learning, and technology-mediated field experience. TESOL Journal, 1(1), 206226.)

Hunt, K. (1966). Recent measures in syntactic development. Elementary English 43, 732 739.

Hyland, K. (2003). Second language writing. Cambridge, UK: Cambridge University Press.

Jones, G. (1986). Children create class stories. Highway One, 9 (2), 21-32.

Kessler, G. (2009). Student-initiated attention to form in wiki-based collaborative writing. Language Learning \& Technology, 13 (1), 79-95.

Kim, Y., \& Kellogg, D. (2007). Rules out of roles: Differences in play language and their developmental significance. Applied Linguistics, 28(1), 25-45.

Kost, C., Arnold, N., \& Ducate, L. (2014, March). L2 writing with wikis: How does technologically mediated collaboration affect the product? Paper presented at the meeting of the American Association of Applied Linguistics, Portland, Oregon. 
Kost, C. (2011). Investigating writing strategies and revision behavior in collaborative writing projects. CALICO Journal, 28 (3), 606-620.

Lantolf, J., \& Thorne, S. (2007). Sociocultural theory and second language learning. In B. Van Patten \& J. Williams (Eds.), Theories in second language acquisition: An introduction (pp.201-224). Mahwah, NJ: Lawrence Erlbaum Associates.

Lee, L. (2010). Exploring wiki-mediated collaborative writing: A case study in an elementary Spanish course. CALICO Journal, 27 (2), 226-276.

Leja, H. (2007). Improving writing skills in foreign language classes. In M. Camilleri, P. Ford, H. Leja, \& V. Sollars (Eds.), Blogs, Web journal in language education. (pp.27-34). Graz, Austria: European Center for Modern Languages, Council of Europe. Retrieved from http://www.ecml.at/documents/D1_Blogs_E_web.pdf.

Mak, B., \& Coniam, D. (2008). Using wikis to enhance and develop writing skills among secondary school students in Hong Kong. System, 36(3), 437-455.

McRae, J. (1991). Literature with a Small 'l'. London: Macmillan.

Morris, G. \& Sharplin, E. (2013). The assessment of creative writing in senior secondary English: A colloquy concerning criteria. English in Education. 47(1), 49-65.

Nassaji, H., \& Tian, J. (2010). Collaborative and individual output tasks and their effects on learning English phrasal verbs. Language Teaching Research, 14(4), 397-419.

Newman, J. (2007). The Evaluation of Creative Writing at MA Level (UK). In S. Earnshaw, (Ed.), The Handbook of Creative Writing (pp.24-36). Edinburgh: Edinburgh University Press.

Norris, J., \& Ortega, L. (2009). Towards an organic approach to investigating CAF in instructed SLA: The case of complexity. Applied Linguistics, 30(1), 555-578. 160 
Oskoz, A., \& Elola, I. (2012). Understanding the impact of social tools in the FL writing classroom: Activity Theory at work. In G. Kessler, A. Oskoz, \& I. Elola (Eds.), Teaching across writing contexts and tasks (pp. 131-153). San Marcos, TX: CALICO Monograph Series.

Patton, M.Q. (1990). Qualitative research and evaluation methods. New York, NY: Sage Publications.

Pomerantz, A., \& Bell, N. D. (2007). Learning to play, playing to learn: FL learners as multicompetent language users, Applied Linguistics 28(4), 556-78.

Robinson, M. \& Ellis, V. (1999). Writing in English and responding to writing, In J. Sefton-Green \& R. Sinker (Eds.), Evaluating Creativity: Making and Learning by Young People (pp.69-87). Hoboken: Routledge.

Rodriguez, A. (2008). The 'problem' of creative writing: Using grading rubrics based on narrative theory as solution. New Writing: The International Journal for the Practice and Theory of Creative Writing, 5(3), 167-177.

Singleton, J. (1992). Creative writing and assessment: A case study. In M. Monteith \& R. Miles, (Eds.), Teaching Creative Writing (pp.66-78). Philadelphia: Open University Press.

Spradley, J.P. (1980). Particpant observation. New York: Holt Rinehart \& Winston

Storch, N. \& Wigglesworth, G. (2007). Writing tasks: The effects of collaboration. In M. del Pilar García Mayo (Ed.), Investigating tasks in formal language learning (pp.157-177). London, England: Multilingual Matters.

Storch, N. (2005). Collaborative writing: Product, process, and students' reflections. Journal of Second Language Writing 14(3), 153-173. 
Storch, N., \& Aldosari, A. (2013). Pairing learners in pair work activity. Language Teaching Research, 17(1), 31-48.

Storch, N. (2009). The nature of pair interaction: Learners' interaction in an ESL class: its nature and impact on grammatical development. Saarbrücken: VDM Verlag.

Storch, N. (2012). Collaborative writing as a site for L2 learning in face-to-face and online modes. In G. Kessler, A. Oskoz, \& I. Elola (Eds.), Teaching across writing contexts and tasks (pp. 113-129). San Marcos, TX: CALICO Monograph Series.

Swain, M. \& Lapkin, S. (2001). Focus on form through collaborative dialogue: Exploring task effects. In M. Bygate, P. Skehan, \& M. Swain (Eds.), Researching pedagogic tasks: Second language learning, teaching and testing (pp. 99-118). Harlow, England: Longman.

Swain, M., \& Lapkin, S. (1998). Interaction and second language learning: Two adolescent French immersion students working together. Modern Language Journal, 82(3), 320-337.

Tin, T.B. (2011). Language creativity and co-emergence of form and meaning in creative writing tasks. Applied Linguistics, 32 (2), 215-235.

Tickoo, A. (2001). How to create a crisis: Empowering the ESL writer with lessons from narrative art. International Journal of Applied Linguistics. 11(1), 21-36.

Tin, T.B. (2013). Towards creativity in ELT: The need to say something new. ELT Journal, 67(4), 385-397.

Tin, T.B. (2016). Creativity in second-langauge learning. In R.H. Jones (Ed.), The Routledge handbook of langauge and creativity (pp. 433-449). London: Routledge. 
Tok, Ş., \& Kandemir, A. (2015). Effects of creative writing activities on students' achievement in writing, writing dispositions and attitude to English. Procedia Social and Behavioral Sciences, 174 (1), 1635 - 1642.

Toolan, M. (2003). An integrational linguistic view of coming into language. In J. Leather \& J.Van Dam (Eds.), Ecology of Language Acquisition (pp.123-140). Dordrecht: Kluwer, Academic Publishers.

Vass, E. (2007). Exploring processes of collaborative creativity: The role of emotions in children's joint creative writing. Thinking Skills and Creativity, 2 (2), 107-117.

Weldon, F. (2009). On assessing creative writing. New Writing: The international Journal of the Practice and Theory of Creative Writing, 6(3), 163-174.

Wigglesworth, G., \& Storch, N. (2009). Pair versus individual writing: Effects on fluency, complexity and accuracy. Langauge Testing, 26 (3), 445-466.

Yagelski, R.P. (1994). Collaboration and children's writing: What 'real' authors do, what children do? Journal of Teaching Writing, 12 (2), 217-233.

Yin, R.K. (1994). Case study research: Design and methods. New York, NY: Sage Publications.

Zhao, Y. (2015). Second Language Creative Writers: Identities and Writing Processes. Bristol, UK: Multilingual Matters.

Zorko, V. (2009). Factors affecting the way students collaborate in a wiki for English language learning. Australasian Journal of Educational Technology, 25(5), 645665. 


\section{Appendix}

\section{Self-assessment Questionnaire}

Based on the rubric below, give a score from 1-5 for the two stories you wrote in this class. (5) is the highest, (1) is the lowest.

- $\quad$ Plot is developed using rising action, climax, falling action, resolution, and includes surprises.

$$
\text { Individual Story Group Story }
$$

- Characters are described using a variety of techniques: Actions, thoughts, reactions, physical descriptions, dialogue, background information, possessions.

$$
\text { Individual Story Group Story }
$$

- $\quad$ Setting is described using sensory details: sight, sound, touch, smell, and taste.

$$
\text { Individual Story Group Story }
$$

- The story explores a theme: The story is about something important to human lives: love, sacrifice, betrayal.

$$
\text { Individual Story Group Story }
$$

- $\quad$ Point of view is appropriate. Who is telling the story? How much knowledge do you have on the characters' thoughts and feelings?

$$
\text { Individual Story Group Story }
$$


- Style: descriptions, examples of metaphors, similes, hyperbole, personification, sensory details (sight, sound, touch, smell, and taste).

Individual Story Group Story

Overall, which story do you think is better: the one you're wrote alone or the one you wrote in a group? Could you explain the difference? 